\title{
FACILITATORS AND INHIBITORS TO VISUALISING INFORMATION IN ORGANISATIONAL PRACTICE
}

by

Cassandra Bei Yi Ong

\author{
A thesis \\ submitted to Victoria University of Wellington \\ in partial fulfilment of the \\ requirements for the degree of \\ Master of Commerce \\ in Management
}

Victoria University of Wellington

2016 

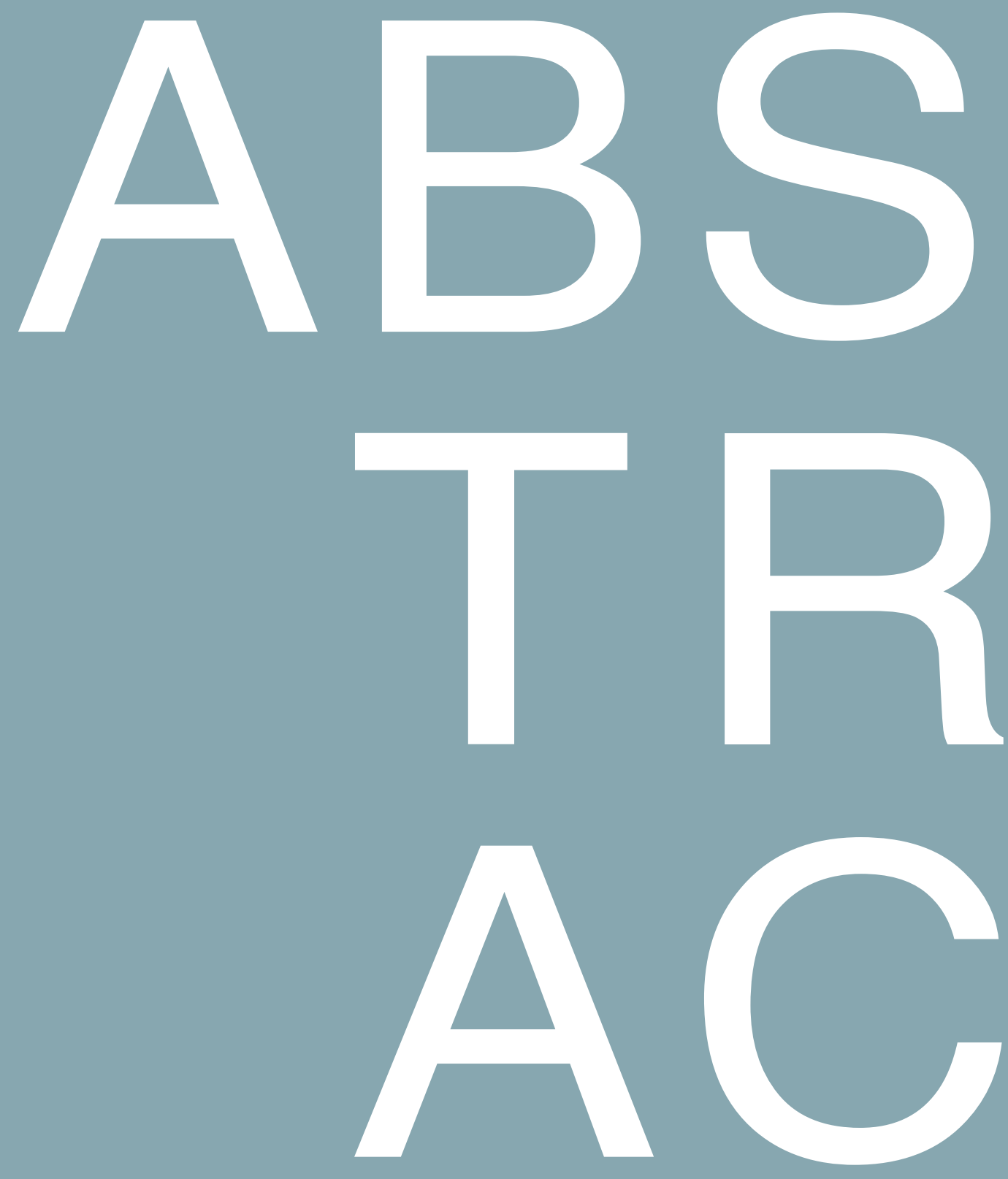

The benefits of visual artefacts and methodologies have been well documented in the strategy literature. However, this work has concentrated on the 'how to do' and 'why to do' of visualisation. It remains unclear why, given this widespread promotion, visualisation is not utilised more for communicating and developing strategy. This thesis explores the 'doing' of strategy visualisation through a practice lens by examining the processes through which visualisation services are adopted by organisations. Using a qualitative approach, I studied ten organisations in five countries that create visualisations for clients and identified common facilitators and inhibitors of visualisation adoption, discussing its implications for strategy.

The study's findings expand upon the literature on facilitators and inhibitors to visualisation, discovering that these factors are personal and contextual in nature. Personal factors include:

- prospective clients' experience of prior visualisation outcomes;

- predispositions for or against visualisation;

- prior knowledge about visualisation and associated services;

- partiality towards particular visualisation consultants; and

the capability to distinguish specific organisational needs for visualisation.

Contextual factors such as organisational culture, and ability to approve the service within an allocated budget, also influence the adoption of visualisation. Based on a greater understanding of these factors, a heuristic framework was developed to relate these facilitators or inhibitors to four process phases:

Pre-contact $\rightarrow$ Contact $\rightarrow$ Commitment $\rightarrow$ and Post-purchase Evaluation

My research findings benefit practitioners, by clarifying facilitating and inhibiting factors to visualisation adoption and suggesting interventions based on these. The findings also have implications for methodology and theory development: they indicate the value of studying strategy visualisation through a practice lens; add to our understanding of how visualisation can clarify and support strategy making; and enable insight into the dynamics of visualisation adoption to provide reasons why visualisation is not as widespread a practice as its proponents suggest it should be. 
There are many people without whom this thesis would not have been possible, and to whom I am greatly indebted to.

First and foremost, I would like to thank my supervisor, Prof. Stephen Cummings. Your enthusiasm, guidance, patience and knowledge have been invaluable in my research journey.

To respondents and their respective organisations, thank you for contributing your insights to the study. I especially thank respondents who gave feedback on the preliminary findings.

To the lecturers who taught me over the years, the knowledge and support you've provided over my years as a student have been foundational to my learning. I extend my sincerest thanks to Dr. Todd Bridgman for the direction, advice and encouragement that you provided me throughout my years as a student. Thank you also for keeping me employed throughout the years and encouraging me to undertake postgraduate study. I must also thank the administrative staff at Victoria who ensured the behind-the-scenes processes ran smoothly, especially Megan Key.

To the 'Disasters from Masters' crew: Alice, Erin, Evie and Hamish. Thank you for the laughs and many fond memories. I couldn't have asked for a better group of people to share this journey with.

There are many others who helped in the completion of this research project, including my family and friends who let me talk through my ideas and kept me sane throughout it all. To Mum and Dad, thank you for your unwavering support and encouragement. To Sunil, thank you for your love, support and always standing by me, even in the most difficult times.

Finally, I am deeply grateful to Alana Inglis, Ian Calder, Ruth Weatherall for the many hours that you spent providing critical feedback and for your continued support 


\section{TABLE OF CONTENTS}

ABSTRACT

ACKNOWLEDGEMENTS

TABLE OF CONTENTS

LIST OF FIGURES

LIST OF TABLES

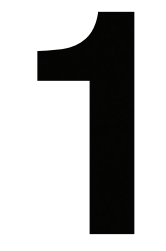

INTRODUCTION

1.1 Chapter Introduction

1.3 Thesis Outline

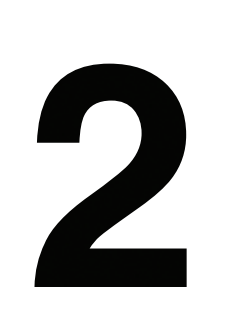

LITERATURE REVIEW

2.1 Chapter Introduction

sualisation?

Benefits of Strategy Visualisation

2.4.1 Cognitive Benefits

2.4.2 Social Benefits

2.5 Challenges of Visualising

2.6 The Rational Perspective

2.7 How are Visuals Adopted?

METHODOLOGY

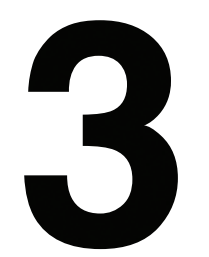

3.1 Chapter Introduction

3.2.1 Applying the Strategy-as-Practice Perspective

3.2.2 Qualitative Research

3.2.3 Abductive Reasoning and Implications for Research

3.3 .3 Interive Recruitment

3.4 Purposive Sampling

3.5 Interviewees

3.5.1 Participant Information

3.5.2 Examples of Visual Styles used by Respondents

3.6 Data Collection

3.6.1 Developing the Interview Guide

3.6.2 Conducting the Interviews

3.7 Data Analysis

3.7.1 Thematic Analysis

3.7.2 Transcription and Data Analysis Process

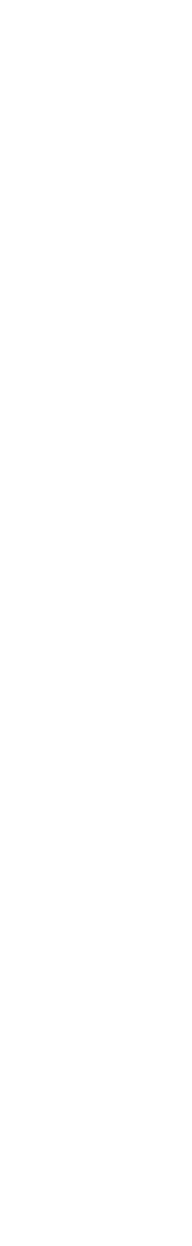

INGS: FACILITATING AND INHIBITING

FACTORS TO VISUALISATION

4.1 Chapter Introduction

4.2 Summary of Facilitating and Inhibiting Factors

4.3 Benefits of Visualisation

4.3.1 Cognitive Benefits

4.3.2 Engagement Benefits

4.3.3 Operational Benefits

4.3.4 Emotional Benefits

4.4 Prior Experience with Visualisation

4.5 Ability to Connect Collaboration Outcomes with

Visualisation and Positive Word of Mouth

4.6 Organisational Need

4.7 User's Predisposition For or Against Visualisation

No Approval for the Service, Cost of the Service and Lack of Education on the Value of Visualisation Services

4.10 Perceived Cultural Fit Between the Visualisation Organisation and Prospective Client

DISCUSSION AND IMPLICATIONS

93

5.1.1 What Encourages Prospective Clients to Transition

Between the Stages?

$5.2 \quad$ Stages of the Visualisation Adoption Process 96

$\begin{array}{lll}\text { 5.2. } & \text { Stage 1: Pre-contact } & \mathbf{9 8} \\ 5.22 & & 101\end{array}$

5.23 Stage 3: Commitment

5.2.4 Stage 4: Post-purchase Evaluation

5.3 Managerial Implications

5.3.1 Variations

5.3.2 Interventions

Facilitating Motivation

Facilitating Implementation

Facilitating Reconsideration

5.4 Limitations and Implications for Future Research

5.5 Key Takeaways from the Research

5.5.1 Key Recommendalions for Praclice

5.5.2 Key Research Contributions

5.6 Conclusion

REFERENCES

APPENDICES

Appendix A: Examples of Strategy Visualisation

Appendix B: Information Sheet for Participants

Appendix C: Consent Form for Participants

Appendix D: Interview Schedule

Appendix E: Results Framework Development 
Figure 2. Visual created to support the vision for a European think tank (JAM visual thinking, n.d.)

Figure 3. Example of a graphic recorder at work (Think in Colour, n.d.)

Figure 4. Example of a multimodal visualisation created to support leadership training (XPLANE, n.d.)

Figure 5. Visual created to help participants in a retreat understand the proposed five year strategic plan

(Graphic Footprints, n.d.)

Figure 6. Visual board game created to help retreat participants understand a five year strategic plan

(Graphic Footprints, n.d.)

Figure 7. An example of a computer-rendered visualisation style used by some of the visual consultancies in the study (INK strategy,n.d.)

Figure 8.

Facilitating and inhibiting factors in the adoption of visualisation services

Figure 9. Pre-contact stage

Figure 10. Contact stage

Figure 11.

Figure 12. Post-purchase Evaluation stage

Figure 13. A sketch made by V7 to show a hypothetical internal decision making process by the client (top four boxes) and its interaction with the visualisation adoption process that I created (bottom four boxes). 
Figure 14. Example of an Organigraph created to show how the

Canadian organisation, Frontec, was developed around its core competences (Mintzberg \& Van der Heyden,

Figure 15. Example of a strategy chart for an auto components manufacturer (Eppler \& Platts, 2009)

Figure 16. The Business Model Canvas (Osterwalder \& Pigneur 2010)

Figure 17. Example of LEGO Factory business model as displayed on the Business Model Canvas (Osterwalder \& Pigneur, 2010)

Figure 18. Generic strategy map from Scholey (2005)

Figure 19. Example of an interactive Balanced Scorecard represented as a visual metaphor, created by Eppler and Platts (2009) to assist with strategy communication

Figure 20. Initial mapping of key themes to see connections between themes

Figure 21. Revision of key themes map

Figure 22. Revision of results framework after member checking interviews

Figure 23. Revisions of results framework after feedback from my supervisor

Figure 24. Revision of key themes in results framework

Figure 25. Last revisions of key themes to results framework 

strengths of visualisation, developed by Eppler and Platts (2009)

Table 2. Information about interviewees

Table 3. List of facilitating and inhibiting factors to the adoption of visualisation services

Table 4.

Cognitive benefits

Table 5.

Engagement benefits

Table 6.

Operational benefits

Table 7. Emotional benefits

Table 8. Prior experience with visualisation

Table 9. Ability to connect collaboration outcomes with visualisation and positive word of mouth

Table 10. Organisational need

Table 11. User's predisposition for or against visualisation

Table 15. Transitions between the stages of the visualisation adoption process 
Table 18. Interventions to facilitate implementation

Table 19. Interventions to facilitate reconsideration 
INTRODUCTION

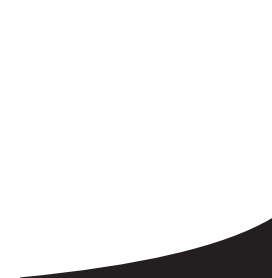

\begin{tabular}{lll}
\hline & & \\
1.1 & Chapter Introduction & 3 \\
1.2 & Research Problem and Research Objectives & 4 \\
1.3 & Thesis Outline & 5
\end{tabular}




\subsection{Chapter Introduction}

Strategy visualisation research over the past two decades has emphasised the value of visualisation for communicating and developing strategy. As someone who has consistently used visualisation throughout my studies, I have experienced its benefits firsthand; this drove my interest to explore visualisation as a research topic. For example, I found concepts were more memorable and clear to myself (and others) when I drew them instead of using the equivalent text. So, I was mystified by why, despite the extensive promotion of its benefits, visualisation is not utilised more for strategising. I observed that the strategy visualisation field concentrates on the outcomes and performance of visualisation, with little focus on the practice of strategy visualisation. As such, little is known about how or why practitioners adopt visualisation. To address this gap in understanding, in this thesis, I have explored strategy visualisation through a practice lens, clarifying facilitators and inhibitors to visualisation adoption.

Although the emphasis of this thesis is on the adoption of visualisation, a topic which is a personal interest of mine, its purpose is not to suggest that visualisation should completely replace other methods for conveying information. Verbal, written and other methods (including bullet points) have their own 'time and place'. For example, presenting this thesis purely through visuals would not replicate the same argumentative power of a coherent, well-structured text document. Rather, this thesis is my attempt to shed light on the littleknown practice of visualisation adoption to provide reasons for why visualisation is not as readily adopted as visualisation advocates indicate it should be.

In this research project, 'visualisation' refers to 1) the graphic representation of information (Eppler \& Platts, 2009; Kernbach, Eppler, \& Bresciani, 2015), 2) the artefacts in which these representations are used (e.g. maps, sketches, pictures) (Garreau, Mouricou, \& Grimand,

2015) and 3) the process by which visualisation tools are used to form mental models of data (Platts \& Hua Tan, 2004) 


\subsection{Research Problem and Research Objectives}

Popular management books of the last couple decades tout the benefits of visualisation for managers (e.g. Business Model Generation, The Back of the Napkin), as do scholarly articles devoted to improving strategising through the use of visualisation (e.g. See Kim \& Mauborgne, 2005; Mintzberg \& Van der Heyden, 1999; Cummings \& Angwin, 2011; 2015). These books and articles comprise a wealth of advice along with useful tools and techniques to encourage managers to incorporate visualisation. All this signals the importance of visualisation in practice.

Strategy visualisation literature has advocated the benefits of visualisation to demonstrate its usefulness for communicating and developing strategy (e.g. Cummings \& Angwin, 2011; 2015; Eppler \& Platts, 2009; Kiyoshi, 1993; Phaal \& Muller, 2009). Such benefits include: enhanced recall of strategy (Kraut, Fussell, \& Siegel, 2003), greater engagement with strategy (Carmona, Iyer, \& Reckers, 2011; Cummings \& Angwin, 2011) and increased strategy buy-in and follow-through (Buzan \& Buzan, 2000; Holloway, 2009). However, there is no indication as to why, in practice, more organisations are not embracing these benefits. An acquaintance of mine expressed her difficulty in 'selling' strategy visualisation to her superiors in a locally based law firm - and it appears that this is not an isolated incident. A 2010 survey of Fortune 500 organisations revealed that only two organisations visualised their strategies on their websites (Cummings \& Angwin, 2015). However, a follow-up survey in 2015 revealed disappointing results, only five organisations visualised their strategy. ${ }^{1}$ These findings were surprising to me, considering the numerous documented benefits in strategy visualisation literature, and my own positive experiences using visualisation.

Despite the documented importance of visualisation in both popular literature and scholarly articles, recent studies indicate that visual tools are rarely used for strategic management. Bititci, Cocca, and Ates (2015) state that visual tools are widely used in operations and lean management (e.g. the $5 \mathrm{~S}$ technique), yet are seldom used in strategic management. Specifically, the authors claim that there is little evidence that organisations use visual management techniques for strategic management (e.g. strategic planning boards and strategic progress boards), and note a paucity of literature on the adoption of visual management (Bititci et al., 2015). Kernbach et al. (2015) observed a discrepancy between the many benefits promoted in visual communication literature and the ubiquity of bullet points for presentations in organisational settings. Kernbach et al. (2015) offer a few reasons for this inconsistency, stating that bullet points may be used simply out of habit, due to personal or institutional preferences or due to limitations of the available tools.

Scholars have called for research into the contexts in which visual practices may be accepted or rejected by managers (Eppler \& Bresciani, 2013). Existing research does not explain why so few organisations use visualisation despite its reported benefits. My exploratory study seeks to make sense of this inconsistency, thus I developed the following research questions:

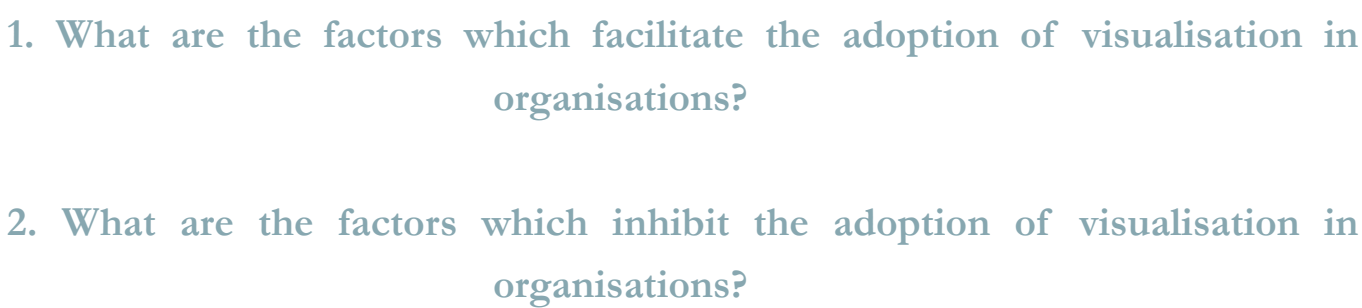

\subsection{Thesis Outline}

In Chapter 2, a review of the literature on the relatively new field of strategy visualisation examines the current state of this field. Techniques to aid visualisation are well documented, as are the benefits of visualisation for strategy practices. Challenges related to creating and implementing strategy visualisation have also been identified in relevant literature, along with possible techniques to overcome them. However, the strategy visualisation literature field focuses on the efficacy of strategy visualisation, neglecting adoption of strategy visualisation. Thus, the facilitating and inhibiting factors to strategy visualisation adoption have yet to be explored. Consequently, applying a strategy-as-practice lens to strategy visualisation helps to answer the research questions, as the strategy-as-practice literature directs our focus to how strategy tools (such as visualisation tools) operate, rather than 'good or bad use' of visualisation.

The methodology used in strategy-as-practice literature underpins the research design. Chapter 3 describes strategy-as-practice, and provides an overview of the practice approach, followed by a justification of how the methodological assumptions of this approach are appropriate and important for answering the research questions. A qualitative research design is most suitable for this exploratory study, given the rich empirical data to be captured. Discussion of the recruitment methods leads to explanation of how the ten semi-structured 
interviews were conducted and how the subsequent data was analysed.

The findings chapter (Chapter 4) compares the facilitating and inhibiting factors identified

in the analysis against extant literature, to ascertain whether the findings confirm, extend or add new insight into this body of research. This chapter reveals how the factors which facilitate and inhibit the adoption of visualisation are not as 'cut-and-dry' as some of the visualisation literature implies. Although the study focused on the factors that facilitates or inhibits visualisation service adoption, findings also have implications for visualisation adoption in general.

Chapter 5 introduces the heuristic framework. This framework provides novel insight to visualisation literature, as it is the first to show the process of visualisation adoption through a practice lens. Drawing on the facilitators and inhibitors identified in the empirical research shows how these factors relate to four phases in the visualisation adoption process. These stages were identified as: 1) Pre-contact, 2) Contact, 3) Commitment and 4) Postpurchase Evaluation. Alongside the explanation and justification of the heuristic framework, discussion includes: implications of this framework for the adoption of visualisation, its implications for strategy visualisation. Practical suggestions show how this heuristic framework could be used to increase the adoption of visualisation within organisations. This framework is interpretive; something that can be adapted to suit different organisations. This discussion also recognises the limitations of the study and how the research can be used as a springboard for future empirical research into why visualisation is not readily adopted in organisations. 


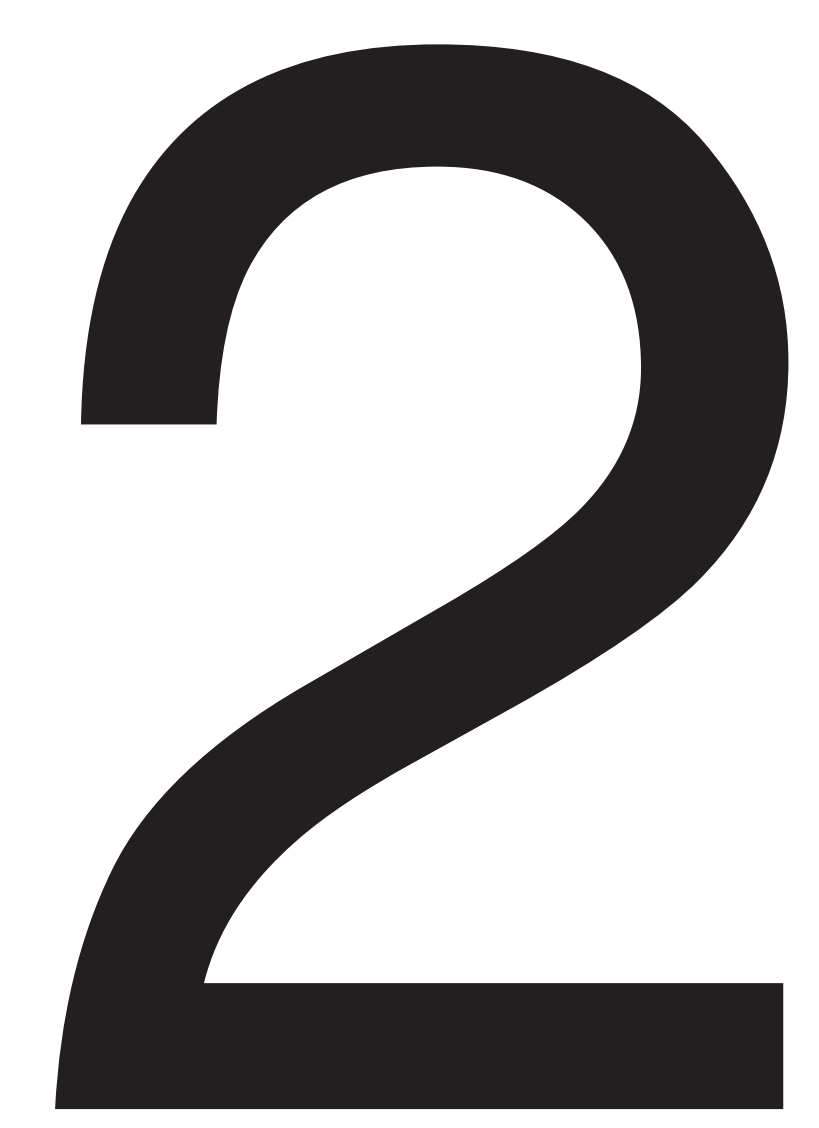

\section{LITERATURE REVIEW}

$\begin{array}{lll} & & \\ \mathbf{2 . 1} & \text { Chapter Introduction } & \mathbf{1 1} \\ \mathbf{2 . 2} & \text { What is Visualisation? } & \mathbf{1 3} \\ \mathbf{2 . 3} & \text { Techniques to Aid or Improve Strategy Visualisation } & \mathbf{1 4} \\ \mathbf{2 . 4} & \text { Benefits of Strategy Visualisation } & \mathbf{1 6} \\ 2.4 .1 & \text { Cognitive Benefits } & 17 \\ 2.4 .2 & \text { Social Benefits } & 18 \\ 2.4 .3 & \text { Emotional Benefits } & 19 \\ \mathbf{2 . 5} & \text { Challenges of Visualising } & \mathbf{2 1} \\ \mathbf{2 . 6} & \text { The Rational Perspective } & \mathbf{2 3} \\ \mathbf{2 . 7} & \text { How are Visuals Adopted? } & \mathbf{2 5}\end{array}$




\subsection{Chapter Introduction}

The literature on 'visualisation' is expansive and diverse, extending to areas such as visual literacy, visual communication, information visualisation, film studies, sociology, psychology and architecture. I determined that reviewing all of this literature was too ambitious for a Master's thesis. As my intention is to study the factors which facilitate or inhibit the adoption of visualisation and its implication for strategy visualisation, this literature review focuses primarily on the current state of research on strategy visualisation. This area of research is a relatively new field, which continues to reference the wider literature on visualisation. Therefore, although the focus of this literature review is strategy visualisation, it will also draw on the wider literature on visualisation.

Firstly, strategy visualisation is discussed, beginning with the establishment of what 'visualisation' means within this field. This is followed by a review of strategy visualisation techniques, and additionally, the benefits and challenges of strategy visualisation. Strategy visualisation literature focuses primarily on the efficacy and performance of visualisation. Consequently, there is a lack of research on how visualisation is adopted. Therefore, in order to understand the factors that facilitate or inhibit the adoption of visualisation, this study will also draw upon strategy-as-practice research.

Unlike strategy visualisation literature, the 'practice lens' directs our attention to the 'doing' of strategy (Güney \& Taylor, 2014; Jarzabkowski, Balogun, \& Seidl, 2007). Within this field, strategy-as-practice scholars have investigated strategy-tools-in-use. This developing area of research examines how tools are developed and used by practitioners, to enhance understanding of how strategy is developed (Jarzabkowski \& Kaplan, 2015). Strategy visualisation is a 'strategy tool' as it encompasses "frameworks, concepts, models and methods" that can help decision makers structure their thinking and cope with the uncertainties of strategy making (Jarzabkowski \& Kaplan, 2015, p. 538). Apart from research by Güney and Taylor (2014) and Paroutis, Franco, and Papadopoulos (2015), little attention has been paid to the examination of strategy visualisation through a practice lens. Existing accounts do not explain how strategy visualisation is adopted. Applying a practice lens to strategy visualisation is thus useful for understanding the factors that facilitate or inhibit the adoption of visualisation.

Throughout this thesis, the term 'strategy' refers to the strategy-as-practice definition. There are multiple definitions of strategy such as the conception that strategy is something that can be planned, versus something that is emergent (Andrews, 1971; Mintzberg, 1987; Quinn, 1978). However, engaging in this debate is outside of the bounds of this thesis. As such, 


\subsection{What is Visualisation?}

strategy is defined using the strategy-as-practice definition; "a situated, socially accomplished activity, while strategizing comprises those actions, interactions and negotiations of multiple actors and the situated practices that they draw upon in accomplishing that activity" (Jarzabkowski \& Sillince, 2007, pp. 7-8)

The term 'visualisation' differs amongst strategy visualisation scholars. Some scholars see visualisation as 'representation', defining it as a "graphic representation of data, information and knowledge" (Eppler \& Platts, 2009, p. 43). This is similar to the definition by Kernbach et al. (2015), where visualisation is conceived as "the graphic representation or mapping of information in a spatial schema" (p. 167). Other scholars focus solely on the artefactual nature of visualisation, stating that visualisation encompasses "maps, photographs, pictures, paintings, drawings and sketches" (Garreau et al., 2015, p. 3). In contrast, strategy visualisation scholars have opted to take a 'process' approach, considering visualisation to be "the process of using visualisation tools to form a mental model of data, thereby gaining insight into that data" (Platts \& Hua Tan, 2004, p. 667)

As there are many definitions of visualisation, and my research into visualisation is intended to be exploratory, I have taken an all-encompassing approach to the definition of 'visualisation' in this thesis. All three aforementioned definitions are considered in the definition of visualisation; visualisation is seen as the graphic representation of information, data, or knowledge, which can include artefacts such as drawings, sketches, or maps. Visualisation can also resemble the process of using tools to form mental models of data. 


\subsection{Techniques to Aid or Improve Strategy}

\section{Visualisation}

Strategists have used visual frameworks or graphs to work through complexity for decades. One such framework, the Organigraph (see Figure 14, Appendix A), is helpful for enabling practitioners to see critical relationships and identify opportunities through visualising organisational charts (Mintzberg \& Van der Heyden, 1999). Other frameworks (such as strategy charting) can be used to visualise and understand the past, present and future strategy of an organisation (Eppler \& Platts, 2009) (see Figure 15, Appendix A), while the Business Model Canvas can be used to visualise the critical elements of a business model without irrelevant detail (Osterwalder \& Pigneur, 2010) (see Figures 16 \& 17, Appendix A) Strategy maps provide users with the ability to visualise linkages between financial objectives, internal business processes, customers/stakeholders and organisational capacity (see Figure 18, Appendix A) (Kaplan \& Norton, 1996).

Of increasing prominence in visualisation literature are articles which present visual methodologies to aid and improve organisational work. For example, in his book, The Back of the Napkin, Roam (2008) advocates 'visual thinking', and argues that one only needs simple tools to create drawings to resolve business problems. Similarly, Visual Meetings builds on this premise, claiming that anyone can employ visual tools, and proposes ways that these creative tools can be used to motivate and enliven organisational group work through visualisation, such as through visual brainstorming sessions and strategy sessions (Sibbet, 2010).

In the strategy visualisation field, the authors of Strategy Builder argue that the most effective way to engage and involve people in strategy is through the use of visuals (Cummings \& Angwin, 2015). Essentially the authors exhort 'rolling your sleeves up' and making strategy happen through drawing it, rather than making strategy become the 100-page document that no one ever reads. The book provides an interactive guide which draws on established strategy frameworks and case examples to demonstrate that anyone can use drawing to increase buyin and involvement with strategy. In the same vein, Phaal and Muller (2009) recommend the use of roadmaps to improve strategy planning. Platts and Hua Tan (2004) suggest that managers should create performance profiles, strategy charts and employ the use of TAPS (Tool for Action Plan Selection).

Cummings and Angwin (2011) argue that strategies should be communicated in ways that are easily understandable for those that are involved in implementing strategy. Using text- heavy formal documents for communicating strategy is counterintuitive to how humans understand complexities best. Presenting strategy as abstract text makes it difficult for people within organisations to understand how to enact the strategy and can result in different interpretations of the strategy. The scholars draw on educational philosophy literature to argue that humans learn and remember information best through the combination of three elements: hands-on learning, graphical aids and symbols (text or numbers) to associate with the first two elements. Cummings and Angwin (2011) propose seven key principles of good 'stratography' to improve the communication of strategy by making strategy easily digestible to those who are not involved in the strategy conceptualisation. 'Stratography' refers to the graphic depiction of unique elements within a strategy to show the interconnections between elements such as competition, core values of an organisation and its intended direction. Similarly, Kiyoshi (1993) recommends six types of visual aids to improve open communication on shop floors. Bürgi and Roos (2003) extends this to multimodal experiences, empirically demonstrating that three-dimensional representations of strategy can help to crystallise participants' understanding of strategy.

Improving strategy implementation is a critical concern in strategy visualisation literature. Both Eppler and Platts (2009) and Kerr, Farrukh, Phaal, and Probert (2013) stress the importance of participant involvement in creating strategy visuals. Phaal and Muller (2009) make suggestions for how to design roadmaps to improve strategy development and implementation, however this is not based on empirical evidence. For example, they suggest that roadmaps should have less than 50 information items in order to prevent information overload. De Salas and Huxley (2014) promote the use of Strategy-as-Process maps. Such maps link strategy closely with organisational processes to increase chances of successful execution.

Additionally, scholars have theorised when different strategy devices are the most suitable and most beneficial in the strategising process. Eppler and Platts (2009) undertook five case studies to demonstrate that a variety of different visualisation methods (strategy charting, parameter ruler, TAPS, synergy map, and the Balanced Scorecard Tree) can be employed within the four stages of the strategy process (analysis, development, planning and implementation). The framework indicates visualisation methods that would be most useful in the strategy process. Platts and Hua Tan (2004) have also built a framework to prescribe when certain strategy visualisation tools would be most appropriate for strategists, depending on the cognitive and operational functions that are desired. For example, if a manager wishes to share understanding (cognitive function) and also see structure, trends and relationships (operational functions) then a strategy chart is optimal. Overall, improving knowledge for how to use visualisation for communicating and developing strategy has received considerable attention in strategy visualisation literature. 


\subsection{Benefits of Strategy Visualisation}

The importance and efficacy of strategy visualisation is another prevalent concern of strategy visualisation researchers. Of major interest within this field are the benefits of visualisation. Eppler and Platts (2009) offer one of the most comprehensive reviews of strategy visualisation benefits. The authors survey wider visualisation literature to identify benefits pertinent for overcoming strategising challenges and also empirically test the benefits with five in-depth case studies. The benefits are grouped into the categories of 'cognitive benefits', 'social benefits' and 'emotional benefits' which correspond to cognitive, social and emotional challenges. Cognitive benefits are related to managerial thinking, social benefits are related to benefits in management communication and coordination, and emotional benefits are related to motivation and engagement of others (Eppler \& Platts, 2009). The strategising challenges and benefits of visualisation are presented in Table 1. This categorisation of visualisation benefits is used in the following three sections to consolidate and review extant literature. My study will add to the categorisation below by exploring whether these benefits are facilitators of visualisation adoption.

Table 1. Summary of strategising challenges and corresponding strengths of visualisation, developed by Eppler and Platts (2009)

\section{Characteristics of strategising} Cognitive challenges Corresponding strengths of visualisation

Struggling with information overloa

Stuck in old view points

Biased comparisons and evaluations Paralysis by analysis

\section{Social cballenger}

Diverging views or assumptions on strategic issues

Incomplete communication of basic assumptions

Un-coordinated strategic action

Emotional challenges

Lacking identification with strategies

Creating identification with (abstract) strategy

Persuading employees of the strategy
Cognitive benefis

Facilitating elicitation and synthesis

Enabling new perspectives

Easier recall and sequencing

Social benefits

Integrating different perspectives

Assisting mutual understanding

Tracking, showing interdependencies

Emotional benefits

Creating involvement and engagement

Providing inspiration

Providing convincing communication
Better, more exhaustive comparison

\subsubsection{Cognitive Benefits}

Strategy visualisation scholars maintain that many of the challenges involved in strategising can be minimised with visualisation. According to Eppler and Platts (2009), cognitive burdens of strategising may be mitigated by exploiting natural human abilities to process greater volumes of information through visualisation. Humans are naturally able to take in more information with visual methods (Larkin \& Simon, 1987; Tversky, 2005) as visual methods take advantage of humans' visual and spatial processing systems (Logie, 1995), helping people to deal with complexity by discerning core relationships rather than peripheral detail (Vessey, 1991). Visual methods also assist cognitive processing capabilities, by enabling people to comprehend key information much more quickly than if the equivalent amount of information was represented through text (Scaife \& Rogers, 1996). Humans will naturally locate patterns (Ware, 2004), and visualisation enables us to locate these patterns amongst copious data (Card, Mackinlay, \& Shneiderman, 1999; Tufte, 1990). We are better able to conceive and understand complexities when they are presented visually, as we have limitations in our visual and verbal working memories (Ware, 2005). Unlike written text, graphic displays can express complex elements and relations to symbolise what happens in real life or to symbolise a metaphoric space (Tversky, 2005). When faced with problem-solving, which is a critical element in strategic decision making (Papadakis, Lioukas, \& Chambers, 1998), visual methods can reduce feelings of 'information overload' by utilising users' innate visual processing abilities to deal with complexity (Cox \& Brna, 1995).

Creativity and imagination is also enhanced with visualisation (Morgan, 2006; Whyte, Ewenstein, Hales, \& Tidd, 2008). Graphics can enable users to view different perspectives as well as restructure users' thinking (De Bono, 1973; Eppler \& Platts, 2009), to overcome being 'stuck' in one frame of mind (Eppler \& Platts, 2009). Carmona et al. (2011) suggests that creativity is enhanced when information is presented visually, as it enables us to see what is missing by forcing us to clarify our thinking processes. This clarification is important for strategy formulation, particularly for ill-defined strategies where there is not a clear link between a current state and an intended goal state (Carmona et al., 2011). Strategy maps help generate creative insights into ambiguous problems, such as connecting low-level actions with higher level 'strategic' initiatives (Carmona et al., 2011). Visuals also allow users to make better comparisons and generate more options (Eppler \& Platts, 2009), investigate what is and is not possible (Garreau et al., 2015), and enhance recall in strategic conversations (Kraut et al., 2003). Greater creativity and innovation have been found to emerge from the bottom up when visuals are used because ideas are shared more readily, thus providing more ideas for selection (Bititci et al., 2015). 


\subsubsection{Social Benefits}

Visualisation is promoted for its ability to support group work. Ideas expressed in group settings can be used and developed collaboratively (Tversky, 2005). Visualisation has been found to support the promotion of an agenda or alternative (Garreau et al., 2015). Visual displays of ideas can open discussion to consider alternative viewpoints (Holloway, 2009), and create parity for participants, balancing dominant views (DiMicco, Pandolfo, \& Bender, 2004). Enhanced dialogue facilitated by strategy maps enables users to learn from the past, promote the evolution of strategy (de Salas \& Huxley, 2014) and even inspire new strategies (Mills, Neely, Platts, \& Gregory, 1998). Displaying ideas visually uncovers areas of conflict (Sparrow, 1998; Whyte et al., 2008) and elements that are not key priorities for the strategy, enabling teams to set more relevant priorities (Bititci et al., 2015; de Salas \& Huxley, 2014). The artefact itself can increase engagement with strategy, as users can draw on the map, making points more salient (Carmona et al., 2011; Cummings \& Angwin, 2011) or add their own interpretations to strategy (Cummings \& Angwin, 2011). Together, these studies outline how visualisation encourages expression of ideas in group situations.

Visuals can create a common level of understanding for participants, by surfacing basic assumptions (Morgan, 2006). Using visuals to articulate the vision of an organisation can make the vision much more accessible and tangible to employees (Bititci et al., 2015). Visualising strategy can support alignment by keeping everyone on the 'same page' (de Salas \& Huxley, 2014; Holloway, 2009) as a medium of common reference while implementing the strategy (Bititci et al., 2015; Eppler \& Platts, 2009); this can improve group coordination and alignment (Bechky, 2003; Bititci et al., 2015; Holloway, 2009; Phaal \& Muller, 2009) to execute the strategy as intended (Eppler \& Platts, 2009).

The visual artefact also enhances knowledge sharing as a 'cache of information' that can be transferred easily (Garreau et al., 2015). Visually displayed messages improve communications to internal and external stakeholders as part of the internal-external 'line of thinking' within organisations (Bititci et al., 2015). Good communication is essential for strategy implementation, as according to Carmona et al. (2011), communication of strategy must be persuasive and accurate; implementers "must understand their role in the whole and come to believe success is achievable" (p. 67). Scholey (2005) similarly observes: "Many strategies fail in the execution stage as a result of communication issues — strategy mapping alleviates many of these communication issues through the use of pictures, something most everyone can understand" (pp. 13-14). This signals the importance of visualisation for executing strategy.

\subsubsection{Emotional Benefits}

The emotional benefits of visualisation are useful for strategy makers; to enliven strategy and engage audiences (Bititci et al., 2015; Buzan \& Buzan, 2000; Huff \& Jenkins, 2002). In the strategising process it can be difficult to distil something tangible from abstractions, and then convince implementers that the strategy merits execution (Holloway, 2009). Employees must be persuaded that the strategy is worth following (Acur \& Bititci, 2003; Digman, 1990), and Eppler and Platts (2009) note that visuals can help with this, due to their persuasive power (Horn, 1998). Specifically, strategy maps can improve strategy execution by illuminating objectives and outcomes that must be monitored, directing attention to the key priorities (e.g. processes and activities) required to change (de Salas \& Huxley, 2014; Kernbach et al., 2015). Graphically depicting causal relations in strategy maps enhances visual rhetoric (the ability to influence using graphics), because some features can be made more salient while other features are played down (Free \& Qu, 2011); and can effectively show links between improvements and desired outcomes (Kaplan \& Norton, 2000). By depicting causality, a strategy map is an influential tool through providing a perception of scientific authority, without the need to empirically verify claims (Free \& Qu, 2011).

When users are involved in the creation of visualisation, this can inspire and excite, as users identify with the strategy (Bititci et al., 2015), increasing their motivation to execute the strategy (Buzan \& Buzan, 2000; Holloway, 2009) because users are proud of what they have accomplished (Bititci et al., 2015). Although not clearly stated to be a 'benefit', Eppler and Platts (2009) observed that management practitioners which created strategy charts, found that the experience was enjoyable and thought-provoking. The use of visualisation has been found to inspire culture change and encourage openness and participation (Bititci et al., 2015), resulting in a continuous improvement culture and increased innovation processes. For example, Bititci et al. (2015) found through action research that visualisation was an effective tool to support the formation of an organisational culture which actively considered responsiveness and therefore, a new way of planning and monitoring within the business. In light of the reported emotional benefits, visualisation supports strategy as the communication, coordination and motivation to undertake strategy appear to be greater when visualisation is used.

The research on cognitive benefits has so far been the most exhaustive. This was also a finding by Bresciani and Eppler (2015), who observed that the literature on strategy visualisation benefits emphasises cognitive benefits in favour of social and emotional benefits. Roos, Victor, and Statler (2004) support this notion, stating: "While social and emotional modes 
of experience are involved in strategy process, in general they are suppressed in favour of cognitive elements" (p. 551). Despite the proliferation of literature on the cognitive benefits of visualisation, there is no empirical data to suggest that cognitive benefits have more utility over social and emotional benefits. The benefits reported thus far are, for the most part, theoretical.

Furthermore, the reported benefits of visualisation do not necessarily mean that al visualisation methods will yield the same benefits. More recent empirical inquiries have been made into the utility of different visual techniques. ${ }^{2}$ However, the empirical research on visualisation to date concentrates on the efficacy and performance of visualisation. Less clear is why so few organisations adopt visualisation; the barriers have yet to be explicitly identified.

\subsection{Challenges of Visualising}

More recent attention in visualisation literature has focused on the challenges of creating and implementing visualisation, and how practitioners may overcome these challenges. Bititci et al. (2015) argues that more insight is needed into the pitfalls of visualisation, noting that visual methods are not perfect and without risk. Says Eppler and Platts (2009),“[i]f used ineffectively, visualisation can lead to superficial analysis, overgeneralization, and to the mere illusion of deep understanding" (p. 62).

A topic of interest to strategy visualisation scholars has been the difficulties associated with the development of strategy visualisation. By observing how managers create strategy visuals, Eppler and Platts (2009) note potential challenges for visualising. During this process of developing visualisation, managers tended to omit information or erase details, especially when this information was considered politically sensitive. Other times, managers would attempt to alter the strategic story to make it sound more logical, after it was displayed visually. The scholars suggest that this could have implications for face-to-face strategy discussions. Additionally, Eppler and Platts (2009) observed that some participants in their study were reluctant to voice their concerns when creating strategy visuals, which could lead to rushed generalisations or at its worst, groupthink. Groupthink is a phenomenon which occurs when group members surrender individual judgment in favour of the group's desire for harmony or consensus, which means alternative courses of action are not considered Janis, 1972). However Mills et al. (1998) claim that in the formation of strategy charts, the validity of the content is less of a concern to managers than the order that is established. The authors argue that strategy charts serve as a springboard for activity; they enable people to anticipate that there is an order, and it is this anticipation in itself which animates managers, inviting managers to impose order on the situation in order to determine and initiate the next action (Mills et al., 1998). Therefore, challenges may also be specific to the type of visualisation methods used.

The use of visuals when creating strategy can also present other challenges. Importan elements of the strategy may be overlooked. Visuals can become such a focal point in discussions as to disconnect the strategy document from the wider company strategy (Garreau et al., 2015). Although visuals permit multiple viewpoints to be considered (DiMicco et al., 2004), visuals can also make it difficult for others to add input when certain participants have dominant views (Garreau et al., 2015), thus contradicting DiMicco et al. (2004). In examining the impact of different visualisation modes on inter-organisation collaboration, Comi and Eppler (2011) found that the use of visual facilitation made conversation less spontaneous. 
Creating strategy visuals that communicate the strategy effectively and help to drive implementation is another difficulty of visualisation. Oversaturated strategic content has been found to make visual displays difficult to read (Eppler \& Platts, 2009). Additionally if visual metaphors are used (e.g. strategy visualised as a literal 'stream' of actions) there is potential for the strategy to become misinterpreted (refer to Figure 19 in Appendix A for an example of a visual metaphor) (Kernbach et al., 2015). One quality of visual metaphors is that they can be ambiguous and can be read in multiple ways (Kernbach et al., 2015) meaning that strategy may not be carried out in the way it was intended. Bresciani and Eppler (2015) offer an extensive review of the managerial challenges of designing and interpreting visualisation, however this is not explicitly related to strategy.

While a number of challenges associated with both viewing and accepting visuals have been put forward, strategy visualisation studies have concentrated on these challenges to improve the efficacy of strategy visualisation or strategising outcomes. Visualisation scholars have stressed the need for acceptance of visuals by the participants who work with strategy visuals, which can be a challenge in itself (Eppler \& Platts, 2009). The level of user acceptance to visualisation can differ amongst individuals (Meyer, 1997). Through developing visuals for five organisations as part of an action research study, Eppler and Platts (2009) observed that subjects involved in the study needed to be open to experimentation with visuals and be willing to adopt a new routine to use their proposed synergy map to implement it.

However visualisation tools can be difficult to use, resulting in unwillingness by managers to engage with visuals. In experimental and action research involving visualisation, participants are often provided a facilitator to instruct and guide participants in the study (e.g. Comi \& Eppler, 2010; Eppler \& Platts, 2009). Eppler and Platts (2009) noted that at times it was difficult for managers to accept visuals because it can take several hours to become proficient with visual tools. Through observing managers' engagement with strategy charts, Eppler and Platts (2009) found that the construction of the map has the potential to generate meaningful discussions, however they claim that these benefits are not attainable if managers are not open-minded and lack the ability to create a "balanced" strategy chart (p. 49). The acceptance of visuals could be linked to a manager's perceptions of their skill sets in relation to a particular visual method. This perception could constrain the list of alternatives that managers consider when deciding whether to use visuals, however these theories have yet to be empirically tested. Overall, it is not clear from the study whether these challenges inhibit the uptake of visualisation in practice, warranting further investigation.

\subsection{The Rational Perspective}

Strategy visualisation literature has concentrated on improving the efficacy of visualisation, by highlighting the benefits of using these methods; providing responses for overcoming challenges; and prescribing when and how to use strategy visuals. However, if there are multiple strategies for how to best employ visualisation, and there are many documented benefits of using visualisation, then why is the use of visualisation not a widely accepted practice? The rational perspective seems to be the pervading lens through which strategy visualisation has been examined, however this perspective does not explain why in practice, there is little evidence to suggest that organisations use strategy visualisation. A paucity of literature exists about the factors that facilitate or inhibit organisations from using visuals.

This rational perspective implies that managers select visualisation as they deem the visualisation to be the most effective for achieving certain outcomes (Gunn \& Williams, 2007; Jarzabkowski \& Kaplan, 2015). For example, Eppler and Platts (2009) present a comprehensive framework of visualisation benefits and associated challenges. One of the practical implications of this framework is that it will help practitioners make wiser choices when selecting visualisation methods for strategy making. Implicitly, practitioners will have the ability to discern what the most effective outcome is and want to implement that visualisation method. This rational perspective is not discussed in strategy visualisation literature, yet the articles are entrenched in this belief. Conversely, we can turn to strategy-aspractice research.

Strategy-as-practice scholars have challenged the assumption that strategy tools are used 'rationally' or 'correctly' (Jarzabkowski \& Kaplan, 2015). This follows research which has cautioned against assigning excessive faith in strategy tools (Mintzberg, 1994, 2004). Overreliance can lead to improper decisions and poor strategic outcomes (March, 2006). Strategy-as-practice research draws our attention to the gap between the theory of how tools should be used and how such tools are used in real life (Jarzabkowski \& Kaplan, 2015). Jarzabkowski and Kaplan (2015) suggests that a user's commitment and recommitment to a tool may not be as rational as we would expect. In particular, Jarzabkowski and Kaplan (2015) reviewed literature that has examined the proliferation of certain visual frameworks like Porter's Five Forces (Porter, 1979) and the SWOT matrix in business schools and in management consultant practice. ${ }^{3}$ Jarzabkowski and Kaplan (2015) go on to argue that these

3 Porter's Five Forces framework describes five forces which can determine the long-term profitability of industries. The five forces are: bargaining power of suppliers, threat of substitutes, bargaining power of buyers, threat of new entrants, and industry rivalry. 'SWOT' is an acronym for: strengths, weaknesses, opportunities and threats. The purpose of conducting a SWOT analysis is to compare the internal environment of firms with the external competitive environment, and locate competitive advantage (Pickton \& Wright, 1998). 
management tools may be used not because they are the 'optimal solutions' but rather from familiarity; ease of use; minimal skill needed; and search and adoption times for better tools. States Jarzabkowski and Kaplan (2015), "the selection of tools may be more dependent on standardized organisational use than on the fit of the tool with the situation in the environment" (p. 542). Through conducting a survey on the usage of strategic tools by Chief Executives, Gunn and Williams (2007) found that strategic tool usage were often linked to the backgrounds of these CEOs. For example, academically trained managers typically used tools such as McKinsey's '7S' framework, while professionally trained managers often used tools common to their industry, such as the Balanced Scorecard. Selection of a strategy tool, like a visualisation tool, may not be as straightforward as selecting the optimal solution; tools might also be adopted because they are simple and easy to remember Jarzabkowski \& Kaplan, 2015) or due to educational backgrounds (Gunn \& Williams, 2007).

While there may be intended uses for strategy tools, Jarzabkowski and Kaplan (2015) also noted that it is not clear whether these tools are selected because of these intended reasons:

There is much to suggest that the choice of tools is shaped by actors' competence in their use, power
in their organisation, and their bounded rational satisficing where, in many cases, a wide variety of in their organisation, and their bounded rational satisticing where, in many
tools would be considered suitable for a particular strategic issue. (p. 541 )

Visuals have been heralded for their ability to create engagement. However, Bititci et al. (2015) observed in their empirical study that visuals were more often used as a way for senior managers to communicate downwards, rather than creating engagement and enabling everyone to participate in strategic conversation. Not all benefits are created equal. There could be reasons why managers choose to adopt or reject visualisation, which the literature has yet to explore.

Jarzabkowski and Kaplan (2015) argue that debating the incorrect (irrational) vs. correct (rational) use of tools is a pointless exercise that does not help us understand the dynamics involved when using these tools. If we can instead examine the dynamics of visualisation adoption, we may begin to understand the factors which facilitate or inhibit the adoption of visualisation in organisations.

\subsection{How are Visuals Adopted?}

While Eppler and Platts (2009) have noted the importance of the acceptance of visualisation for its implementation, empirical research is necessary to understand how visualisation is adopted. Applying a practice lens to strategy visualisation can help examine how visualisation is chosen and adopted. Proponents of the strategy-as-practice perspective argue that we cannot separate the strategy tool from its use (Jarzabkowski \& Kaplan, 2015; Orlikowski, 2000, 2010; Orlikowski \& Scott, 2008).

The process of developing visuals has begun to receive greater acknowledgement in strategy visualisation literature. As indicated in the discussion of visualisation benefits, developing strategy visuals has been found to be important for developing successful strategies (Bititci et al., 2015). Along the same sentiment, Eppler and Platts (2009) assert that the process of developing visuals is more valuable than the artefacts alone. They argue that this development stimulates dialogue between participants and imparts an ability to create consensus. Visualising the strategy makes strategy come alive; it is something that people take ownership of, rather than becoming something that is done and forgotten. Phaal and Muller (2009) observe that the success of strategy roadmaps relies on the user's ownership of the roadmaps and the road-mapping process. Consequently, the tools used to create strategy visuals may be less important than the overarching processes in which the tools are used, warranting research into the process by which visuals are adopted.

Exploring strategy tools as a means to an end is a parallel concern of strategy-as-practice research and answers calls to enhance strategy communication. Practice scholars advocate more research into the practical usage of strategy tools, in order to better bridge the gap between theory and practice (Wright, Paroutis, \& Blettner, 2013). One such empirical study examined the perceived usefulness of strategy tools. The authors found that managers sought strategy tools for specific features, such as facilitating multiple perspectives, idea generation, easing communication and seeing interconnections (Wright et al., 2013). Such characteristics imply visualisation benefits, as reported in Section 2.4. While this research provides greater understanding of features that are actually useful for managers, scholars have pointed out that seeking tools is not the same as adoption (Jarzabkowski \& Kaplan, 2015). Jarzabkowski and Kaplan (2015) theorise the relationship between actors and the affordances of tools, in terms of how tools are selected, applied and the consequent outcomes of using these tools. This has yet to be empirically tested, and the process of adopting visualisation has yet to be explored. If we can understand how visuals are adopted, we may begin to get a greater understanding of why visuals are not adopted as readily in real-life, despite the many reported benefits of visuals. 
As argued by Gunn and Williams (2007); a greater understanding of tools (such as visualisation) is useful not only for research but also for practice. With decision making as an integral part of strategy making (Papadakis et al., 1998), Wright et al. (2013) argue that the purpose of strategy tools is to enable better decision making. Managers are expected to deal with increasing complexity and ambiguity, while juggling multiple issues simultaneously (Gunn \& Williams, 2007). Consequently, Gunn and Williams (2007) predict that managers will need tools and techniques to manage these challenges. This argument aligns with the view of strategy visualisation scholars described in this chapter, who detail 'how to' and 'why to' use visualisation for strategy making. Researching the adoption of visualisation would thus complement research on strategy visualisation and strategy tools with a better understanding of how to improve visualisation or the processes by which it is implemented so that it is actually adopted in practice. 


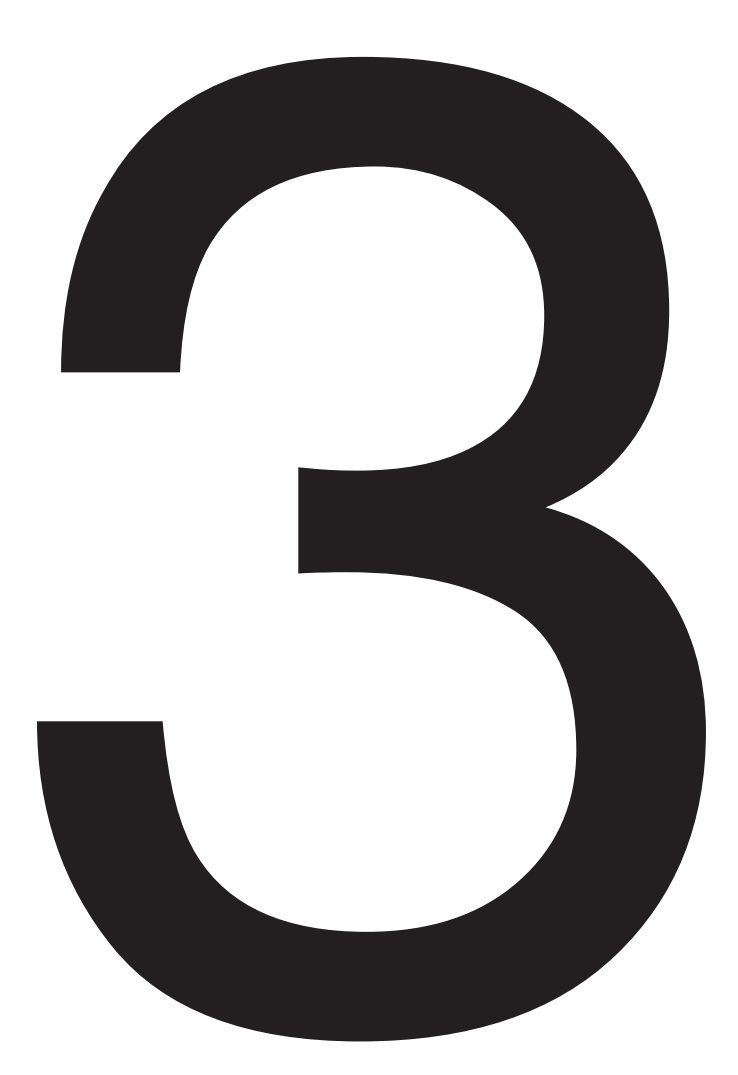

METHODOLOGY

\begin{tabular}{lll}
\hline $\mathbf{3 . 1}$ & Chapter Introduction & $\mathbf{3 1}$ \\
$\mathbf{3 . 2}$ & Methodological Approach & $\mathbf{3 2}$ \\
3.2 .1 & Applying the Strategy-as-Practice Perspective & 32 \\
3.2 .2 & Qualitative Research & 35 \\
3.2 .3 & Abductive Reasoning and Implications for Research & 37 \\
$\mathbf{3 . 3}$ & Interviewee Recruitment & $\mathbf{3 8}$ \\
$\mathbf{3 . 4}$ & Purposive Sampling & $\mathbf{4 0}$ \\
$\mathbf{3 . 5}$ & Interviewees & $\mathbf{4 1}$ \\
3.5 .1 & Participant Information & 41 \\
3.5 .2 & Examples of Visual Styles used by Respondents & 44 \\
$\mathbf{3 . 6}$ & Data Collection & $\mathbf{4 8}$ \\
3.6 .1 & Developing the Interview Guide & 48 \\
3.6 .2 & Conducting the Interviews & 49 \\
$\mathbf{3 . 7}$ & Data Analysis & $\mathbf{5 0}$ \\
3.7 .1 & Thematic Analysis & 50 \\
3.7 .2 & Transcription and Data Analysis Process & 51
\end{tabular}




\subsection{Chapter Introduction}

The theoretical gap this research will address has been established. This chapter describes the methodology that directed my research inquiry. I believed the approach taken by Guba and Lincoln (1994) to be convincing; they considered how the methodological approaches taken when conducting research is shaped by each researcher's ontological and epistemological beliefs. Ontology represents one's 'nature of reality' while epistemology refers to the nature of the relationship between the knower and the subject of inquiry (Guba \& Lincoln, 1994). Alvesson and Sköldberg (2000) stress the primacy of understanding one's ontology and epistemology over strictly following methods for generating good social science research. Accordingly, my thesis was approached with the belief that a researcher's philosophical assumptions influence the research design and should be acknowledged (Rose, Spinks, \& Canhoto, 2014). This chapter describes the paradigm and explains why this research is suitable for the paradigm. Further sections describe the research design and sample that I used. The limitations of the research design are noted in Section 5.4 


\subsection{Methodological Approach}

\subsubsection{Applying the Strategy-as-Practice Perspective}

As argued in Chapter 2, the strategy-as-practice view can offer new insights to strategy visualisation research. This potential for new insights made the strategy-as-practice view appropriate for informing the research design. Doing so would help demonstrate a need to direct some of the conversation about strategy visuals from 'good or poor use' towards an understanding of how visualisation is adopted (Jarzabkowski \& Kaplan, 2015), particularly those factors that facilitate or inhibit the adoption of visualisation. This would also contribute to extant strategy-tools-in-use literature (a particular research stream in strategy-as-practice literature).

I believed that the ontological and epistemological assumptions that underpin the strategy-aspractice perspective to yield greater utility for this research over other research paradigms. The positivist and post-positivist traditions underline most of the strategy visualisation research. Such approaches are underscored by the 'realist' epistemology, which conceives that there is a "real" reality that can be determined through research (Guba \& Lincoln, 1994). However I am of the belief that ontological beliefs or assumptions are individual and subjective, so we cannot completely eliminate bias. In my view, we cannot ever completely locate 'reality', because reality is something that is a product of our constructions. This put me at odds with the realist perspective, and much more at ease with a constructivist epistemology which conceives that research cannot be completely objective and interpretation free. According to Steedman:

Nothing means anything on its own. Meaning comes not from seeing or even observation alone, for there is no 'alone' of this sort. Neither is meaning lying around in nature waiting to be scooped up by the sense: rather it is constructed. 'Constructed' in this context, means produced in acts of interpretations. (1991, p. 54)

In other words, in the constructivist worldview, data and facts are not free from interpretation and are socially constructed. Strategy-as-practice scholars have adopted this ontology, viewing strategy as socially constructed (Jarzabkowski, 2004), and a human activity; they emphasise that strategy should be studied like any other social practice (Whittington, 2007). ${ }^{4}$ Thus, I found the ontological assumptions of this practice perspective the most persuasive.

4 For brevity, only an overview of the strategy-as-practice ontology is presented here. However, Seidl and Whittington (2014) provide a comprehensive review of the multiple ontological positions in strategyas-practice research pertaining to the relationship between 'micro' strategising practices and 'macro' social phenomena.
The strategy-as-practice perspective conceives strategy as "a continuously unfolding stream of activity that is constructed through the interactions and negotiations between different actors" (Jarzabkowski \& Balogun, 2009, p. 1261). Taking a strategy-as-practice approach to strategy visualisation literature enables us to recognise the importance of context, highlighting how visualisation practices are embedded in their contexts (Whittington, 2007), as opposed to a focus on the performance of strategy visualisation tools. Rather than viewing visuals as a means to an end, this approach recognises the dynamic interplay between actors adopting visualisation, and the roles of individual and organisational objectives (Jarzabkowski \& Kaplan, 2015). This approach emphasises the need to study micro-phenomena or 'the mundane' (such as visualisation) in relation to a wider context (Jarzabkowski et al., 2007). Indeed, strategy-as-practice researchers have begun to conceive strategy tools in this way (Carlile, 2006; Golsorkhi, Rouleau, \& Vaara, 2010; Hendry, 2000; Jarzabkowski \& Paul Spee, 2009; Whittington, 2006). For example, Carlile (2006) examines how strategy tools such as Gantt charts and process maps can help to clarify inter-functional dependencies. Other scholars have examined socio-materiality in organisations and how the use of material artefacts in organisations is fundamental for accomplishing strategy work (Heracleous \& Jacobs, 2008; Jarzabkowski, Spee, \& Smets, 2013).

The strategy-as-practice approach considers strategising as an activity that sits at the nexus of practice, practitioners and praxis (Jarzabkowski et al., 2007). 'Praxis' represents the flow of actions between actors and the broadly accepted embedded institutions that these actors engage (Jarzabkowski et al., 2007). In simpler terms, 'praxis' represents what strategy practitioners actually $d o$, the activities that are taken (Whittington, 2006). 'Practices' refers to the "shared routines of behaviour" (Whittington, 2006, p. 619). This can include norms, traditions, frameworks for thinking and acting (Whittington, 2006). Practices can encompass many interconnected elements, including: physical activities, mental activities, objects and how these objects are used, knowledge, know-how, emotions, and motivations (Reckwitz, 2002). Inextricably linked to practice are 'practitioners'; these individuals "shape strategic activity through who they are, how they act and what practices they draw upon in that action" (Jarzabkowski et al., 2007, p. 10). The practice perspective recognises the importance of understanding the backgrounds of practitioners, what enables practitioners to act upon practices and also the situation and context in which their actions are enabled (Jarzabkowski et al., 2007). In this view, strategy is something that people 'do' rather than something that organisations 'have' (Güney \& Taylor, 2014; Jarzabkowski et al., 2007). This is in stark contrast to the prevailing realist approach that sees strategy visualisation as something that an organisation 'has', for example it focuses on the performance of artefacts for improving strategy. 
While a few studies have begun to study visualisation as a practice (Güney \& Taylor, 2014; Paroutis et al., 2015), I believed recognising the subjectivist epistemology inherent to constructionism would contribute new insights to visualisation literature. The current practice research on strategy visualisation assumes an objectivist epistemology. Such approach plays down the presuppositions of the researcher in order to study the phenomenon (visualisation) in context, on its own terms (Rose et al., 2014). However, as a constructivist researcher, I am of the belief that the research findings consequently unfold through a process of interaction between and among the researcher and the respondents (Guba \& Lincoln, 1994). Recognising these implications for the findings was an important consideration for the research design to establish trustworthiness in my research findings (Guba \& Lincoln, 1994) and I believed this novel approach would add to our understanding of strategy visualisation.

\subsubsection{Qualitative Research}

The heavy emphasis on studying the interconnections between people, practitioners and context indicated to me that qualitative methods would be most appropriate for the research. Such research would capture rich detail about the lived experiences of visualisation adoption, which would facilitate a better understanding of these connections (Rose et al., 2014). This detail would be difficult to acquire with quantitative methods that promote standardisation (Alvesson \& Sköldberg, 2000). My study was also intended to be exploratory, making quantitative research unsuitable. Quantitative research typically tests relationships between 'known' variables (O'Leary, 2014), with predetermined, fixed research designs being common characteristics (Rose et al., 2014). However, qualitative research promotes flexibility and the ability for concepts to emerge (O'Leary, 2014). Qualitative research aligns with suggested methodologies for constructivist researchers, which highlights that constructions are personal and variable and may change or become refined through processes of interaction between the investigator and the investigated (Guba \& Lincoln, 1994).

Furthermore, undertaking qualitative research is warranted when little is known about a phenomenon (Rose et al., 2014). Although there are a variety of other methods that could be employed in qualitative research (such as observation, focus groups and open-ended questionnaires) (O’Leary, 2014), I considered in-depth qualitative interviews the most efficient method for obtaining rich empirical data about the facilitating or inhibiting factors of visualisation adoption. This method enables the participants' experience with their 'lived world' (or the adoption of visualisation) to quickly be elucidated (Kvale \& Brinkmann, 2009; Rose et al., 2014). The individual and subjective nature which characterise in-depth qualitative interviews (Kvale \& Brinkmann, 2009; Rose et al., 2014) provides insight into the interconnection between context and the facilitating and inhibiting factors to visualisation from a variety of perspectives. Interviews also highlight the influences of biases and the interpretation process between myself and the interviewees, which is in keeping with the research paradigm (Alvesson \& Sköldberg, 2000).

The rich contextual information gained from the interview data collected would also generate understanding about the discrepancies between what is stated in strategy visualisation literature and what is done in practice. As seen in Chapter 1, while the visualisation benefits are well documented, this optimism is disproportionate to the amount of organisations which use visualisation for strategising. Action research has been undertaken by strategy visualisation scholars, where visualisations were developed for real-life organisations to help 
support strategy making and implementation (e.g. Bititci et al., 2015; Bürgi \& Roos, 2003; de Salas \& Huxley, 2014; Holloway, 2009). However, I believe that participants of this action research would have a predisposition for visualisation methods as engaging in this research requires willingness to invest time and effort to implement the visualisation. In other instances, scholars directed participants of experimental research into strategy visualisation to use specific visualisation methods (e.g. Comi \& Eppler, 2011). Although useful for examining the efficacy of visualisation methods or comparing visualisation methods, the settings in which this research was conducted favour the utilisation and outcomes of visualisation, which does not tell us why visuals are not used in practice.

\subsubsection{Abductive Reasoning and Implications for}

\section{Research}

I used abductive reasoning in this empirical research to answer the research questions. This approach synthesises the inductive and deductive approaches. Applying a deductive approach requires that researchers attempt to prove or disprove theories or arguments that exist in literature (Alvesson \& Sköldberg, 2000; 2009). In contrast, applying inductive reasoning to empirical research means that researchers do not restrict research inquiry to existing theories or arguments, and enable concepts and connections to emerge from the raw data (Alvesson \& Sköldberg, 2000). This research attempts to build theory from the interview data; there is very little research on the adoption of visualisation to 'test'. However, I also wanted to approach the data with an 'open mind' in order to see new possibilities (Alvesson \& Sköldberg, 2000). Going back and forth between the data and existing literature fits with the abductive approach that Alvesson and Sköldberg (2009) define as a "hermeneutic process during which the researcher, as it were, eats in to the empirical matter with the help of theoretical pre-conceptions, and also keeps developing and elaborating the theory” (pp. 5-6).

This hermeneutical approach is consistent with the constructivist stance taken in my research, as hermeneutic methods are recommended for constructivist research (Guba \& Lincoln, 1994); such approach is also consistent with recommendations for reflexive research (Alvesson \& Sköldberg, 2000). Reflexive research is important for this constructivist approach as it encourages myself to question and clarify taken-for-granted assumptions, as a check against my own biases and constructions of social reality. Thus, I took a suggested approach by Alvesson and Sköldberg (2000) for reflexive research whereby I had a "general look through the broad outlines of the theoretical and empirical research field, followed as quickly as possible by a leap into one's own empirical material" (Alvesson \& Sköldberg, 2000, p. 17); the research process alternated between established theory and empirical facts, "whereby both are successively interpreted in the light of each other" (Alvesson \& Sköldberg, 2009, p. 5). To maintain this abductive approach, I constantly and reflexively referred to strategy visualisation literature and other related areas of research identified in the literature review during the research process. Interpretations of empirical data were not confined to extant theory, as there were no existing theories which have sufficiently discussed the facilitating or inhibiting factors to the adoption of strategy visualisation or strategy tools. 


\subsection{Interviewee Recruitment}

Initially, I wanted to interview representatives from organisations that have developed visualisation within their organisation in order to understand, from their perspective, the factors that facilitate or inhibit their use of visualisation. Ultimately, I decided that this study would not ask managers to self-report on their visualisation experiences and activities. It would have been too difficult to find a credible sample, to meet the criteria of 'trustworthiness' and 'authenticity' for constructivist research (Guba \& Lincoln, 1994).

I investigated organisations that provide visualisation services and deemed them an appropriate population to draw a sample for the study, as I believed that representatives from these organisations could provide a comprehensive view of their clients' adoption activities (Rose et al., 2014). These organisations would have experience dealing with clients who choose to use visualisation or not use visualisation. Therefore, I believed that this experience affords these organisations the ability to identify different facilitators or inhibitors to the adoption of visualisation. Studying visualisation consultants would also enable extension of research on strategy-as-practice. Practice scholar, Whittington (2007) argues that we need to consider the multiple actors involved in strategy making, including middle managers and consultants.

The existence of visualisation organisations strongly suggests that there is a demand for visualisation services which these organisations fulfil. However, discussion of these organisations has received no attention in visualisation literature. While attempting to locate a sample through a web search, I located an International Forum of Visual Practitioners which has 350 visual practitioners as of April 2016 ; this number is not inclusive of all the visualisation organisations which can be located on the web. Additionally, it is evident that these organisations have developed novel methods of visualising information to support organisations (see Section 3.5.2), which differ to the visualisations discussed in the literature review. Interviewing visualisation organisations would thus provide a comprehensive understanding of the visualisation methods used in practice and a better insight into the external adoption of visualisation (i.e. hiring visualisation services). Strategy visualisation literature has yet to clarify the difference between internal adoption of visualisation and external adoption (i.e. developing visualisation with or without external help), and its implications for participants involved in visualisation

5 The original IFVP website indicates there are 350 IFVP members as at April 28, 2016 (hitp://ifvpcommunity.ning.com/proflies/members/), however as of May 2016, the aforementioned website was disestabished. See https://www.ifvp.org for the new website.
As the major objective of this study was to examine the facilitating and inhibiting factors to strategy visualisation my original intention was to study interview representatives from strategy visualisation organisations, however my Google search on "strategy visualisation" in July 2015, indicated that this would prove more difficult than anticipated. I found the term 'strategy visualisation' to have no common lexicon in practice. This is unsurprising given that there are multiple definitions of strategy visualisation (see Section 2.2). Through an initial scan of the websites of visualisation organisations, it appeared to me that some organisations offered visualisation services that could have been used to support strategy, but were not always explicitly linked to "strategy". ${ }^{6}$ Many of the visualisation organisations that offered "strategy visualisation" services, also offered general visualisation services to organisations with the intention of helping support these organisations in their work. Tackling the topic of what 'strategy visualisation' entails or does not entail was outside the scope of my research. For this reason, I expanded my web search to include "strategy visualisation organisations" as well as graphic recording, graphic facilitation and other forms of visualisation which serve to support organisational activities. 'Graphic recording' is the act of visually noting ideas while a discussion unfolds; this often involves mapping ideas and making the key concepts prominent (Sibbet, 2010). This practice of recording visual ideas is also undertaken in 'graphic facilitation'. However in 'graphic facilitation', these ideas are often presented on a large-scale and its purpose is to help participants learn complex topics easily and the visual process is guided by a group facilitator (Galagan, 1993).

Although my study did not explicitly research 'strategy visualisation', contribution to strategy visualisation literature was a goal for me. I decided that the study would make its contribution through discussion of how the findings could enhance strategy visualisation literature. Additionally, I would discuss how the findings could have implications for strategy making as well as the adoption of visualisation in general.
6 In doing this I wished to see which visualisation organisations associated their services with the term 'strategy', as opposed to suggesting that there is a commonly agreed upon definition of strategy. 


\subsection{Purposive Sampling}

To select interviewees to partake in the research, I used purposive sampling. The intention of qualitative research is to develop rich and detailed insights rather than make claims of statistical representativeness, as is the case in quantitative research (Rose et al., 2014). In purposive sampling, cases are selected for their theoretical relevance to the subject of research inquiry (Rose et al., 2014). I decided representatives from visualisation organisations who had regular dealings with clients to be the most suitable for the study, as they could provide an overview of the facilitators and inhibitors to visualisation that their clients face, and any relationships between the constructs. I screened organisations based on the descriptions of the visualisation services that they provided and visualisations available on their website (to confirm that they did in fact visualise).

Ten was the ideal number of respondents to answer the research questions sufficiently. Kvale and Brinkmann (2009) recommend that researchers conduct between 5-25 interview studies in order to gain enough knowledge about the topic of inquiry. However they caution against assuming that a larger sample size is 'better', suggesting that the larger the sample, the less time there is to thoroughly analyse the data due to complexity and volume (Kvale \& Brinkmann, 2009). Ten interview studies was thus my tentative goal to obtain. To acquire this, I contacted 17 visualisation organisations via email. Introductory emails were sent to the potential interviewee directly or to a generic company email address located on the website of the organisation. Following this, an information sheet and consent form were sent to participants who agreed to participate (see Appendix B \& C). I clearly stated in the emails and information sheet that the study sought information on the factors which facilitate or inhibit their clients' adoption of visualisation, to ensure potential interviewees were those who had dealings with clients. One respondent was contacted through a personal connection and two other respondents were contacted through professional connections that my supervisor had obtained. To avoid making potential study participants feel pressured into undertaking the interview I made it clear in emails to these three participants that it was optional to participate. These participants were presented with the same information form and consent form that the other participants received. Out of the 17 visualisation organisations contacted, ten consented to interviews.

After the tenth interview, I judged that theoretical saturation had been reached, whereby interviewing more respondents would have added little improvement to theory; I felt that the themes that were emerging were very similar to previous interviews (Kvale \& Brinkmann,
2009). There was sufficient data to answer the research questions (Kvale \& Brinkmann, 2009), to meet the criteria of 'trustworthiness' and 'authenticity' for quality constructivist research (Guba \& Lincoln, 1994). Furthermore, the schedule required progression to the analysis stage, in order to have ample time to prepare and analyse the data (Kvale \& Brinkmann, 2009).

\subsection{Interviewees}

\subsubsection{Participant Information}

The respondents resided in five different countries. However, in a few instances, the respondents were the only visualisers (i.e. visualisation consultants, graphic recorders and/ or graphic facilitators) who met the interviewee criteria in their respective city or country. Thus, to protect the confidentiality of all respondents, only general geographic locations of respondents can be provided (see Table 2 and Figure 1). Also indicated in Table 2 is whether participants partook in member checking interviews. Including more descriptive information (e.g. about their services) would yield little value for this exploratory study.

Table 2. Information about interviewees

\begin{tabular}{lll} 
Interviewees & Geographic location & $\begin{array}{l}\text { Provided feedback on preliminary } \\
\text { findings }\end{array}$ \\
\hline V1 & Midwest, USA & Y \\
V2 & West Coast, USA & N \\
V3 & Middle East & Y \\
V4 & West Coast, USA & Y \\
V5 & United Kingdom & N \\
V6 & Western Europe & N \\
V7 & Australasia & Y \\
V8 & United Kingdom & N \\
V9 & West Coast, USA & Y \\
V10 & West Coast, USA & N
\end{tabular}




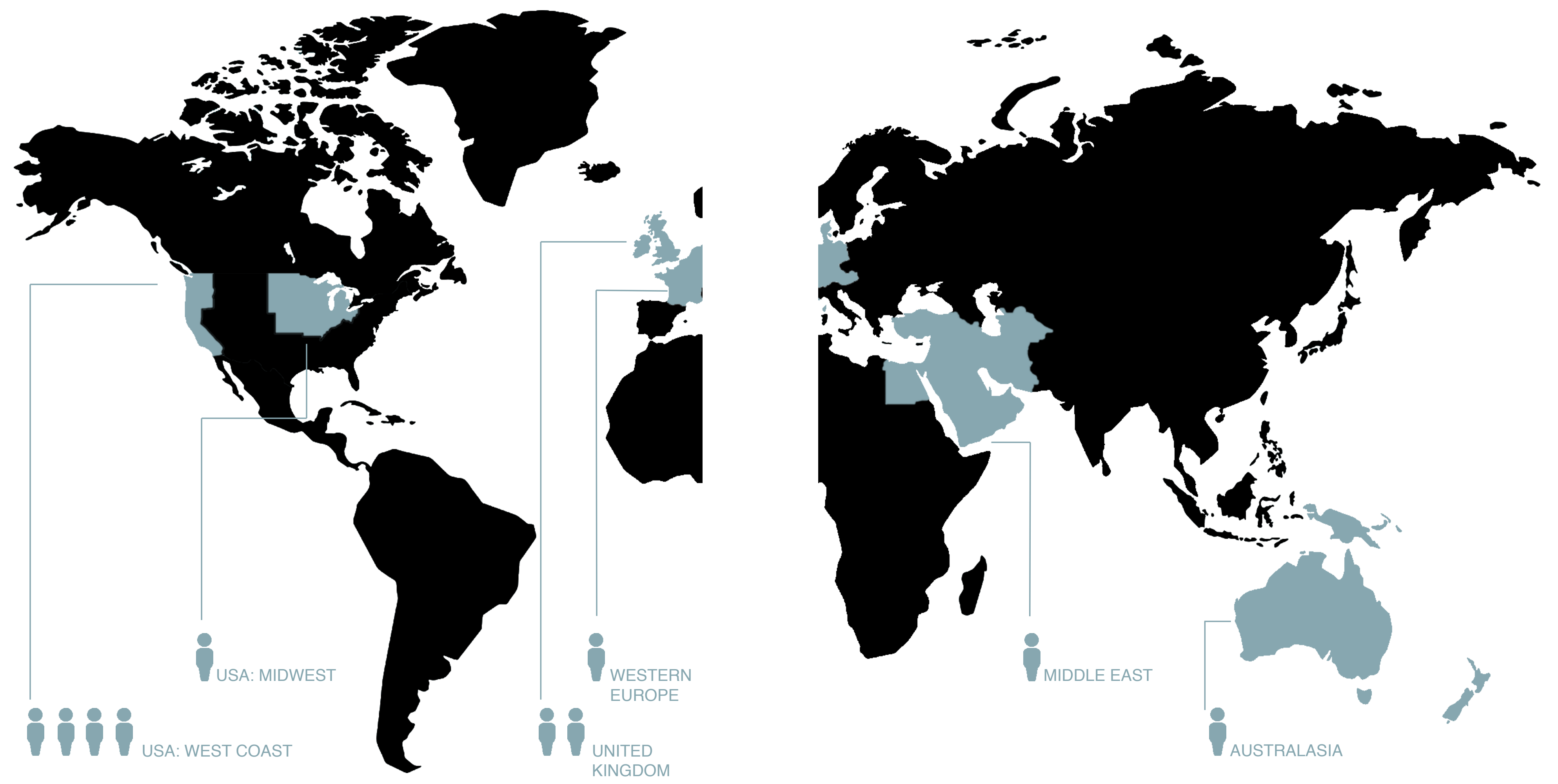


3.5.2 Examples of Visualisation Styles used by

Respondents

To protect the confidentiality of respondents, the images displayed below are only used to illustrate the types of visuals used by respondents. Images included here may or may not have been sourced from the websites of organisations that are involved in the study.

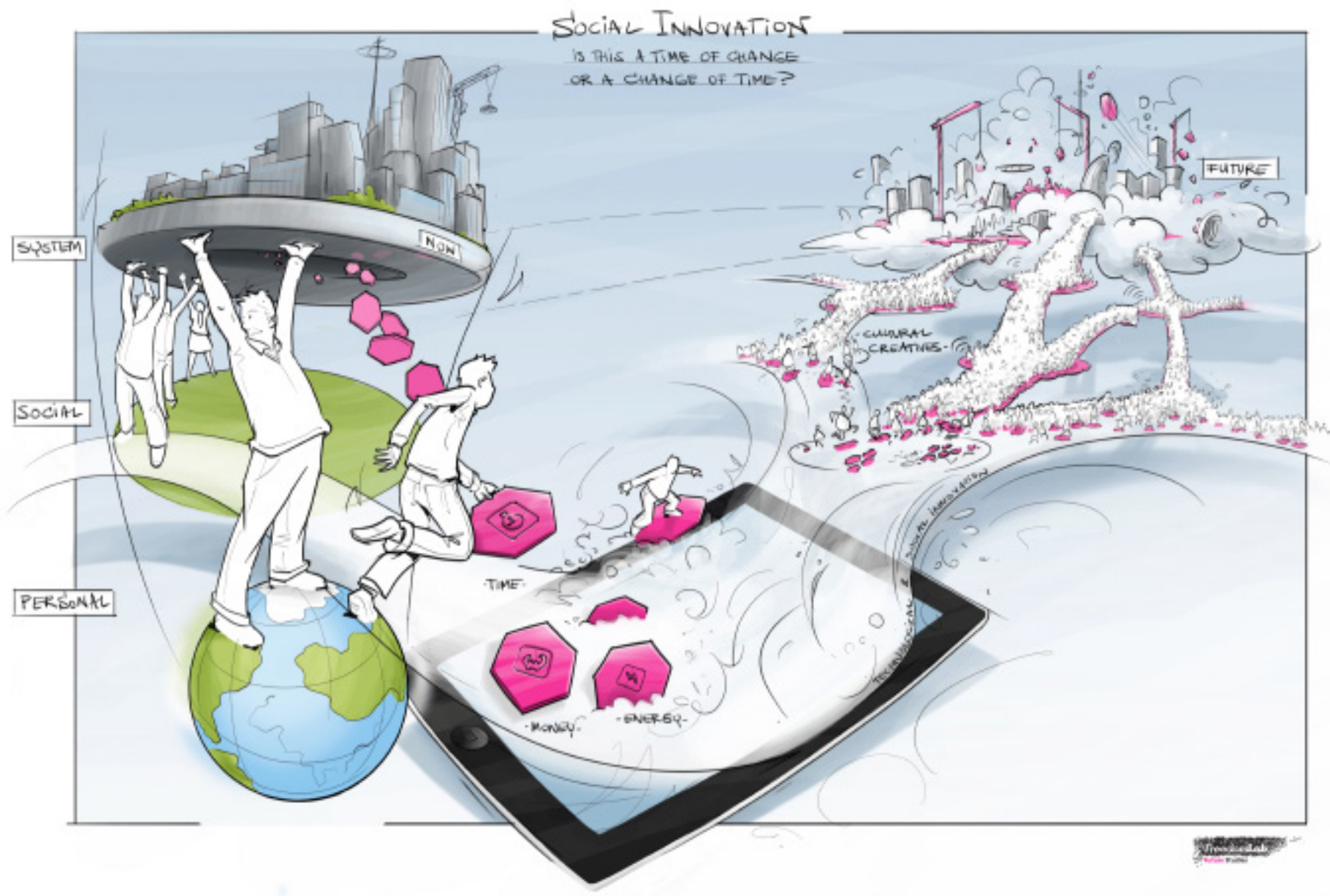

Figure 2. Visual created to support the vision for a European think tank (JAM visual thinking, n.d.)
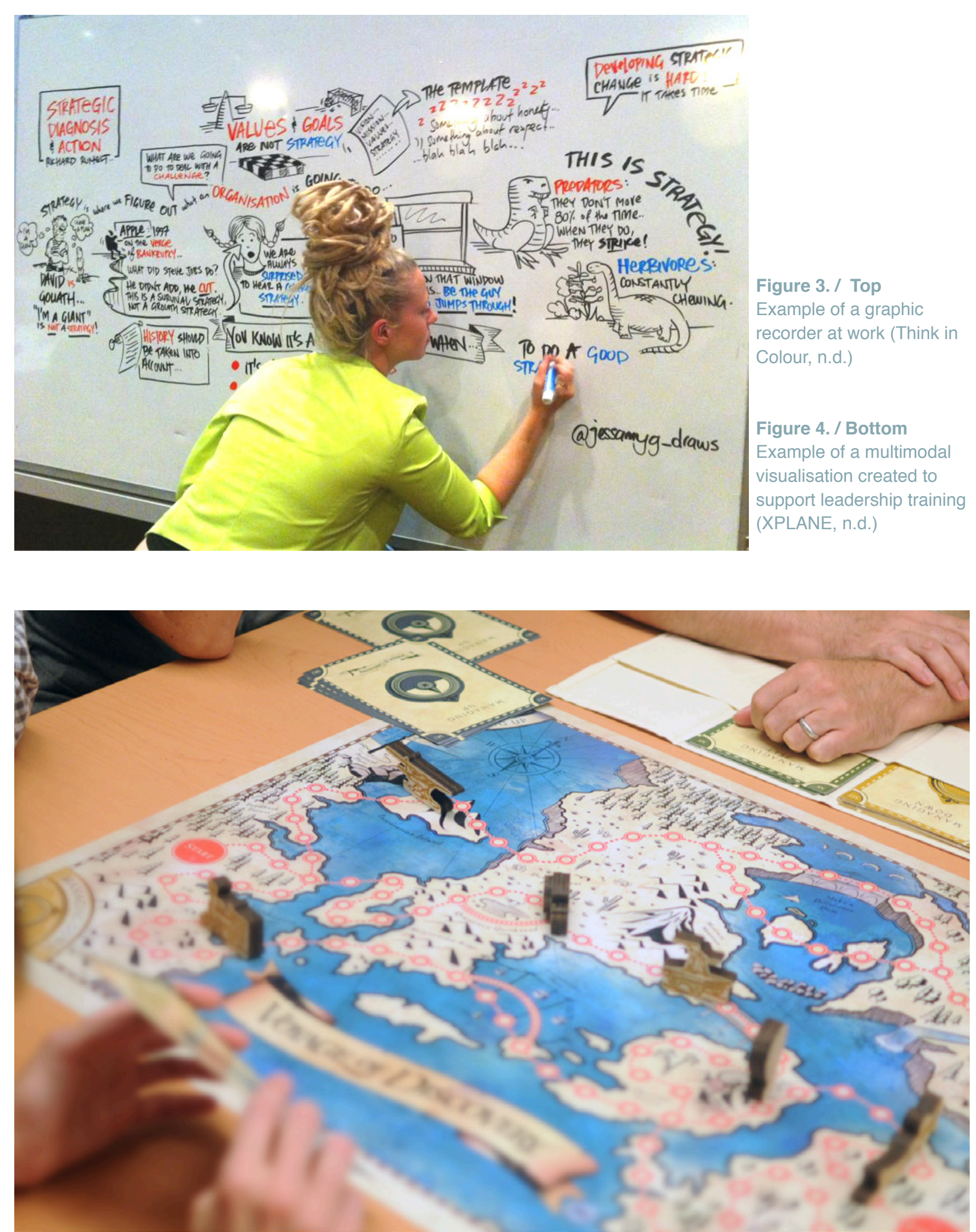

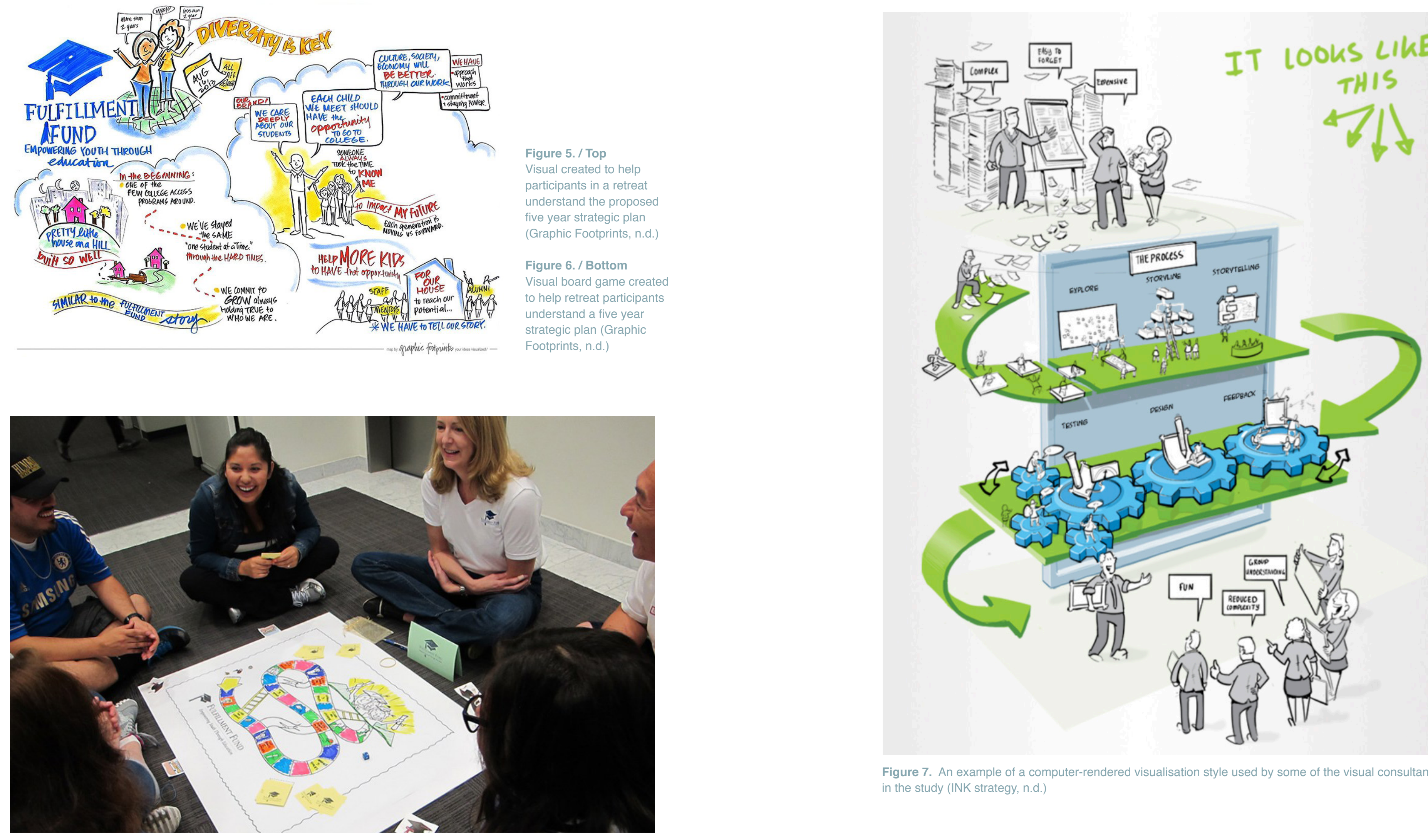


\subsection{Data Collection}

\subsubsection{Developing the Interview Guide}

A key consideration of my research design was ensuring that the construction of the interview guide would provide useful responses for answering the research questions, while also showing commitment to the constructivist paradigm. The adoption of visualisation has yet to be explored in management research, therefore I developed the interview schedule inductively. This guide can be viewed in Appendix D.

The semi-structured interview format was used. This approach enabled me to ask followup questions to request clarification on respondents' answers and in some cases, extend the interviewees' statements to precisely describe a particular phenomenon (Kvale \& Brinkmann, 2009). The flexibility of the semi-structured interview approach afforded the opportunity for me to gain more insight into the topic (Rose et al., 2014). I found this particularly useful for understanding the novel visualisation methods that the visualisation organisations use.

The interview guide deliberately uses colloquial language. As a constructivist researcher, I viewed the research interview as a process of social construction (Kvale \& Brinkmann, 2009) therefore I did not wish to position myself as an 'authority' on the subject of visualisation or position myself as more intelligent than the interviewees (Kvale \& Brinkmann, 2009). The questions were deliberately open ended to allow respondents to focus on aspects that were most important to them, and the questions were not always asked in numerical order. In keeping with the semi-structured format, I considered it appropriate to ask questions out of order and omit questions, if the respondent began to discuss or answer points related to other questions in the interview guide. Conducting interviews in this way afforded a natural flow to conversation than if I had stuck to a prescribed interview format, enabling respondents to build rich descriptions.

The first section of the interview guide includes questions to develop rapport, to encourage respondents to feel comfortable speaking with me (Questions 1-3) (Kvale \& Brinkmann, 2009). This was followed by opening questions (Questions 4-7), designed to "encourage spontaneous and rich descriptions" of their experiences with clients (Kvale \& Brinkmann, 2009, p. 133). A definition of 'visualisation' was deliberately not provided to respondents. This enabled participants to speak to their definition of visualisation, rather than be constrained to what they believed I wanted to hear. Questions 8-12 were asked to ascertain the respondents' observations of how prospective clients adopted visualisation and the factors which facilitated or inhibited clients' adoption of visualisation. Finally, respondents were asked if there was anything which they wanted to add to the interview. This helped interviewees to articulate important points that had been overlooked in the interview and served as a good way to draw the interview to a close without being too abrupt.

\subsubsection{Conducting the Interviews}

All interviews were digitally recorded and transcribed by myself. Interviews with international respondents were conducted over Skype, FaceTime, and respondents' video conferencing software or via phone call, depending on which method the participant preferred. Whenever possible, video was used, however audio was used if necessary to improve the quality of the call. Conducting interviews in this way was appropriate because face-to-face interviews would have been expensive and challenging considering the broad geographic dispersion of the interviewees (Deakin \& Wakefield, 2013). One face-to-face interview was conducted with the representative from the Australasian organisation at the university campus in Wellington. Follow-up interviews were performed in similar means to the first interviews, with the exception of the Australasian representative, which was conducted in person at a café.

One of the risks of interviews that are not conducted in the traditional face-to-face format is that the interviewer may not be able to establish the same level of rapport with interviewees due to the lack of visual cues (Deakin \& Wakefield, 2013; Irvine, Drew, \& Sainsbury, 2013). However I mitigated this by exchanging emails and details of the interview before the scheduled interview took place, so when the interviews took place, I was acquainted with the respondents, and they understood the research objectives and interview requirements. At the beginning of the interview with the participant with whom I had a prior connection, I suggested that this interviewee pretend that I was a stranger when communicating their answers to questions, to limit the chance that crucial information was excluded from the interview.

All participants were asked for consent before the digital recording began and consented to the interview in writing (see Appendix $\mathrm{C}$ for consent form). Interviews ranged from 30 minutes to just over an hour. I enabled respondents to speak at some length if they felt necessary, to ensure they were not 'steered' into answers, which can be the case if structured questionnaires are used (Alvesson \& Sköldberg, 2000). 


\subsection{Data Analysis}

\subsubsection{Thematic Analysis}

I used thematic analysis to analyse the interview data in order to search for meanings in the often messy and complex data that characterise qualitative data (O'Leary, 2014). In this process, researchers identify themes based on observed patterns across the data set (Boyatzis, 1998). While there are prescribed methods for thematic analysis, flexibility in the data anlysis process was important to account for my abductive reasoning. This approach is close to an approach to theory building that Orton (1997) describes, which combines inductive and deductive reasoning; this recognises how researchers' knowledge about the phenomenon of interest shifts as we read. I continuously went back and forth between theory and the empirical data to establish meaningful themes. As a reflexive researcher, I preferred this personal and intuitive approach over 'systematically following procedures' without understanding its implications for my research (Alvesson \& Sköldberg, 2000). Alvesson and Sköldberg (2000) argue that the thoughtfulness of considering the characteristics of good research (e.g. empirical arguments; credibility; open attitude to examining interpretations and social phenomena; and consideration of the representation-authority problem) will enable researchers to be more attentive to a wide range of literature, viewpoints and facilitates coherence and thoughtfulness in the production of empirical material. Thus, I used an intuitive approach to thematic analysis in order to establish meaning from the gathered data.

\subsubsection{Transcription and Data Analysis Process}

I transcribed interviews in full, except for eliminating non-linguistic elements (e.g. eliminating "ums" and "ahhs") (Kvale \& Brinkmann, 2009). My data analysis began immediately after the first interview, in October 2015, and continued until the very last 'member checking' interviews were completed in February 2016. This overlap of data analysis and data collection is appropriate for qualitative research due to the iterative nature of qualitative research; typically research questions and constructs shift as more insight is gained during the process of analysis (Rose et al., 2014). Overlapping data analysis with data collection enabled ample time for thorough analysis of anticipated knowledge shifts. Keeping field notes and memos was one method I used to manage the overlap, to document hunches about relationships and other related notes (Rose et al., 2014). A sample of these notes are presented in Appendix E.

As the research questions aim to shed light on the factors which facilitate or inhibit the use of visualisation adoption, I used template analysis to find common themes and patterns across the data set that enabled me to identify these factors. Template analysis is a type of thematic analysis in which researchers develop conceptual themes identified in the raw data (King, 2004). I found the flexibility of this approach favourable due to its recognition of both a priori codes and emergent themes from the data, and additionally, its emphasis on adaptability and interpretation rather than strictly using analysis as a means to an end (King, 2004).

Hierarchical coding is a key characteristic of template analysis, in which similar codes or themes are grouped together to establish a broader higher-level code (King, 2004). The analysis usually begins with a few pre-defined codes to guide the analysis. These codes may be elicited from a variety of sources, including the researcher's experience and the literature. To begin segmenting the data, I established four broad a priori codes based on the interview guide. These categories were: 'factors which facilitate initial commitment', 'factors that facilitate recommitment', 'factors which inhibit initial commitment' and 'factors that inhibit recommitment'. I read interview transcriptions line-by-line, and coded based on in vivo themes; concepts that have previously been established in the literature; or new codes were created for themes that had not been identified in literature. It was only after this initial listing of important emergent analytical factors that I divided these categories into more distinct facilitating and inhibiting factors. For example, I considered 'novelty' and 'demonstrating personal competence' to be 'factors that facilitate initial commitment', but believed they were commonly linked because they were both an 'organisational need' 
To establish the most important themes for the research, I constantly questioned whether concepts present in one case were also present in another case, and were related to the research objectives (Rose et al., 2014). However, King (2004) caution against solely relying on the frequency of codes to establish key themes. Doing so can be at the detriment to understanding the meaning of the data. As established in Chapter 2, not everyone who uses visualisation may do so in the exact same manner. Alvesson and Sköldberg (2000) argue that in reflexive research, individual interpretations can be emphasised if it is believed that such interpretations are fruitful or there is potential to contribute new insights or new theoretical ideas to literature. Taking this into account, I did not simply ignore less recurrent themes in template analysis, but included them if I considered them pertinent for theory-building. Themes evolved as I reviewed interview transcripts and consulted the literature, in order to avoid production of trivial or unrelated findings (Alvesson \& Sköldberg, 2000). These key themes were supplemented with interviewee quotes, as recommended by Boyatzis (1998). At times parallel coding was used, in which interviewee data that seemed to apply to more than one code were included under more than one code as appropriate (King, 2004).

As recommended by Rose et al. (2014), I visually mapped themes throughout the coding and interpreting process. This concurrent process of coding and visualisation enabled me to clarify ill-formed ideas, establish relationships between different constructs and identify gaps in my thinking. Mapping concepts visually also helped me to develop a framework to show the linkages between the themes. As seen in Appendix E, multiple developments took place before the final framework was developed. I added memos to each iteration to constantly question and clarify my assumptions of the framework. Through this development, I soon came to the realisation that: 1) there was a difference between the factors which facilitate/ inhibit commitment and the factors that facilitate/inhibit recommitment and 2) the difference seemed to occur either side of the client experiencing the benefits of visualisation. This realisation made me question whether the grouped factors (e.g. organisational need) that had been identified were not as dichotomic as first thought (i.e. factors that facilitate initial commitment versus factors that facilitate recommitment), and whether some factors would have more impact before or after different stages of the adoption process. Throughout the entire process I went back to visualisation literature and strategy-as-practice literature to determine whether the data confirmed, extended or contributed a new insight to these fields of research. This process helped to clarify a final list of themes seen in Section 4.2 which would have theoretical relevance.

An important concern for qualitative researchers is the establishment of trustworthiness in the research (Guba \& Lincoln, 1994). One consideration pertaining to the problem of authority and representation was that the empirical data that were created was the result of my own interpretations (Alvesson \& Sköldberg, 2000). I believed that this could risk confirmation bias, which can occur when researchers favour information that confirms preexisting ideas or beliefs about the topic (Onwuegbuzie \& Leech, 2007). To limit this bias, I undertook member checking; respondents were given the opportunity to comment on how well the framework (detailing the facilitating and inhibiting factors of visualisation service adoption) represented their experience. Asking for feedback on findings is an established procedure which enables people who have an interest in the evaluation of the data, such as participants, to provide comment on the categories or interpretations that the researcher has made (Kvale \& Brinkmann, 2009; Rose et al., 2014; Thomas, 2006). This approach is consistent with hermeneutic methodologies used within the constructivist paradigm, and is one that Guba and Lincoln (1994) argue is important to a constructivist worldview; to reduce the threat to the internal credibility of the data (Onwuegbuzie \& Leech, 2007).

After the member checking interviews I developed a heuristic framework based on the insights gained from interviewee responses, to describe the visualisation service adoption process. I went back and forth between the framework, interview findings and literature to construct a list of the final overarching themes and sub-themes, then established how these themes relates to four process phases in the framework. I generated 14 first level codes (main themes) and 46 second level codes (sub-themes), supporting these findings with interview data. The themes are discussed in Chapter 4. I also established four different stages in which these themes occurred, which formed the four main sections of discussion of the results framework in Chapter 5. Additionally, I created an 'Other Themes' section during my analysis which documented other factors which were important but not directly related to the research focus, or could not be probed in much depth. The section included individual strategies that visualisation organisations took or suggested to encourage prospective clients to adopt or reconsider their services. These 'Other Themes' ended up forming part of the discussion section in Chapter 5. 


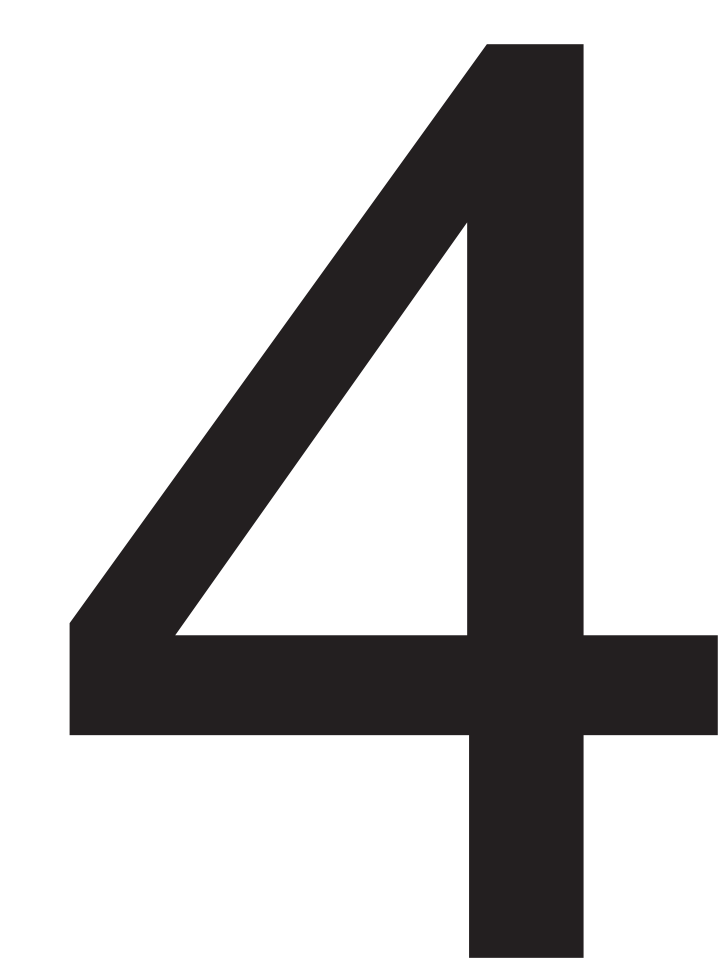

\section{FINDINGS:}

FACILITATING AND INHIBITING FACTORS TO VISUALISATION

\begin{tabular}{|c|c|c|}
\hline 4.1 & Chapter Introduction & 57 \\
\hline 4.2 & Summary of Facilitating and Inhibiting Factors & 58 \\
\hline 4.3 & Benefits of Visualisation & 61 \\
\hline 4.3.1 & Cognitive Benefits & 62 \\
\hline 4.3.2 & Engagement Benefits & 64 \\
\hline 4.3.3 & Operational Benefits & 68 \\
\hline 4.3.4 & Emotional Benefits & 71 \\
\hline 4.4 & Prior Experience with Visualisation & 74 \\
\hline \multirow[t]{2}{*}{4.5} & Ability to Connect Collaboration Outcomes with & \\
\hline & Visualisation and Positive Word of Mouth & 76 \\
\hline 4.6 & Organisational Need & 78 \\
\hline 4.7 & User's Predisposition For or Against Visualisation & 82 \\
\hline 4.8 & 'Likeability' of the Visualiser(s) & 85 \\
\hline 4.9 & $\begin{array}{l}\text { No Approval for the Service, Cost of the Service } \\
\text { and Lack of Education on the Value of Visualisation }\end{array}$ & \\
\hline 4.10 & ived Cultural Fit Between the Visualisation & 87 \\
\hline & Organisation and Prospective Client & 90 \\
\hline
\end{tabular}




\subsection{Chapter Introduction}

Through data collection and data analysis, I identified multiple factors that facilitate or inhibit visualisation to address the research questions. These facilitators and inhibitors are summarised in Table $3{ }^{7}$ This chapter provides explanation and justification of the overarching themes (first level codes). Alongside this, specific facilitators and inhibitors (second level codes) are compared against the extant literature, and implications for strategy making are highlighted. Rather than repeating existing research, only new contributions to literature are discussed, to support theory building. Representative quotes appear alongside the findings to enhance understanding of the facilitating and inhibiting factors identified, and justify their establishment. This format reflects the abductive approach to research I have taken.

Additionally, this format enables readers to understand the facilitators and inhibitors and the significance of these findings for research prior to further discussion in Chapter 5. Greater insight into the findings in the current chapter led to the development of a framework (see Section 5.2) which relates the facilitators and inhibitors to phases in the visualisation adoption process, and establishment of interventions to facilitate the adoption of visualisation services. 


\subsection{Summary of Facilitating and Inhibiting} Factors

Table 3 summarises the facilitating and inhibiting factors that I found through analysis.

Table 3. / Opposite List of facilitating and inhibiting factors to the adoption of visualisation services ist level code

+) Cognitive benefits

(+) Engagement benefits

(+) Emotional benefit

( $)$ Ability to connect the collaboration outcomes

(+) Positive word of mouth

+ ) Organisational need $2^{\text {nd }}$ level code

Creating clarity

Cutting through complexity

Revealing the 'invisible obvious'

Connecting ideas

Improving recall of ideas

Freeing up headspace

Maintaining interest

Inspiring change

Provoking conversation

Increasing ownership and follow-through

Creating alignment

Increasing influential power

Listening to others

Generating buzz

Capturing ideas

Focusing discussion

Making the strategy tangible

Increasing productivity

Rapid prototyping of ideas

Increasing the shelf-life of conten

Communicating across borders

Demonstrating personal competence

Having fun

Feeling heard or understood

Ability to connect the collaboration outcomes with visualisation

Positive word of mouth

Need for accountability

Stimulating creativity

Communicating out

Communicating up

Novelty

Client's role is to create engagement

Client's aptitude for visulisaion

$( \pm)$ User’s predisposition for or against visualisation

Belief that visualisation is not 'serious work'

Belief that visuals are a distraction

Cost of the service

(-) Cost of the service

No approval for the service

(-) No approval for the service

Lack of education on the value of visualisation services

(-) Lack of education on the value of visualisation

(+) 'Likeability' of the visualiser(s)

Ease of collaborating with the visualiser(s)

Knowhow of the visualiser(s)

Good experience with visualisation services

Bad experience with visualisation services

No experience with visualisation services

Familiarity with visual ideas

Openness to collaborative work

( \pm ) Perceived cultural fit between the visualising

Shared expectation of collaboration outcomes

Key: (+) Facilitator (-) Inhibitor ( \pm ) Facilitator or Inhibito 


\subsection{Benefits of Visualisation}

To categorise the benefits found in the analysis, I decided against using Eppler and Platts' (2009) categorisation used in Chapter 2 (i.e. 'cognitive', 'social' and 'emotional' benefits). Despite its usefulness for the literature review, this categorisation was confusing when coding the facilitators and inhibitors found in the analysis. For example, a second level facilitator that I identified in the process of analysing interview data was 'inspiring change'. Using Eppler \& Platts' definitions (see Section 2.4), this facilitating factor could be categorised as both a 'social' and 'emotional' benefit. The benefits of visualisation were instead categorised as: cognitive benefits, engagement benefits, operational benefits and emotional benefits. The definitions of these benefits and contribution to literature are discussed in the following four sections. My categorisation benefits researchers, providing distinct categories of visualisation benefits should researchers wish to further investigate the benefits of visualisation.

Overall, interviewees expressed a positive attitude to visualisation and were enthusiastic about its implications for organisational work. Respondents identified numerous benefits to visualisation which attracted potential clients to make first contact with the visualising organisation, or encouraged existing clients to reconsider using their services. This is evidenced in the following four sections. The quotes below reflect one of the most prevalent and interesting themes expressed by all respondents, that the experience of the benefits of visualisation facilitates clients to return.

V10: “...people tend to think it looks cool and then it's only after they work with me, especially in a facilitated session versus graphic recording, that they realise how useful it is."

V9: "We have about [a] 90 percent repeat business rate. So the lesson in that...once people experience the magic of the session, of what we do, they come back...."

V1: "I just do the best I can trying to describe [visualisation] in words, and talk about it on the videos, but it's not until the experience that it makes perfect sense. Because it is extremely experiential [emphasis by the interviewee]. So a lot of times there will be somebody who'll say: 'Oh yea I was in a meeting and that was really great!' And they don't have a lot of vocabulary to talk about it....”

These extracts suggest that it is not sufficient to merely discuss the benefits of visualisation to encourage its adoption. We also need to consider that visualisation is a practice rather than an abstract process. 


\subsubsection{Cognitive Benefits}

Cognitive benefits are defined here as the positive effects associated with the mental processes of how we acquire knowledge, which holds a broader scope than the definition of 'managerial thinking' that Eppler and Platts (2009) use to classify cognitive benefits.

Table 2. Cognitive benefits

\begin{tabular}{|c|c|c|c|c|}
\hline $1^{\text {st level code }}$ & $2^{\text {nd }}$ level code & $\begin{array}{l}\text { Inter- } \\
\text { view- } \\
\text { ees- }\end{array}$ & Other representative quotes & $\begin{array}{l}\text { Contribution to liter- } \\
\text { ature }\end{array}$ \\
\hline \multirow{15}{*}{$\begin{array}{l}\text { Cognitive ben- } \\
\text { efits }\end{array}$} & \multirow[t]{4}{*}{ Creating clarity } & V4 & \multirow{4}{*}{$\begin{array}{l}\text { V7: "Visualisation] actually removes that need to dumb down } \\
\text { text. When you tell the story through visualisation it's clear }- \text { at } \\
\text { least when it's done well - it's clear - it's glanceable and com- } \\
\text { prehendible by a range of peoplea... you're talking at a level that } \\
\text { they're capable of managing." }\end{array}$} & \multirow{4}{*}{$\begin{array}{l}\text { Confirms } \\
\text { Vessey (1991) }\end{array}$} \\
\hline & & V7 & & \\
\hline & & v8 & & \\
\hline & & V9 & & \\
\hline & \multirow{2}{*}{$\begin{array}{l}\text { Cutting through } \\
\text { complexity }\end{array}$} & V2 & \multirow{2}{*}{$\begin{array}{l}\text { V2: "Putting things on a display so you can compare and con- } \\
\text { trast and organise a lot of complicated stuff, is extremely helpful } \\
\text { to groups who do this on a shared display...." }\end{array}$} & Confirms \\
\hline & & V7 & & Vessey (1991) \\
\hline & \multirow{3}{*}{$\begin{array}{l}\text { Revealing } \\
\text { the 'invisible } \\
\text { obvious' }\end{array}$} & $\mathrm{V} 1$ & \multirow{3}{*}{ 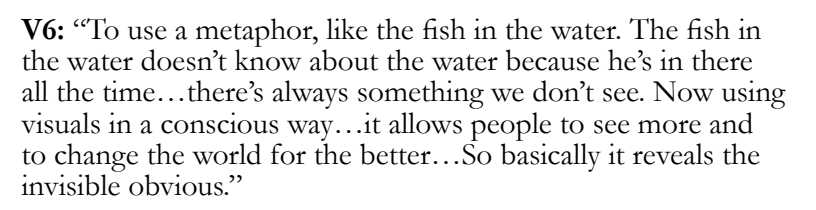 } & Confirms \\
\hline & & V6 & & \multirow{2}{*}{$\begin{array}{l}\text { Card et al. (1999); Tufte } \\
\text { (1990) }\end{array}$} \\
\hline & & v8 & & \\
\hline & \multirow{2}{*}{$\begin{array}{l}\text { Connecting } \\
\text { ideas }\end{array}$} & $\mathrm{V} 2$ & \multirow{2}{*}{$\begin{array}{l}\text { V2: "The entire room is covered with their thinking [emphasis } \\
\text { added by interviewee]. And they can then walk up to one wall } \\
\text { and connect it to another wall and they can remember what they } \\
\text { said yesterday and back and forth." }\end{array}$} & Confirms \\
\hline & & V7 & & $\begin{array}{l}\text { Card et al. (1999); } \\
\text { Eppler and Bresciani } \\
\text { (2013); Tufte (1990) }\end{array}$ \\
\hline & \multirow{3}{*}{$\begin{array}{l}\text { Improving } \\
\text { recall of ideas }\end{array}$} & $\mathrm{V} 4$ & \multirow{3}{*}{ 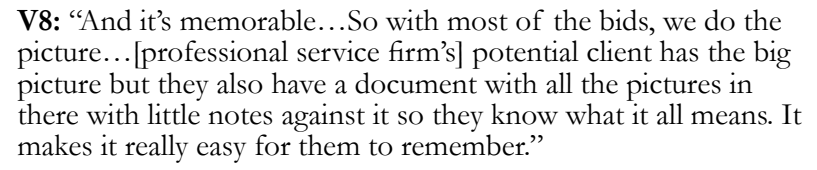 } & Confirms \\
\hline & & V7 & & \multirow{2}{*}{ Kraut et al. (2003) } \\
\hline & & V8 & & \\
\hline & $\begin{array}{l}\text { Freeing up } \\
\text { headspace }\end{array}$ & $\mathrm{V} 4$ & $\begin{array}{l}\text { V4: "But you don't want the attendees to have to frantically take } \\
\text { notes the whole time, because they're there because they need } \\
\text { to participate and they need to give their ideas. Let un handle } \\
\text { the note taking laughs] so that everyone can relax. And when } \\
\text { they're relaxed theyre coming out with new ideas. So they don't } \\
\text { have to worry about taking notes..." }\end{array}$ & New insight \\
\hline
\end{tabular}

Previous literature has focused on the internal development of visualisations (i.e. without using visualisation services). However by focusing on visualisation as a practice, I discovered novel benefits. Participants reported that visualisation enables the 'freeing up [of] headspace'. Here, 'headspace' refers to the availability of mental capacity and energy for creative thinking. Although scholars have argued that visualisation can enhance cognitive processing capabilities (e.g. Card et al., 1999; Tufte, 1990; Vessey, 1991), extant literature has not specifically discussed the effects of this enhanced processing capability. As one respondent noted, when clients want to increase participation in a meeting:

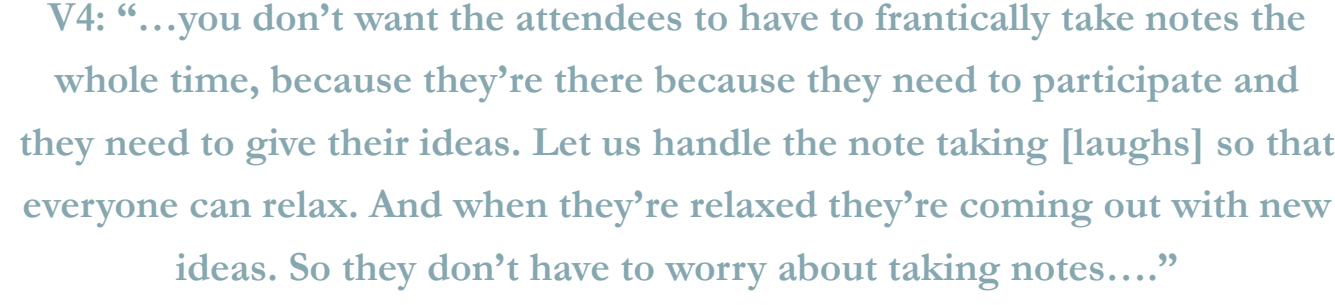

Although this is a provisional finding, it has theoretical importance. Using an external visualiser enables the participants to focus on what is important. Instead of concentrating on taking notes, participants have additional headspace to use for idea generation. Greater creativity and novel insights could be uncovered if an experienced visualiser facilitates strategy making, permitting participants to focus on the essential content, rather than administrative tasks like note taking. 


\subsubsection{Engagement Benefits}

Engagement benefits are those benefits associated with the social interactions between actors, which facilitates involvement from internal or external actors to an organisation. This is more specific than the 'social benefits' that Eppler and Platts (2009) describe, which are not explicitly linked to participant involvement.

A common reflection expressed by interviewees was that the engagement benefits were the most memorable benefits for clients.

V1: "Generally I think what brings people back to visualisation is people are engaged, they're excited, they feel ownership over their work, especially if we're doing things where we're giving them some of the tools and they're doing some of the work themselves. So a big part of it is...there's much more buy-in from the group because they're helping making it happen."

The utility of visualisation is clear when participants are engaged and excited with the visualisation.

Two respondents noted that 'listening to others' was a benefit of visualisation. Although strategy visualisation scholar Holloway (2009) has mentioned that 'listening to others' is a benefit of visualisation, the scholar does not explain why people are more likely to listen to others through the use of visualisation. Respondents observed that group participants were more likely to listen to each other when visualisation was used because ideas were "divorced from the person who is talking about it" (V9) (see Table 5 for extended quote). This builds on suggestions that visualisation can minimise the effect of dominant views (DiMicco, Pandolfo, \& Bender, 2004).Visualising group ideas enables fruitful and creative discussions because ideas can be expressed freely if the ideas are not attached to the person who expressed them. This has implications for strategy. If participants of strategy visualisation are able to listen to each other, they might feel safer expressing ideas when visualisation is used presenting a greater representation of viewpoints. This could improve the productivity of strategy making sessions, by: providing more ideas to choose from, limiting the effects of groupthink and preventing issues with inter-organisational politics.

Another less recurrent benefit reported by respondents was that visuals stimulated participants in meetings or conferences to talk about the visual and share it outside of organisational events (generating 'buzz’)
V5: "So for example when people have particularly public sector things where they share on Twitter, then that can go on for months, where people are still tweeting it and generating links and keeping the conversation going on for them that for them would be unusual. So I think it has the potential to have a much greater reach than they would expect."

Generating 'buzz' is a novel insight to strategy visualisation literature, yielding important implications for strategy development. The excitement and interest that visuals create would be useful when internal buy-in is needed such as in strategic change initiatives (Whittington, Molloy, Mayer, \& Smith, 2006). However, due to the transparency of strategy visuals, a visualised strategy can draw too much attention to aspects of the strategy (Eppler \& Platts, 2009), potentially inviting more scrutiny than if the strategy was less interesting. Consequently, this could result in more consultation and over thinking during the formation of the visualisation, making the strategy visual a time consuming artefact to produce (Bresciani \& Eppler, 2015). Strategists thus need to weigh up the benefits of generating interest in strategy visuals, with its potential time cost. 
Table 5. Engagement benefits

\begin{tabular}{|c|c|c|c|c|}
\hline $1^{1^{t}}$ level code & $2^{\text {nd }}$ level code & $\begin{array}{l}\text { Inter- } \\
\text { view- } \\
\text { ees- }\end{array}$ & Other representative quotes & $\begin{array}{l}\text { Contribution to liter- } \\
\text { ature }\end{array}$ \\
\hline \multirow{25}{*}{$\begin{array}{l}\text { Engagement } \\
\text { benefits }\end{array}$} & \multirow{3}{*}{$\begin{array}{l}\text { Maintaining } \\
\text { interest }\end{array}$} & V3 & \multirow{3}{*}{ 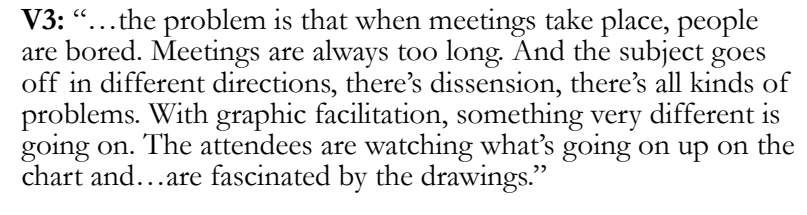 } & \multirow{3}{*}{$\begin{array}{l}\text { Confirms } \\
\text { Cummings and Angwin } \\
\text { (2011); Eppler and } \\
\text { Platts (2009) }\end{array}$} \\
\hline & & V4 & & \\
\hline & & v5 & & \\
\hline & \multirow{2}{*}{$\begin{array}{l}\text { Inspiring } \\
\text { change }\end{array}$} & $\mathrm{V} 2$ & \multirow{2}{*}{$\begin{array}{l}\text { V6: "And on the other side of the spectrum, they book this } \\
\text { because they want transformation. They want to support a shift, } \\
\text { they want to support a change, or a culture shift in the organisa- } \\
\text { tion or a team." }\end{array}$} & Confirms \\
\hline & & V6 & & $\begin{array}{l}\text { Bititci, Cocca, and Ates } \\
\text { (2015) }\end{array}$ \\
\hline & \multirow{2}{*}{$\begin{array}{l}\text { Provoking } \\
\text { conversation }\end{array}$} & \multirow[t]{2}{*}{ V8 } & \multirow{2}{*}{$\begin{array}{l}\text { V8: "It means they get the conversation and dynamic and } \\
\text { relationship going much more quickly.... [emphasis added by in- } \\
\text { tervieweed. W We quite often might lay them on a table, like a map, } \\
\text { and people stand around it. And immediately they're pointing } \\
\text { and talking about things, and so you're getting a conversation } \\
\text { going and that's what it's all about." }\end{array}$} & Confirms \\
\hline & & & & Mills et al. (1998) \\
\hline & \multirow{5}{*}{$\begin{array}{l}\text { Increasing } \\
\text { ownership and } \\
\text { follow-through }\end{array}$} & V2 & \multirow{5}{*}{$\begin{array}{l}\text { V10: "I think its engagement, the participation, so you're really } \\
\text { getting people involved in the process. So that they're bonding } \\
\text { to what they agreed on so that afterwards there's a better chance } \\
\text { it's gonna get followed through." }\end{array}$} & Confirms \\
\hline & & V3 & & \multirow{4}{*}{$\begin{array}{l}\text { Bititici et al. (2015); Bu- } \\
\text { zan and Buzan (2000); } \\
\text { Holloway (2009) }\end{array}$} \\
\hline & & v4 & & \\
\hline & & V9 & & \\
\hline & & V10 & & \\
\hline & \multirow{6}{*}{$\begin{array}{l}\text { Creating align- } \\
\text { ment }\end{array}$} & V1 & \multirow{6}{*}{$\begin{array}{l}\text { V2: "The second reason is getting alignment on how to get } \\
\text { toward that vision. And so people want roadmaps, they want } \\
\text { process masps; they want to show people the big picture as well } \\
\text { as the specific jobs." }\end{array}$} & \multirow{6}{*}{$\begin{array}{l}\text { Confirms } \\
\text { De Salas and Huxley } \\
\text { (2014); Holloway (2009) }\end{array}$} \\
\hline & & V2 & & \\
\hline & & v3 & & \\
\hline & & v5 & & \\
\hline & & v9 & & \\
\hline & & V10 & & \\
\hline & \multirow{3}{*}{$\begin{array}{l}\text { Increasing in- } \\
\text { fluential power }\end{array}$} & $\mathrm{V} 4$ & \multirow{3}{*}{$\begin{array}{l}\text { V4: "Yes, sometimes they'll have a story that they want to tell. I } \\
\text { did a job once for a company where they were basically trying to } \\
\text { explain why they fired somebody and why they hired somebody } \\
\text { else. So sometimes they just want a nice way to say something } \\
\text { that is maybe not a nice subject to talk about." }\end{array}$} & \multirow{3}{*}{$\begin{array}{l}\text { Confirms } \\
\text { Carmona et al. (2011); } \\
\text { Eppler and Platts } \\
\text { (2009); Free and Qu } \\
\text { (2011); Garreau et al. } \\
\text { (2015); Kaplan (2008) }\end{array}$} \\
\hline & & V5 & & \\
\hline & & v8 & & \\
\hline & \multirow{2}{*}{$\begin{array}{l}\text { Listening to } \\
\text { others }\end{array}$} & V1 & \multirow{2}{*}{$\begin{array}{l}\text { V9: "....visualisation is a great democratisation of language or of } \\
\text { conversation, because if you have everyone drawing......hathat you } \\
\text { start to get is the ideas that come up are now on a wall. And they } \\
\text { are divorced from the person who is takling about it...they lose } \\
\text { their ownership from individuals and they start to be judged on } \\
\text { the merit of the idea itself.". }\end{array}$} & \multirow{2}{*}{$\begin{array}{l}\text { Extends } \\
\text { Holloway (2009) }\end{array}$} \\
\hline & & V9 & & \\
\hline & \multirow{2}{*}{$\begin{array}{l}\text { Generating } \\
\text { 'buzz' }\end{array}$} & $\mathrm{V} 4$ & \multirow{2}{*}{$\begin{array}{l}\text { V4: "So that's another problem that people have, they want peo- } \\
\text { ple on social media to be talking about them for their event and } \\
\text { we are there to really get multiple levels of engagement. Even if } \\
\text { poople aren't there, they can see it on social mediamenthat's going } \\
\text { on - oh, there's all this buzz about this event.". }\end{array}$} & \multirow{2}{*}{ New insight } \\
\hline & & V5 & & \\
\hline
\end{tabular}




\subsubsection{Operational Benefits}

Respondents believed operational benefits facilitated clients' return to the respondent for visualisation services (see Table 6). Operational benefits are defined here as the functional benefits associated with the completion of organisational tasks. Distinguishing operational benefits from cognitive benefits is an approach also taken by Platts and Hua Tan (2004), however they do not define the two concepts.

An interesting benefit indicated by four respondents, which has yet to receive much attention in strategy visualisation literature, is the rapid prototyping of ideas.

V3: "People also increasingly want to be creative and innovative because they're stuck in one way of doing things... and lots of them want to change their condition. So how do you get people to do something completely different that they've never tried before? Well doing different versions visually or doing what designers do, which is doing prototypes of things making little models of it — is a very good way to do it."

V4: "It's like rapid prototyping basically, you can create a visual and you can decide on the idea or scrap the idea so much quicker. We sometimes go into things and storyboards things out, and people can say yes or no right away."

The extracts above highlight how engaging in the process of visualisation has value for those involved. Seeing ideas and iterating upon them, enables people to see, in a tangible way, how the idea might unfold. Although visualisation scholars have pointed out that visualisation can generate options (Eppler \& Platts, 2009), and investigate what is or is not possible (Garreau et al., 2015), there is little discussion of the benefits of being able to see and to grasp or scrap ideas quickly. In their examination of the cognitive processes associated with using material artefacts, Stigliani and Ravasi (2012) have signified the importance of visualisation as a tool to capture and build upon emerging ideas. For strategy development, this indicates the usefulness of visualisation for quick problem solving, such as in the formulation or revision of strategy.
Table 6. Operational benefits

\begin{tabular}{|c|c|c|c|c|}
\hline${ }^{1 \text { s level code }}$ & 2nd level code & $\begin{array}{l}\begin{array}{l}\text { Inter- } \\
\text { view- } \\
\text { ees }\end{array}\end{array}$ & Other representative quotes & $\begin{array}{l}\text { Contribution to liter- } \\
\text { ature }\end{array}$ \\
\hline \multirow{32}{*}{$\begin{array}{l}\text { Operational } \\
\text { benefits }\end{array}$} & \multirow[t]{4}{*}{ Capturing ideas } & V4 & \multirow{4}{*}{$\begin{array}{l}\text { V5: “....because the thing that people come to me the most for } \\
\text { which is graphic recording is....you know their challenge is... } \\
\text { how to capture a lot of diverse content." }\end{array}$} & \multirow{4}{*}{ Bititci et al. (2015) } \\
\hline & & v5 & & \\
\hline & & V7 & & \\
\hline & & V8 & & \\
\hline & \multirow{6}{*}{$\begin{array}{l}\text { Focusing dis- } \\
\text { cussion }\end{array}$} & V4 & \multirow{6}{*}{$\begin{array}{l}\text { V8: “...She [the client] could always then relate [the visual] with } \\
\text { everything else theyrte doing... you can get back to what you } \\
\text { wanna tallk about which is the overall strategy and success of the } \\
\text { business." }\end{array}$} & \multirow{6}{*}{$\begin{array}{l}\text { Confirms } \\
\text { Bititci et al. (2015) }\end{array}$} \\
\hline & & V5 & & \\
\hline & & V7 & & \\
\hline & & V8 & & \\
\hline & & V9 & & \\
\hline & & $\mathrm{V} 10$ & & \\
\hline & \multirow{3}{*}{$\begin{array}{l}\text { Making the } \\
\text { strategy tan- } \\
\text { gible }\end{array}$} & $\mathrm{V} 1$ & \multirow{3}{*}{$\begin{array}{l}\text { V7: “...you've got an artefact, you've got something you can } \\
\text { write on. You can make changes, edits, notes etceterea and you } \\
\text { take it away with you. Younve got this artefact of your discus- } \\
\text { sion, .So it becomes this physical manifestation of strategy in a } \\
\text { way." }\end{array}$} & \multirow{3}{*}{$\begin{array}{l}\text { Confirms } \\
\text { Holloway (2009) }\end{array}$} \\
\hline & & V7 & & \\
\hline & & V9 & & \\
\hline & \multirow{8}{*}{$\begin{array}{l}\text { Increasing } \\
\text { productivity }\end{array}$} & V1 & \multirow{8}{*}{$\begin{array}{l}\text { V1: "And people come out of this thing - they come out of } \\
\text { this three day workshop saying that they've done like six months } \\
\text { to a year's worth of work because it was like, so like, brilliant the } \\
\text { process." }\end{array}$} & \multirow{8}{*}{$\begin{array}{l}\text { Confirms } \\
\text { Bititci et al. (2015) }\end{array}$} \\
\hline & & V2 & & \\
\hline & & V3 & & \\
\hline & & V4 & & \\
\hline & & V5 & & \\
\hline & & V6 & & \\
\hline & & V9 & & \\
\hline & & V10 & & \\
\hline & \multirow{4}{*}{$\begin{array}{l}\text { Rapid prototyp- } \\
\text { ing of ideas }\end{array}$} & V3 & \multirow{4}{*}{$\begin{array}{l}\text { V5: “...and also I do sometimes use it for like problem solving } \\
\text { [which definitely helps severybody get to [a] different headspace } \\
\text { when theyret trying to osove a problem, that makeses it more likely } \\
\text { that they're gonna come to a conclusion I think." }\end{array}$} & \multirow{4}{*}{$\begin{array}{l}\text { Extends } \\
\text { Eppler and Platts } \\
\text { (2009); Garreau et al. } \\
\text { (2015); Stigliani and } \\
\text { Ravasi (2012) }\end{array}$} \\
\hline & & $\mathrm{V} 4$ & & \\
\hline & & v5 & & \\
\hline & & V9 & & \\
\hline & \multirow{5}{*}{$\begin{array}{l}\text { Increasing the } \\
\text { shelf-life of } \\
\text { content }\end{array}$} & V1 & \multirow{5}{*}{$\begin{array}{l}\text { V6: "So a company asks us to create something where they're } \\
\text { trying to show the vision of the company or the mission...then } \\
\text { it stays there for a couple years." }\end{array}$} & Extends \\
\hline & & v5 & & \multirow{4}{*}{$\begin{array}{l}\text { Eppler and Platts } \\
\text { (2009); Kraut et al. } \\
\text { (2003) }\end{array}$} \\
\hline & & V6 & & \\
\hline & & V7 & & \\
\hline & & V8 & & \\
\hline & \multirow{2}{*}{$\begin{array}{l}\text { Communicating } \\
\text { across borders }\end{array}$} & V4 & \multirow{2}{*}{ 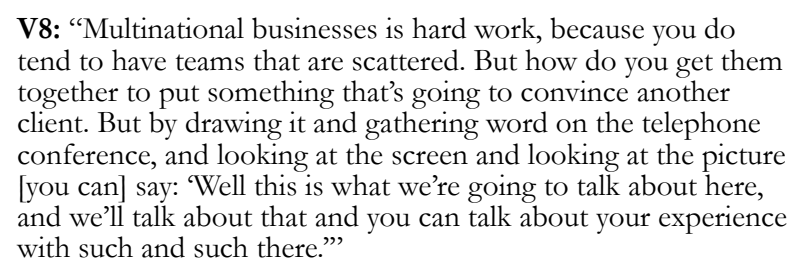 } & Extends \\
\hline & & V8 & & $\begin{array}{l}\text { Comi and Eppler } \\
\text { (2011) }\end{array}$ \\
\hline
\end{tabular}


'Increasing the shelf life of content' was a facilitating factor reported by half of the respondents and extends existing visualisation literature. Visual artefacts created by participants were reportedly referred to by their clients long after their collaboration ended (see Table 6). Although extant literature has suggested that visualisation increases the memorability of content (Kraut et al., 2003), and increases engagement with the artefact by lower level staff (Eppler \& Platts, 2009), there has been no discussion on how visuals can produce benefits long after the visual was initially created. Visualisation is an efficient tool for communicating strategy, as participants will continue to refer to the strategy, so the document will not need to be replaced as frequently. Visualised strategy contributes to the salience of strategic content, indicating that strategy implementors are able to carry out the strategy more clearly (i.e. increasing how long the strategy is useful) with visualisation.

One respondent also noted that visuals resolve issues with inter-organisational work, such as the need to communicate quickly when organisations are scattered. The respondent expressed that visualisation facilitated 'communicating across borders' as the visual served as a talking point, and displayed role responsibilities and tasks to organisational members scattered across different countries (see Table 6). Not only was coordination reported to be easier through the use of visuals, so too was the communication across different cultures.

V4 speaks about an international non-profit event: “...And you have your language barriers, your cultural barriers, but they wanted everything to be communicated. So they had us drawing a lot of the concepts that they were

talking about and the audience loved it. They understood everything; they really appreciated what we were doing."

Visualisation helps to overcome language and cultural differences. The respondent above reported that visualising key concepts clarified these points to audience members from different cultures. The significance of this has already been expressed by Comi and Eppler (2011), who, in their comparison of the impact of visual facilitation on inter-organisational collaboration, found that visual representations benefited teams working across organisational boundaries. In relation to strategy, organisations attempting to build or refine strategies while working in different countries would yield more productive discussions with the use of visuals. Visuals can facilitate strategic planning activities amongst participants spread across different locations, and support communication of such strategies to multicultural audiences.

\subsubsection{Emotional Benefits}

Emotional benefits refer to the positive feelings afforded to visualisation users as a result of its use. This is distinct from the definition that Eppler and Platts (2009) offer, which is confined to motivation and engagement of stakeholders.

Table 7. Emotional benefits

$\begin{array}{lllll}1^{\text {st }} \text { level code } & 2^{\text {nd }} \text { level code } & \begin{array}{l}\text { Inter- } \\ \text { view- } \\ \text { ees }\end{array} & \text { Other representative quotes } & \text { Contribution to liter- } \\ \text { ature }\end{array}$

Bresciani and Eppler (2015) observed that the emotional and social modes of experience are played down in favour of cognitive experience in visualisation literature. Nevertheless, respondents indicated the importance of the emotional experience as it motivates visualisation clients to return to visualisation services. Demonstrating personal competence was a common emotional benefit that facilitated this return.

V2: “...lots of people want to look good when they're presenting. So they will retain us to do visualisation that helps them come across [as] more effective-looking."

V5: "So for some, it is having that creativity in the room — so having a way of engaging an audience...by default, they look creative too...So that changes the mood of the dialogue that they're having at their end, so that's of a sort of real time benefit.

V8: "It makes the client look more innovative. Because they're coming in with something that's not thirty-six slides of PowerPoint." 
For strategy communication, this finding suggests that emotional attachments to visualised strategies increase their 'shelf-life', increasing their value.

The benefits of visualisation extend beyond the outcomes related to the artefact or the process of visualisation, to the way that the user is perceived when they use the visualisation:

V9: “'They're wallking away going: '...I've been trying to talk to these guys and get stuff done for years. And suddenly I've got all this stuff done, it's all written on the wall, it's all really clear, and we all agree on it....' That's the magic...that's the piece where they just go: 'I don't know how you guys do

it, we had really low expectations and while we're having a good time, we're getting an immense amount of work done."”

This quote above describes how it is not simply the ability to 'get things done' or the operational benefits that is important to users of visualisation services, but that the feeling of accomplishing tasks through the use of visualisation elicits a powerful and positive emotional response. This relates to the benefit of having fun which has yet to be regarded as a benefit in strategy visualisation literature. However, this has been a selling point for the 'visual thinking' movement (e.g. see Roam (2008)).

V3: "I just spent two days doing recording for [a] summit on accounting, auditing and accountability. And the reason they were so interested is basically it's a really boring subject [laughs]. I tell you this is what they said! It is really dull and they're trying to make a way to make it fun! And in fact there was an accountant as I was working and he said: 'That's really funky! That's really amazing because we're not funky' [emphasis by interviewee]."

The representative quote above shows how visualisation enables participants to actually enjoy engaging with their work. Through visualisation, boring strategic tasks or topics can be made more interesting to participants and capture their attention, rather than waste valuable time. Although Eppler and Platts (2009) have found that people enjoyed the experience of creating strategy visuals, the scholars do not explicitly define enjoyment as a benefit of strategy visualisation.

Another emotional benefit mentioned by three respondents was feeling heard or understood.

V1: “...First one is the 'power of being listened to' and that gets people out of their own heads and once they put an idea up on the wall, they're like: "Now I can listen, my card is on the table." $\nabla 1$ 's statement illustrates how clients of visualisation services engaged with others the group validated their ideas. Expressing ideas visually enables group participants to feel that their contributions are legitimate, and therefore allows them to consider alternative ideas. This is theoretically important, as a wider selection of ideas to choose from is valuable when strategists are faced with ambiguous problems (Carmona et al., 2011) and need to consider alternative perspectives (De Bono, 1973; Eppler \& Platts, 2009). 


\subsection{Prior Experience with Visualisation}

One of the most important factors that facilitates or inhibits the adoption of visualisation is a prospective client's prior experience with visualisation. Bresciani and Eppler (2015, p. 6) define prior experience with visualisation as the "previous domain knowledge on how to interpret the content and positive or negative experience with a specific visualisation influences the willingness of people to use it". The significance of prior experience with visualisation is expressed by scholars in the fields of Visual Literacy and Visual Communication (Avgerinou \& Pettersson, 2011).

Respondents reported that bad experiences with visualisation services are a significant barrier to reconsideration of visualisation services (see Table 8). A common view was that a bad experience with visualisation creates a misunderstanding of the 'quality' of visualisation services. Specifically, respondents stated that if a competitor 'dumbs down' the ideas too far, or misunderstands what the organisation desires, this inhibits the client's reconsideration of visualisation services, as organisational outcomes have not been achieved. This belief is illustrated below:

V1: "Unfortunately I think some people, they hire somebody and then they go, 'We just paid that much money for that?' [Emphasis added by interviewee.] Because they end up getting somebody who is like really caught up in the drawing part of it, and they might make something that is really cartoony or something. But if they don't capture the content, you know, how are they serving the client?"

This quote shows how bad experiences with visualisation services form. As seen in Section 4.3, a good experience with visualisation services facilitates the adoption of visualisation services (see Table 8 for quotes). Conversely, no experience with visualisation services is an inhibitor as it presents another obstacle for visualisation organisations to overcome (see Table 8).

More broadly, familiarity with visual ideas acts as a facilitator or inhibitor to visualisation adoption. Respondents noted that clients who had seen the visuals before (e.g. in the media), or had worked with visual ideas before were more likely to adopt visualisation services (see Table 8). However, not all practitioners are aware of visualisation or what it entails.

V3: "Somebody who has never even heard of a mind map before, they're fascinated by it because it's so interesting but there's a little bit more of an obstacle to get over."

Clients such as the those V3 describes above may have little 'domain knowledge' about mind maps and how they should be interpreted (Bresciani \& Eppler, 2015). How then can we expect practitioners to adopt visualisation if it is a foreign concept to them? This inhibitor suggests further education about visualisation is needed to inform practitioners on the merits of visualisation to reduce perceived risk in adopting visualisation.
Table 8. Prior experience with visualisation

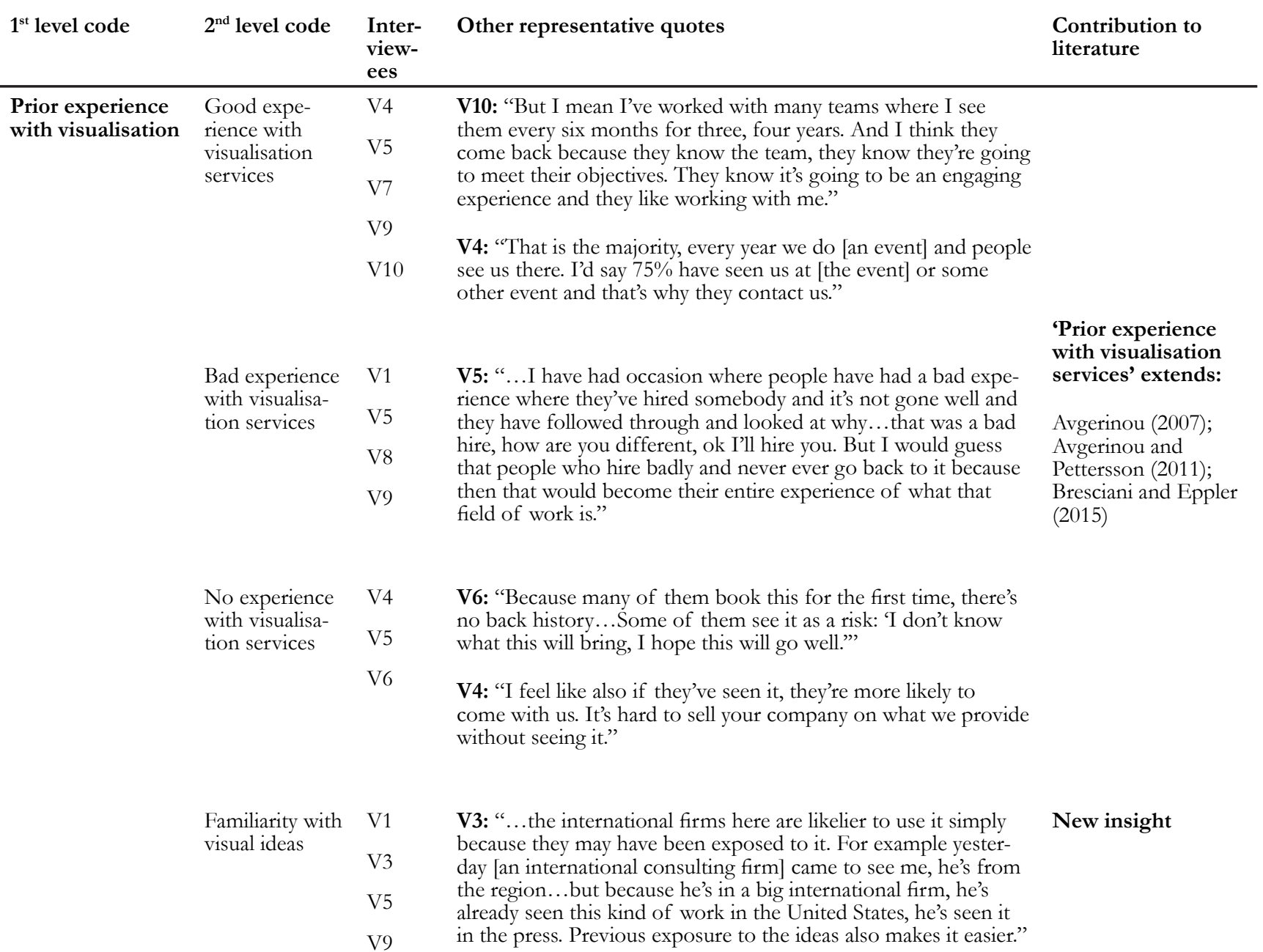




\subsection{Ability to Connect Collaboration Outcomes} with Visualisation and Positive Word of Mouth

Although respondents stated that the experience of visualisation benefits was a powerful facilitator, interviewees expressed frustration that some clients' lacked the ability to connect outcomes from the collaboration with visualisation, often impeding their reconsideration of visualisation services.

V5: "If you don't understand the benefits and you're just looking at the money, then it doesn't make sense because it's more expensive than I don't know, having someone come along [and] play the guitar at the break kind of thing".

V10: “But that I think if you ask them later, 'Why?' I don't think they would even say it's because of the visuals. I don't know what they would say. But no...they don't say to me: 'We want visuals because we know it makes people efficient, productive'. No, they come for the cool factor, they stay for the other stuff."

The quotes indicate that an inability to understand how the outcomes of the visualisation are linked to the visualisation practice, results in a superficial understanding of the value of visualisation. This value is evidently not widely understood by practitioners, and it is this lack of understanding which can inhibit reconsideration of visualisation services. Although the benefits of visualisation and techniques have been heralded in strategy visualisation literature, the findings suggest that practitioners also need to learn bow to associate the benefits of visualisation with the outcomes that visualisation can provide.

Although a lack of understanding of visualisation was a recurrent theme, respondents also specified that some clients immediately understood the connection between outcomes and visualisation benefits. Such clients were reported to become "champions" (V2) of the visualisation service who would return to the visualiser time and time again. Additionally, respondents reported that champions would "cheerlead this stuff to death" (V9), encouraging other organisations to use visualisation. The positive word of mouth spread by these 'champions' of the visualisation services was indicated to be a facilitator by more than half of the respondents (see Table 9). This adds new insight to literature on strategy visualisation, as visualisation research rarely extends beyond the benefits directly related to the artefact or process of visualisation. This also contributes new insight to strategy-aspractice literature. Such literature has examined how strategy tools diffuse in practice (Gunn \& Williams, 2007), however this finding extends this further, by showing how strategy tools, like visualisation, diffuses among practitioners as they gather positive intelligence about strategy tools.
Table 9. Ability to connect collaboration outcomes with visualisation and positive word of mouth

\begin{tabular}{|c|c|c|c|c|}
\hline $1^{1 \mathrm{st}}$ level code & $2^{\text {nd }}$ level code & $\begin{array}{l}\text { Inter- } \\
\text { view- } \\
\text { ees }\end{array}$ & Other representative quotes & $\begin{array}{l}\text { Contribution to } \\
\text { literature }\end{array}$ \\
\hline $\begin{array}{l}\text { Ability to connect } \\
\text { the collaboration } \\
\text { outcomes with } \\
\text { visualisation }\end{array}$ & $\begin{array}{l}\text { Ability to } \\
\text { connect the } \\
\text { collaboration } \\
\text { outcomes with } \\
\text { visualisation }\end{array}$ & $\begin{array}{l}\text { V1 } \\
\text { V2 } \\
\text { V5 } \\
\text { v9 } \\
\text { V10 }\end{array}$ & $\begin{array}{l}\text { V5: “...so I think that people who come back are the people } \\
\text { who make use of it, who make a sort of effort to understand } \\
\text { it or engage with the [visualisert in a way that helps them...I I } \\
\text { think those people make the most out of it, so therefore keep } \\
\text { coming." }\end{array}$ & New insight \\
\hline $\begin{array}{l}\text { Positive word of } \\
\text { mouth }\end{array}$ & $\begin{array}{l}\text { Positive word } \\
\text { of mouth }\end{array}$ & $\begin{array}{l}\text { V1 } \\
\text { V3 } \\
\text { V5 } \\
\text { V7 } \\
\text { V8 } \\
\text { V10 }\end{array}$ & 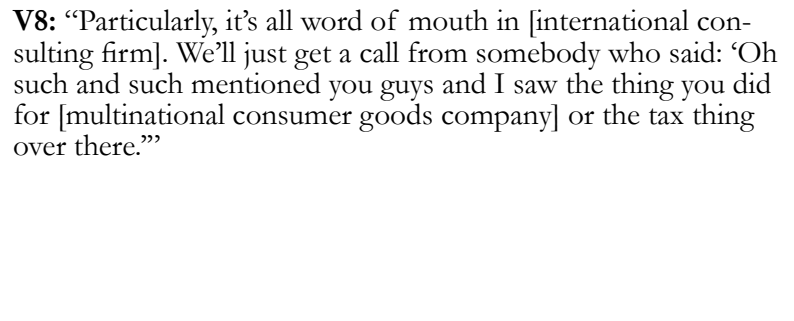 & New insight \\
\hline
\end{tabular}




\subsection{Organisational Need}

There is a lack of association between the benefits of visualisation and the need for visualisation in extant literature. A common facilitating factor identified by respondents was the organisational need for visualisation (see Table 10). ${ }^{8}$

Communicating up through the use of visualisation is a facilitating factor mentioned by three respondents that has received little attention in existing literature (see Table 10). Although Garreau et al. (2015) discusses how strategy visuals can promote a certain agenda the scholars do not indicate that visualisation can be used as a tool to communicate to senior executives who are time poor. However, the significance of communicating up as a facilitating factor is reported in strategy-as-practice literature, with Jarzabkowski and Kaplan (2015) stating that middle managers may view strategy tools as a device to "influence upwards" (p. 541). This theme is important for strategy visualisation literature, as it shows that practitioners use visualisation not only to communicate to subordinates, but also to influence and communicate to senior managers.

Respondents' clients also sought the novelty of the visual solutions, as indicated below.

V1: "[The client] has to do a leadership retreat, twice a year, and so for her she's just trying to find the new thing that keeps people engaged. So for her it was like novelty and engagement, she didn't quite see past that."

Visualisation may be sought simply because it adds something 'different'. Eppler and Platts (2009) recommend employing novel visual methods to communicate strategy, inspire participants and increase buy-in. However, the findings show that novelty can be an end in itself (i.e. practitioners will actively seek novelty, not because it is the most optimal solution).

Three participants indicated that clients requested their services in order to demonstrate personal competence of the user. Visualisation researchers, Kernbach et al., (2015), have found that a person's perception of a visual is a strong predictor of the perception of the presenter. The extract below extends this, showing that clients who understand this association reconsider using visualisation services to appear favourable to stakeholders.
V3: "When you've got twenty or thirty people standing there with their iPhones taking pictures, it gets noticed. Clients love that [emphasis added by interviewee] People get so excited and they go to the client...And they'll say: 'Wow, this is so genius that you're doing this'. And so it makes the client feel like they've been very clever. 'That's when you know you're going to be going back."

The significance of showing personal expertise through the use of tools has been addressed by strategy-as-practice scholars, Jarzabkowski and Kaplan (2015), who suggest that consultants use strategy tools to show their status and expertise. Strategy scholars claim that strategists do not use tools simply for effectiveness but also for the benefits that are returned to the user of the tool, for example, demonstrating competence as a strategist (Mantere \& Vaara, 2008). The use of strategy visualisation is fuelled not only by desirable outcomes of visualisation, but also by how the user is perceived by others when using it.

While Gunn and Williams (2007) find that strategy tool preferences can be shaped by decision makers' contextual backgrounds, the implications of an actor's role in an organisation for visualisation adoption are yet to be discussed in extant literature. Respondents highlighted certain organisational roles (e.g. human resources) which create engagement were more inclined to use their visualisation services (see Table 10). For strategy literature, this suggests strategy tool preference and adoption may be facilitated by actors' organisational roles. 
Table 10. Organisational need

\begin{tabular}{|c|c|c|c|c|}
\hline $1^{\text {st }}$ level code & $2^{\text {nd }}$ level code & $\begin{array}{l}\text { Inter- } \\
\text { view- } \\
\text { ees }\end{array}$ & Other representative quotes & $\begin{array}{l}\text { Contribution to } \\
\text { literature }\end{array}$ \\
\hline \multirow[t]{24}{*}{$\begin{array}{l}\text { Organisational } \\
\text { need }\end{array}$} & $\begin{array}{l}\text { Need for ac- } \\
\text { countability }\end{array}$ & V7 & $\begin{array}{l}\text { V7: "So I'm thinking particularly large publicly held companies } \\
\text { with an emphasis on investor relations, return on investment and } \\
\text { ensuring that management is clear that they're doing a good job } \\
\text { managing people's money." }\end{array}$ & $\begin{array}{l}\text { Confirms } \\
\text { Bititci et al. (2015); } \\
\text { de Salas and Huxley } \\
\text { (2014); } \text { pppler and } \\
\text { Platts (2009); Kern- } \\
\text { bach et al. (2015) }\end{array}$ \\
\hline & \multirow{5}{*}{$\begin{array}{l}\text { Stimulating } \\
\text { creativity }\end{array}$} & V1 & \multirow{5}{*}{$\begin{array}{l}\text { V5: "Or also the flip side of that is the teams that are like inno- } \\
\text { vation teams so theyree already trying to be different in order to } \\
\text { get different outcomes." }\end{array}$} & Confirms \\
\hline & & V2 & & Bititci et al. (2015) \\
\hline & & v3 & & \\
\hline & & v5 & & \\
\hline & & V6 & & \\
\hline & \multirow{3}{*}{$\begin{array}{l}\text { Communicating } \\
\text { out }\end{array}$} & V5 & \multirow{3}{*}{ 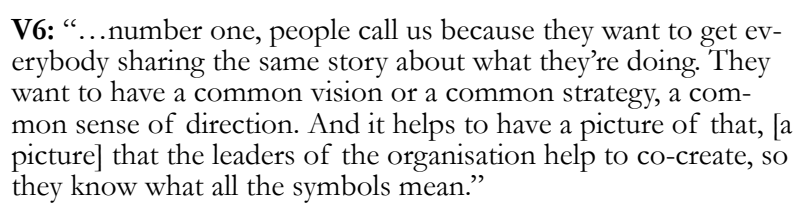 } & \multirow{3}{*}{$\begin{array}{l}\text { Confirms } \\
\text { Bititci et al. (2015) }\end{array}$} \\
\hline & & V6 & & \\
\hline & & V7 & & \\
\hline & \multirow{4}{*}{$\begin{array}{l}\text { Communicat- } \\
\text { ing up }\end{array}$} & $\mathrm{V} 1$ & \multirow{4}{*}{ 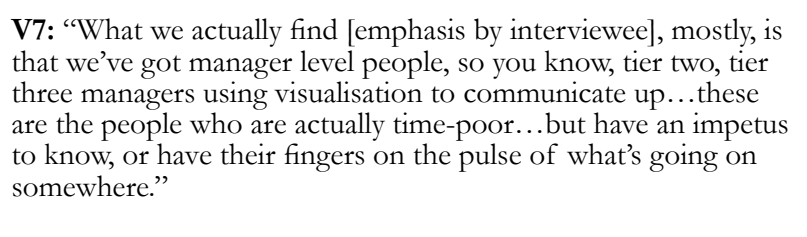 } & \multirow{4}{*}{$\begin{array}{l}\text { Extends } \\
\text { Garreau et al. (2015) }\end{array}$} \\
\hline & & v5 & & \\
\hline & & V7 & & \\
\hline & & v9 & & \\
\hline & \multirow[t]{4}{*}{ Novelty } & V4 & \multirow{4}{*}{$\begin{array}{l}\text { V6: "Here, we find that some organisations are event managers } \\
\text { [whol just book graphic recording for the sake of decorating } \\
\text { event tand making their event more innovative. So ot't like a de- } \\
\text { cor, its like an add-on. It's not really contributing anything." }\end{array}$} & Extends \\
\hline & & V6 & & $\begin{array}{l}\text { Eppler and Platts } \\
(200)\end{array}$ \\
\hline & & V8 & & \\
\hline & & V10 & & \\
\hline & \multirow{3}{*}{$\begin{array}{l}\text { Demonstrating } \\
\text { personal com- } \\
\text { petence }\end{array}$} & V3 & \multirow{3}{*}{ 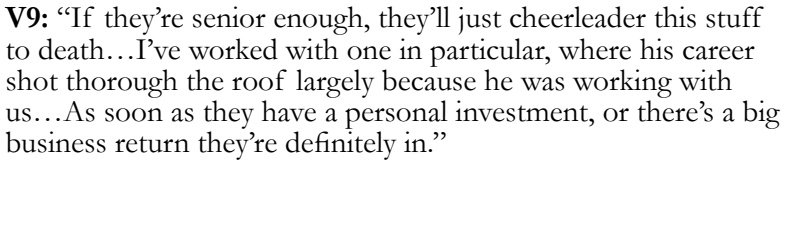 } & \multirow{3}{*}{$\begin{array}{l}\text { Extends } \\
\text { Jarzabkowski and } \\
\text { Kaplan (2015); Ker- } \\
\text { nbach et al. (2015); } \\
\text { Mantere and Vaara } \\
\text { (2008) }\end{array}$} \\
\hline & & $v_{6}$ & & \\
\hline & & vy & & \\
\hline & \multirow{4}{*}{$\begin{array}{l}\text { Client's role } \\
\text { is to create } \\
\text { engagement }\end{array}$} & $\mathrm{V} 1$ & \multirow{4}{*}{$\begin{array}{l}\text { V5: "So [] tend to work quite a bit with organisational develop- } \\
\text { ment kind of roles, like HR, like internal comms, those kind of } \\
\text { roles...So I guess either people who have a real drive and need } \\
\text { to engage people or teams...so they tend to be quite common } \\
\text { characteristics of people who hire me, I would say." }\end{array}$} & \multirow{4}{*}{$\begin{array}{l}\text { Extends } \\
\text { Gunn and Williams } \\
(2007)\end{array}$} \\
\hline & & V3 & & \\
\hline & & v5 & & \\
\hline & & V7 & & \\
\hline
\end{tabular}




\subsection{User's Predisposition For or Against \\ Visualisation}

Just as the capability to identify organisational needs for visualisation differs depending on the individual, so too does the user's affinity for visualisation. In their review of visualisation challenges in organisations, Bresciani and Eppler (2015) indicate that potential challenges to the use of visualisation are 'personal likes and dislikes' of potential users, reporting that differen visualisations gain more attention because of a viewer's personal biases. Similarly, Grinder and Bandler (1975) report that some people respond better to non-textual communications better than others. Such findings are corroborated in this study. Respondents commented that the selection of visualisation was not always a 'rational' decision; clients who identified with visualisation were more likely to use visualisation.

V1: "I think for other folks, you know, it's sort of this intuitive thing, that they're more visual people, they're more spatial thinkers."

V4: “People will say they're visual people...personally, everyone I talk to, is like: 'Oh, I appreciate what you're doing because I'm a visual person'. I don't know what a non-visual person is [laughs]."

Participants reported that visualisation was not used solely because of the known outcomes that could be attained with visualisation. V7 observed that managers' inclination towards visualisation was used as a leverage point to communicate information to senior managers. This participant stated that a typical client doing this might say:

“We're doing this because so-and-so, my manager, is a very visual person'. And so you're using this as part of a kind of tactical way of getting something across."

The notion that personal agendas can facilitate the use of strategy tools has yet to be explored in visualisation literature however it has been discussed by strategy-as-practice scholars. By applying a practice lens, this finding shows how the use of visualisation tools for strategy does not eliminate politics in strategy making, but can be considered a method for aligning interests in an organisation (Jarzabkowski \& Kaplan, 2015). This confirms strategy-aspractice literature, by showing how practices like visualisation are "implicated in political and interpretive processes” (Jarzabkowski \& Kaplan, 2015, p. 551).
Although personal preferences can facilitate visualisation adoption, it can also inhibit its adoption if the user has a negative predisposition towards it. Five out of ten respondents reported that clients disliked visualisation due to a belief that visualisation is not 'serious work'; clients saw visualisation as a "shiny toy" (V1) or a "fluffy extra" (V5). V1 also spoke about arriving at an event to provide graphic facilitation services but was faced with animosity from a manager who held a belief that visualisation is a distraction:

“...And [the client's] like: 'This is going to be distracting, you can't do this. This is going to be distracting, you need to be at the back of the room not facing the group'...I think unfortunately for a lot of folks it's like: 'Is this competing with what I'm trying to do?"”

Two other respondents also reported that potential clients were 'turned off' to visualisation due to this belief that visuals are a distraction. Yet, as shown in Chapter 2, visualisation literature has demonstrated that humans are adapted to think visually. If humans are inherently 'visual', 'then personal biases against visualisation are due to bad experiences or are based on fiction. This points to why strategy visualisation is not a widely spread practice. To overcome these misgivings with visualisation, further education is needed to show how strategists can harness the strategy-facilitating benefits of visualisation.
9 The debate on whether humans are adapted to think visually, or whether there are different 'types' of people who are more receptive to visuals, has been a contentious subject in educational and psycholog iterature. I ascribe to the belief that we are all, at least on some level, visual thinkers? So while I acknowledge alternato this 


\section{8 'Likeability’ of the Visualiser(s)}

Table 11. User's predisposition for or against visualisation

\begin{tabular}{|c|c|c|c|c|}
\hline $1^{\text {st }}$ level code & $2^{\text {nd }}$ level code & $\begin{array}{l}\text { Inter- } \\
\text { view- } \\
\text { ees }\end{array}$ & Other representative quotes & $\begin{array}{l}\text { Contribution to } \\
\text { literature }\end{array}$ \\
\hline \multirow{11}{*}{$\begin{array}{l}\text { User's predisposi- } \\
\text { tion for or against } \\
\text { visualisation }\end{array}$} & \multirow{3}{*}{$\begin{array}{l}\text { Client's aptitude } \\
\text { for visualisation }\end{array}$} & $\mathrm{V} 1$ & \multirow{3}{*}{$\begin{array}{l}\text { V7: "And so what keeps people coming back, I think there is } \\
\text { actually a[n] orientation or an aptitude or, you know, a type of } \\
\text { persono that gels with it in particular, a type of organisation that } \\
\text { it works better [with]." }\end{array}$} & \multirow{3}{*}{$\begin{array}{l}\text { Bxtends } \\
\text { Bresciani and Eppler } \\
\text { (2015); Grinder and } \\
\text { Bandler (1975); Jarz- } \\
\text { abkowski and Kaplan } \\
\text { (2015) }\end{array}$} \\
\hline & & $\mathrm{V} 4$ & & \\
\hline & & V7 & & \\
\hline & \multirow{5}{*}{$\begin{array}{l}\text { Belief that } \\
\text { visualisation } \\
\text { is not 'serious } \\
\text { work' }\end{array}$} & $\mathrm{V} 1$ & \multirow{5}{*}{ 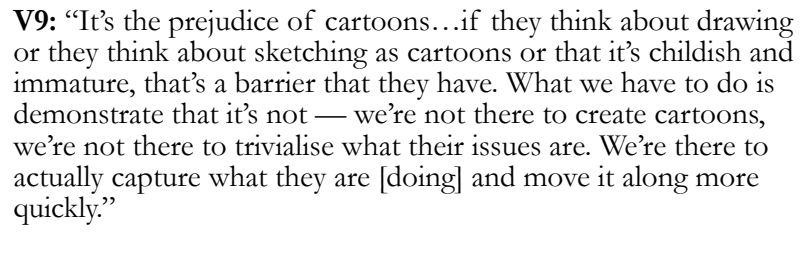 } & \multirow{5}{*}{$\begin{array}{l}\text { Extends } \\
\text { Bresciani and Eppler } \\
\text { (2015) }\end{array}$} \\
\hline & & V3 3 & & \\
\hline & & V5 & & \\
\hline & & V8 & & \\
\hline & & v9 & & \\
\hline & \multirow{3}{*}{$\begin{array}{l}\text { Belief that } \\
\text { visuala sera a } \\
\text { distraction }\end{array}$} & $\mathrm{V} 1$ & \multirow{3}{*}{ 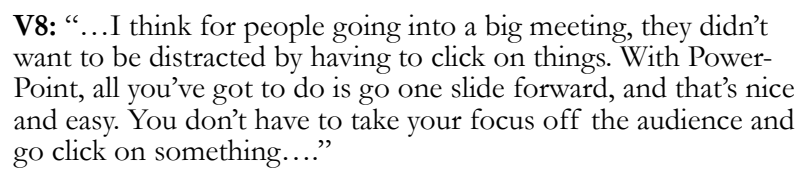 } & \multirow{3}{*}{$\begin{array}{l}\text { Extends } \\
\text { Bresciani and Eppler } \\
(2015)\end{array}$} \\
\hline & & $\mathrm{V} 4$ & & \\
\hline & & v8 & & \\
\hline
\end{tabular}

A factor that encouraged clients to use or reconsider visualisation was the degree to which a client liked the visualiser(s) that they engaged. By 'liked' I mean whether clients were fond of the personal attributes and capabilities of visualisers. 'Visualiser' refers to the people who create the visualisations and other consultants that interact with the client the most (e.g. group facilitator) while providing the visualisation service. When providing a service such as visualisation, respondents reported that the impression of the visualisation is tied to the person involved in providing the service, confirming visualisation research (Kernbach et al., 2015). Respondents noted that their clients' impression of the visualisation was linked to the knowhow of the visualiser: the technical skills of the visualiser or the visualiser's subject matter expertise.

V7: “That being said, [a] typical engagement is, 'Hey [V7], we've got a strategy process underway, we want you to consult on it'. Which means they want my advice about how to manage it; they want my advice about what strategy should entail."

'Likeability' is also tied to the ease of collaborating with the visualiser(s). Confidence, adaptability and the ability to understand organisational issues are qualities that make collaboration easier for clients (see Table 12). Interviewees stated that their individual capabilities for making clients' work easier provided clients ease of mind about the visualisation service, so clients were comfortable with following through and adopting the service.

V1: "I think for me specifically, the biggest things are: I'm super easy to work with...especially when I'm on a call with a client and they say: 'What kind of information do we need to get to you? And do you need all the decks?' And blah blah blah. And I'm like 'Nope! All I need is just contextsetting, I hit the ground running when I get there, I respond to what's happening in the room.' And over the phone you can just hear the ease in their voice...."

This quote further confirms that organisations use visualisation for reasons other than the direct benefits resulting from the visualisation artefact or visualisation process, to their perception of the person delivering the service. Although strategy visualisation scholars Kernbach et al. (2015) find the perception of a presenter is associated with the perception of the visual that the presenter uses, no scholars have discussed the connection between the perception of a visualiser and the decision to adopt visualisation. This demonstrates the value of viewing strategy visualisation as a practice. 
Table 12. 'Likeability' of the visualiser(s)

\begin{tabular}{|c|c|c|c|c|}
\hline $1^{\text {st }}$ level code & $2^{\text {nd }}$ level code & $\begin{array}{l}\text { Inter- } \\
\text { view- } \\
\text { ees }\end{array}$ & Other representative quotes & $\begin{array}{l}\text { Contribution to } \\
\text { literature }\end{array}$ \\
\hline \multirow{8}{*}{$\begin{array}{l}\text { 'Likeability' of } \\
\text { the visualiser(s) }\end{array}$} & \multirow{4}{*}{$\begin{array}{l}\text { Ease of collab- } \\
\text { orating with the } \\
\text { visualiser(s) }\end{array}$} & V1 & \multirow{3}{*}{ 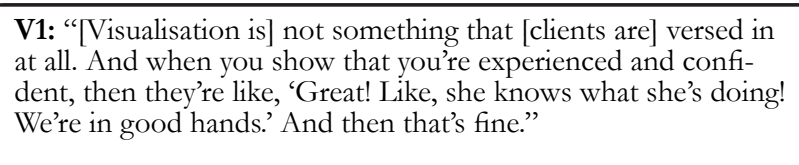 } & \multirow{4}{*}{$\begin{array}{l}\text { Extends } \\
\text { Kernbach et al. } \\
\text { (2015) }\end{array}$} \\
\hline & & V6 & & \\
\hline & & $\mathrm{V} 10$ & & \\
\hline & & & V6: "And then they want somebody who is trustworthy." & \\
\hline & \multirow{4}{*}{$\begin{array}{l}\text { Knowhow of } \\
\text { the visualiser(s) }\end{array}$} & V1 & \multirow{3}{*}{$\begin{array}{l}\text { V5: "So I guess then [that] the benefit of me as opposed to } \\
\text { another person is that the visual plus the knowhow together is } \\
\text { more effective than one on its own." }\end{array}$} & \multirow{4}{*}{$\begin{array}{l}\text { Extends } \\
\text { Kernbach et al. } \\
\text { (2015) }\end{array}$} \\
\hline & & v5 & & \\
\hline & & V7 & & \\
\hline & & v9 & 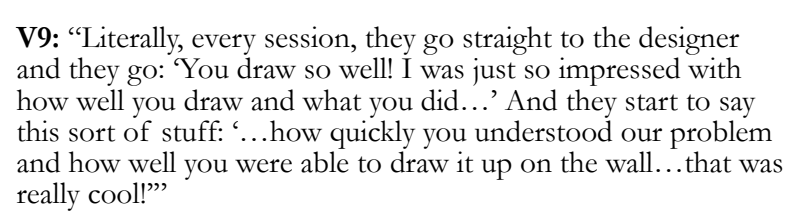 & \\
\hline
\end{tabular}

\subsection{No Approval for the Service, Cost of the Service and Lack of Education on the Value of Visualisation Services}

Facilitators and inhibitors that are personal in nature have been discussed so far. However contextual facilitators and inhibitors were also discovered. If a manager within a client organisation does not like visualisation and/or respect the political prowess of the person who brings it to their attention, the client will receive no approval for the service.

V3: "The barriers would be convincing top management...And the marketing guy said to me 'we want to do this' and he pointed to the manager and said: 'Just look at her over there. You see her with her head down? She just doesn't have the time to take one iota more of information, so I'm sorry, it's just not going to happen this year.' "'

The above quote highlights that the client representative who makes contact with a visualisation organisation is not the only 'client' that needs to be considered when examining the adoption of visualisation services; other decision makers also need to approve the visualisation service.

V1: "I think sometimes it's somebody's doing fact-finding and they're not the decision maker...That's the tricky thing, like who is your real client? personally think my true client is the participants in the room [sic]...only one of those people is signing my cheque and working on the contract with

me, but I feel like when I show up I'm serving that whole group."

The extract above is a new insight for visualisation literature. Multiple competing interests are involved in the evaluation and adoption of visualisation. Approval of a service, which is an ordinary and commonplace practice in most organisations, could shape how a strategy is developed and carried out. However, approval must be accompanied with willingness to pay for visualisation services.

V1: "I think a lot of times, it's tough because a lot of times people contact me and then I send my services documents and they see my rate and they go: 'Oh! I had no idea it cost that much money."”

V3: "Larger firms are likelier to use it simply because they can afford it."

Eight out of the ten respondents observed that the cost of the service inhibited visualisation service adoption. This contradicts Meyer (1997) who states that cost is a minor obstacle to 
using visualisation. However Meyer's study focuses on internal adoption of visualisation (i.e. visualisation developed without using visualisation services), not the adoption of visualisation services. This finding contributes to visualisation literature, suggesting that hiring external visualisation consultants will be a greater barrier to smaller organisations than larger organisations with comparatively larger budgets. This might make it difficult for smaller organisations to find value in these services.

V10: "Everybody loves the idea right? But sometimes the budget gets in the

$$
\text { way for sure." }
$$

Three respondents also reported an increase in market differentiation in the visualisation services market, suggesting that this has provided a plethora of cheaper alternatives to their services. As such, participants stated that prospective clients often struggled to understand why higher priced services differed to similar but less expensive services (see Table 13), so it was harder for these clients to justify purchasing the service.

V5: “...there's now maybe more market differentiation...And I think 'cause people don't really understand yet - they don't understand the benefit of it... So it can be done better and it can be done not so well... and not many appreciate it and so a lot of people are put off right at the beginning...."

The above extract relays another frustration expressed by respondents: a widespread lack of education on the value of visualisation services. As suggested above, this deficiency in understanding spurs prospective clients to use cheaper services due to an inability to discern what 'quality' means. This finding indicates that practitioners require an understanding of how strategy visualisation will enable achievement of outcomes, otherwise it may be perceived as too costly. Without this knowledge, practitioners may default to strategy tools due to familiarity and ease-of-use, rather than efficacy (Jarzabkowski \& Kaplan, 2015).
Table 13. Situational and purchasing decision making factors

\begin{tabular}{|c|c|c|c|c|}
\hline $1^{\text {st level code }}$ & $2^{\text {nd }}$ level code & $\begin{array}{l}\text { Inter- } \\
\text { view- } \\
\text { ees }\end{array}$ & Other representative quotes & $\begin{array}{l}\text { Contribution to } \\
\text { literature }\end{array}$ \\
\hline $\begin{array}{l}\text { Cost of the } \\
\text { service }\end{array}$ & $\begin{array}{l}\text { Cost of the } \\
\text { service }\end{array}$ & $\begin{array}{l}\text { V1 } \\
\text { V3 } \\
\text { V4 } \\
\text { V6 } \\
\text { V7 } \\
\text { V8 } \\
\text { V9 } \\
\text { V10 }\end{array}$ & $\begin{array}{l}\text { V9: "Cost is a barrier. I's an expensive art and not that many } \\
\text { people know how to do it well. There's kind of a right brain, left } \\
\text { brain connection that the best of us have to be able to deliver } \\
\text { this and do it well." }\end{array}$ & $\begin{array}{l}\text { New insight: Con- } \\
\text { tradicts Meyer (1997) }\end{array}$ \\
\hline $\begin{array}{l}\text { No approval for } \\
\text { the service }\end{array}$ & $\begin{array}{l}\text { No approval } \\
\text { for the service }\end{array}$ & $\begin{array}{l}\text { V1 } \\
\text { V3 } \\
\text { V4 } \\
\text { V5 } \\
\text { V7 }\end{array}$ & $\begin{array}{l}\text { V7: "....and often it's that they think it's a good idea but the } \\
\text { person who holds the purses strings goes: "Ahh I don't want any } \\
\text { exposure to that, no thanks." } \\
\text { v4: "And it's usually one person that sees us and they tell their } \\
\text { company and they have to convince their company." }\end{array}$ & New insight \\
\hline $\begin{array}{l}\text { Lack of educa- } \\
\text { tion on the value } \\
\text { of visualisation } \\
\text { services }\end{array}$ & $\begin{array}{l}\text { Lack of } \\
\text { education on } \\
\text { the value of } \\
\text { visualisation } \\
\text { services }\end{array}$ & $\begin{array}{l}\mathrm{V} 1 \\
\mathrm{~V} 4 \\
\mathrm{~V} 5\end{array}$ & $\begin{array}{l}\text { V1: "I would say years ago, when there were a lot fewer people } \\
\text { doing the work, I would say probably about seventy percent of } \\
\text { the people would actually hire me. Nowadays I'd say that's more } \\
\text { like thirty percent, but I think that's purely because of cost and } \\
\text { the number of the people doing the work. Nowadays there are } \\
\text { so many more people doing the work and they can hire someone } \\
\text { for half the price of me." }\end{array}$ & New insight \\
\hline
\end{tabular}




\subsection{Perceived Cultural Fit Between the Visualisation Organisation and Prospective Client}

Table 14. Perceived cultural fit between the visualising organisation and prospective clien

\begin{tabular}{|c|c|c|c|c|}
\hline $1^{\text {st }}$ level code & 2nd level code & $\begin{array}{l}\text { Inter- } \\
\text { view- } \\
\text { ees }\end{array}$ & Other representative quotes & $\begin{array}{l}\text { Contribution to } \\
\text { literature }\end{array}$ \\
\hline \multirow{9}{*}{$\begin{array}{l}\text { Perceived cul- } \\
\text { tural fit between } \\
\text { the visualising } \\
\text { organisation and } \\
\text { prospective client }\end{array}$} & \multirow{6}{*}{$\begin{array}{l}\text { Openness to } \\
\text { collaborative } \\
\text { work }\end{array}$} & $\mathrm{V} 1$ & \multirow{6}{*}{$\begin{array}{l}\text { V2: "So extremely hierarchical, commananding and controll-driven } \\
\text { organisations dont' particularly like this way of working." }\end{array}$} & Extends \\
\hline & & $\mathrm{V} 2$ & & \multirow{5}{*}{$\begin{array}{l}\text { Carmona et al. } \\
\text { (2011); Eppler and } \\
\text { Platts (2009) }\end{array}$} \\
\hline & & V7 & & \\
\hline & & V8 & & \\
\hline & & V9 & & \\
\hline & & V10 & & \\
\hline & \multirow{3}{*}{$\begin{array}{l}\text { Shared ex- } \\
\text { pectation of } \\
\text { collaboration } \\
\text { outcomes }\end{array}$} & V1 & $\begin{array}{l}\text { V10: "They're so far from working with me because they have a } \\
\text { completely different mindset about people as their kev resources. }\end{array}$ & \multirow[t]{3}{*}{ New insight } \\
\hline & & V9 & They see the people as a machine, versus a garden. Of course & \\
\hline & & V10 & $\begin{array}{l}\text { those are the people that I would love to help but they're not go- } \\
\text { ing to put money because they don't value it, they just don't val- } \\
\text { ue working in that way. They think they know all the answers." }\end{array}$ & \\
\hline
\end{tabular}

Another contextual facilitator or inhibitor to the adoption of visualisation services was the perceived cultural fit between the client organisation and the visualising organisation. Eppler \& Platts (2009) suggested that the efficacy of the visualisation workshops depended on the social, cultural and political environments in which the workshop is located. Other strategy visualisation research has shown that national cultures respond to visualisation in different ways (Carmona et al., 2011). However this research is extended to show that organisational cultures respond differently to visualisation adoption.

V10: "Well...the people that call me are already the type of people that want to work collaboratively and in a less hierarchical fashion. Like you don't call a facilitator

$$
\text { unless you're already down with working in that way..." }
$$

V1: “It's not an industry that doesn't get it...the time I see people who aren't receptive to it, it's when it's a culture that's afraid of the transparency of it."

Respondents believed that client organisations who were open to working collaboratively were more likely to use visualisation services. In contrast, client organisations that did not value working collaboratively were reported to be less inclined to work with visualisation organisations. This extends research by Eppler and Platts (2009) who observed that managers had a greater reluctance to share strategic information if they knew it was being captured, suggesting that this reluctance depends on the degree to which the organisational culture is open to working collaboratively

However, the prospective client and the visualisation organisation both need to have a shared expectation of collaboration outcomes. Misalignment in the expectation of collaboration outcomes due to differing organisational values was a reported inhibitor by three respondents. For example, V9's organisation strongly values working co-creatively and reported difficulties working with client organisations that only wanted a solution, to the extent to which they stopped working with client organisations that did not share the same expectation of the collaboration.

V9: "There is a strong influencer there, which is, some corporations want to work with people in what we often call the agency model. So [the model is:] 'Us: brief, You: solution, come on back'. Or traditional management consulting roles, the same kind of thing. 'We hire you, you come in, you walk around, you read a lot, you create a giant report and off you go and we pay the bills and you're done.' But those are very hard clients to win if that's the way they want to work."

V9: "Sometimes we have barriers where people say, 'Oh yea I want that', but once we get in, they'll want to work in a traditional way. So we have to split ways or move through it in a safer way."

Another participant said that they deliberately chose not to work with organisations if it was perceived that the collaboration would not serve a serious purpose.

V1: “...there's two types of clients that I have real difficulty working with, and I generally say no to now, after all these years of experience. And one of them is advertising agencies. Because you're usually hired as a 'shiny toy' and it's used as a sales pitch. It's like, you're hired for the sales pitch and then you're like, they're

never going to hire me to do like the first strategies of the project...."

Although this was a less recurrent theme, it is theoretically important for strategy visualisation literature. This finding has highlighted that cultures play an important role in whether strategy tools, like visualisation, are adopted. 


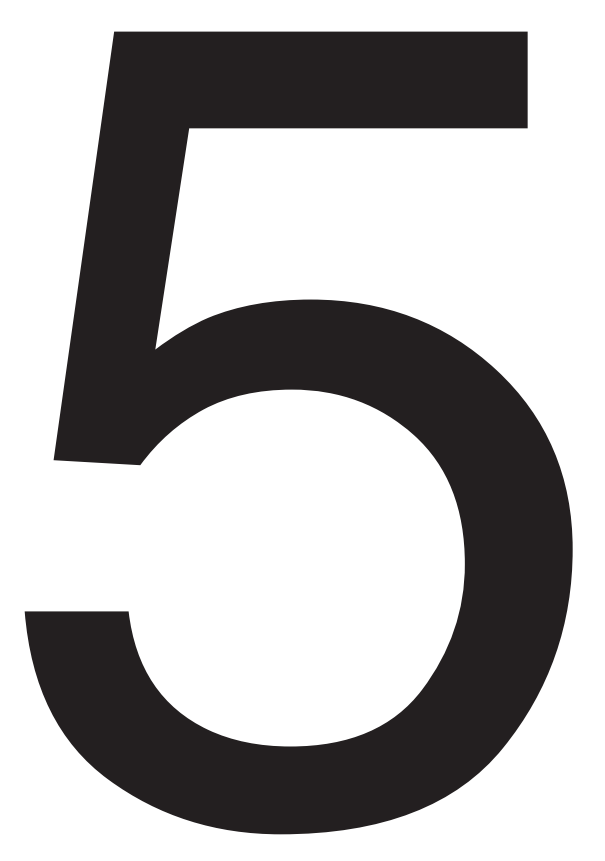

\section{DISCUSSION AND IMPLICATIONS}

$\begin{array}{ll}\mathbf{5 . 1} & \text { Chapter Introduction } \\ 5 \text { 5.1.1 } & \text { What Encourages Prospective Clients to Transition } \\ & \text { Between the Stages? } \\ \mathbf{5 . 2} & \text { Stages of the Visualisation Adoption Process } \\ 5.2 .1 & \text { Stage 1: Pre-contact } \\ 5.2 .2 & \text { Stage 2: Contact } \\ 5.2 .3 & \text { Stage 3: Commitment } \\ 5.2 .4 & \text { Stage 4: Post-purchase Evaluation } \\ \mathbf{5 . 3} & \text { Managerial Implications } \\ 5.3 .1 & \text { Variations } \\ 5.3 .2 & \text { Interventions } \\ & \text { Facilitating Motivation } \\ & \text { Facilitating Continuation } \\ & \text { Facilitating Implementation } \\ & \text { Facilitating Reconsideration } \\ \mathbf{5 . 4} & \text { Limitations and Implications for Future Research } \\ \mathbf{5 . 5} & \text { Key Takeaways from the Research } \\ 5.5 .1 & \text { Key Recommendations for Practice } \\ 5.5 .1 & \text { Key Research Contributions } \\ \mathbf{5 . 6} & \text { Conclusion }\end{array}$




\subsection{Chapter Introduction}

Further analysis of the facilitating and inhibiting factors revealed that these factors were more prevalent within different stages of the adoption process. For example, a client organisation's predisposition for or against visualisation services was more significant in facilitating or inhibiting the adoption of visualisation before a client had made contact with the visualisation organisation.

As established in Chapter 3, the practice lens emphasises the importance of how the enactment of everyday actions have implications for strategy making (Whittington, 2006). It is therefore beneficial to have a framework to show how the identified facilitators and inhibitors relate to phases in the process of adopting visualisation services. Doing so contributes greater insight into the facilitating and inhibiting factors and provides a framework for discussion of implications for practitioners and researchers. I thus devised a framework from the empirical investigation (see Figure 8) which will be discussed in Section 5.2. Using this framework, I discuss interventions to overcome inhibitors and exploit facilitators to aid management practitioners wishing to encourage visualisation adoption. I demonstrate how the framework can be used; it is a tool that should be moulded to suit the needs of practitioners. Finally, I note limitations to the research and present the key conclusions. 


\subsubsection{What Encourages Prospective Clients to}

Transition Between the Stages?

V9: “If it doesn't start to add up that you're actually solving the problem, no amount of drawing or visualisation is going to save you. They're looking at you and saying: 'You're not solving our problem'. And that's what ultimately matters."

Respondents indicated that prospective clients' perceived value of the solution affected clients' decision to transition from one stage to the next. As the above quote suggests, visualisation is perceived by clients as a means to an end, rather than an end in itself. If clients perceive that there is little value in the solution, they will be less inclined to engage (or further engage) with the visualisation organisation. I interpreted the 'perceived value of the solution' to be an internal consideration of a prospective client organisation. It is an assessment that changes through each of the adoption stages depending on the facilitating and inhibiting factors that are experienced at each stage. If the client has a high perceived value of the visual service, this will motivate the client to transition to the next stage (motivation, continuation, implementation or post-purchase evaluation). As an example, if a prospective client perceives value in the solution (i.e. the facilitating factors outweigh any inhibiting factors) in the contact stage, the prospective client will be motivated to make contact with the visualisation organisation (i.e. progression to the contact stage), However if the inhibiting factors outweigh the facilitating factors in the contact stage, the prospective client will have a low perceived value in the solution and will be less likely to proceed to the commitment stage. 


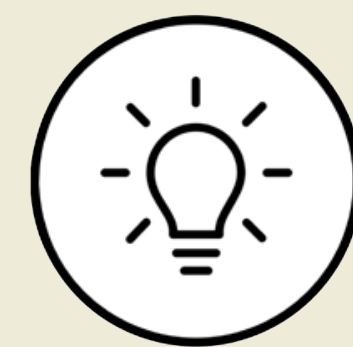

Motivation

1. PRE-CONTACT

1. PRE-CONTACT

\section{+ Organisational need}

+ Positive word of mouth

\pm User's predisposition for

or against visualisation

\section{\pm Prior experience with}

visualisation

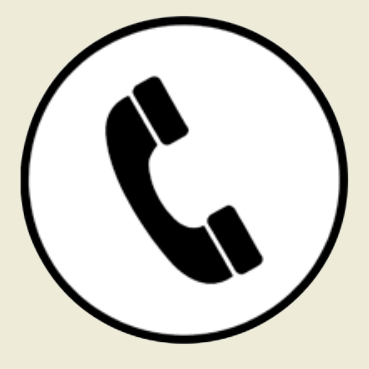

2. CONTACT \pm Perceived cultural fit between the visualising organisation and prospective client

\begin{tabular}{|l||}
\hline - Cost of the service \\
\hline - No approval of the service \\
\hline - Lack of education on the \\
value of visualisation services
\end{tabular}

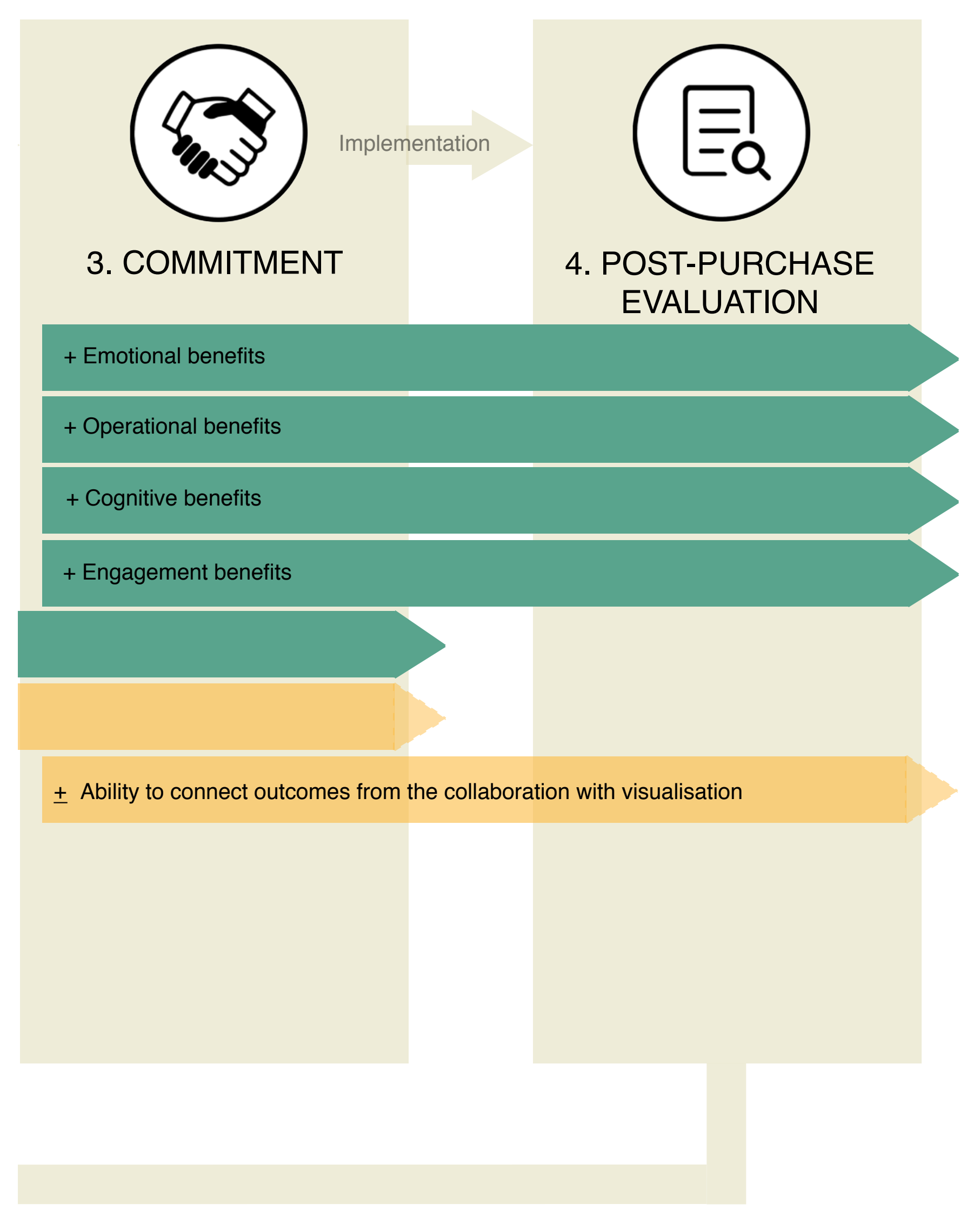




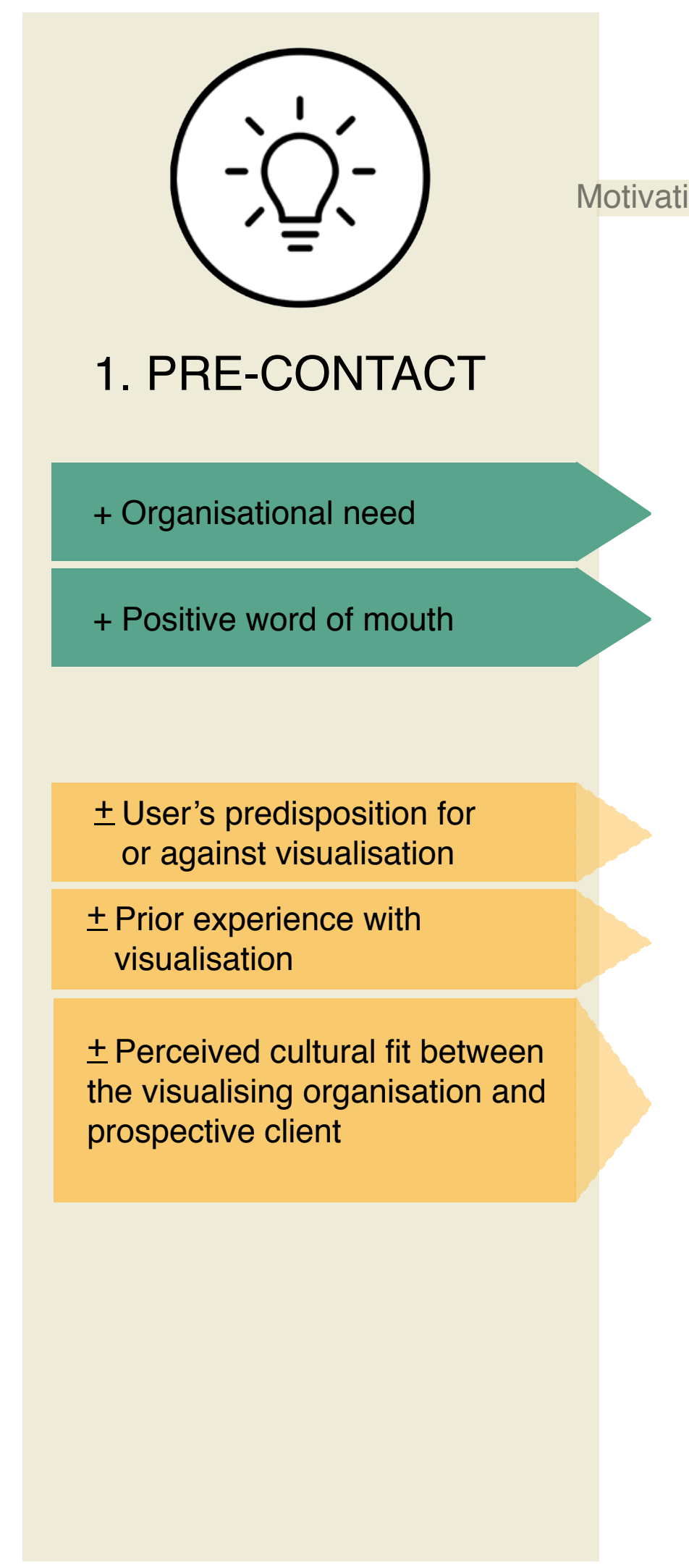

\subsubsection{Stage 1: Pre-contact}

Pre-contact is the first stage that a prospective client experiences before making contact with a visualisation organisation. In this stage there are factors which impact whether a client is encouraged to move to the contact stage (motivation). 'Prospective clients' are returning or new clients coming to visualisation services. My analysis revealed facilitating and inhibiting factors that impacted a prospective client's decision to adopt visualisation services, prior to their contact with a visualisation organisation. Additionally, the theoretical contributions go beyond the scope of visualisation services. Although my study has focused on the adoption of visualisation services, the facilitators and inhibitors could be extended to the broader adoption of visualisation.

In some cases, respondents' clients had made contact because the client had previously established an organisational need for visualisation. Respondents indicated that this need was established because the organisation had experienced visualisation benefits previously. However, there is little distinction in extant literature between visualisation benefits and an organisational need for visualisation. From my analysis, I can provide a distinction between these concepts: benefits of visualisation refer to the positive outcomes of visualisation, while organisational needs are organisational outcomes which practitioners believe visualisation can meet.

Prospective clients did not always have a clearly defined organisational need for visualisation services; prospective clients were also motivated to make contact due to positive prior experience with visualisation, a predisposition for visualisation or because they had received positive word of mouth about the visualisation services. Additionally, personal agendas shape whether visualisation is considered. Respondents reported that clients used visualisation to demonstrate their personal competence or because it helped them to fulfil their particular role in an organisation. Conversely, if the prospective clients have had negative experiences, no experience, or hold prejudice against visualisation (e.g. the belief that visualisation is not serious work), they are less inclined to make contact with visualisation service providers. While the role of personal interests in visualisation has yet to receive attention in strategy visualisation, its significance has been established in literature which examines the use of strategy tools as a socially situated activity (Jarzabkowski \& Kaplan, 2015; Kaplan, 2008) 
The perceived cultural fit between the client organisation and the visualisation organisation is a critical facilitating or inhibiting factor. If the client is not open to a visualisation organisation's way of working, they will perceive incongruence in 'cultural fit' and therefore will not make contact. Viewing the adoption of visualisation services as a socially situated activity revealed that the inhibiting and facilitating factors to visualisation are not fixed. Respondents reported that the perception of cultural fit could change throughout the adoption process as the two organisations interacted, and they discovered each other's motives and values. Some respondents also indicated that the client needed to be the right fit for the visualisation organisation if they were to consider or reconsider working with the client. For this reason, cultural fit is depicted as spanning across the pre-contact, contact and commitment stages. By examining these ordinary practices, the important role of external visualisation consultants, rather than just senior management (Güney \& Taylor, 2014), is recognised for the adoption of visualisation services. Consultants can facilitate and, importantly, inbibit the implementation of strategy visualisation.

This corroborates existing literature that has asserted the selection of strategy tools are not always used for rational reasons (Jarzabkowski \& Kaplan, 2015), and literature that highlights how personal tendencies affect the degree of attention given to visualisation (Bresciani \& Eppler, 2015). 


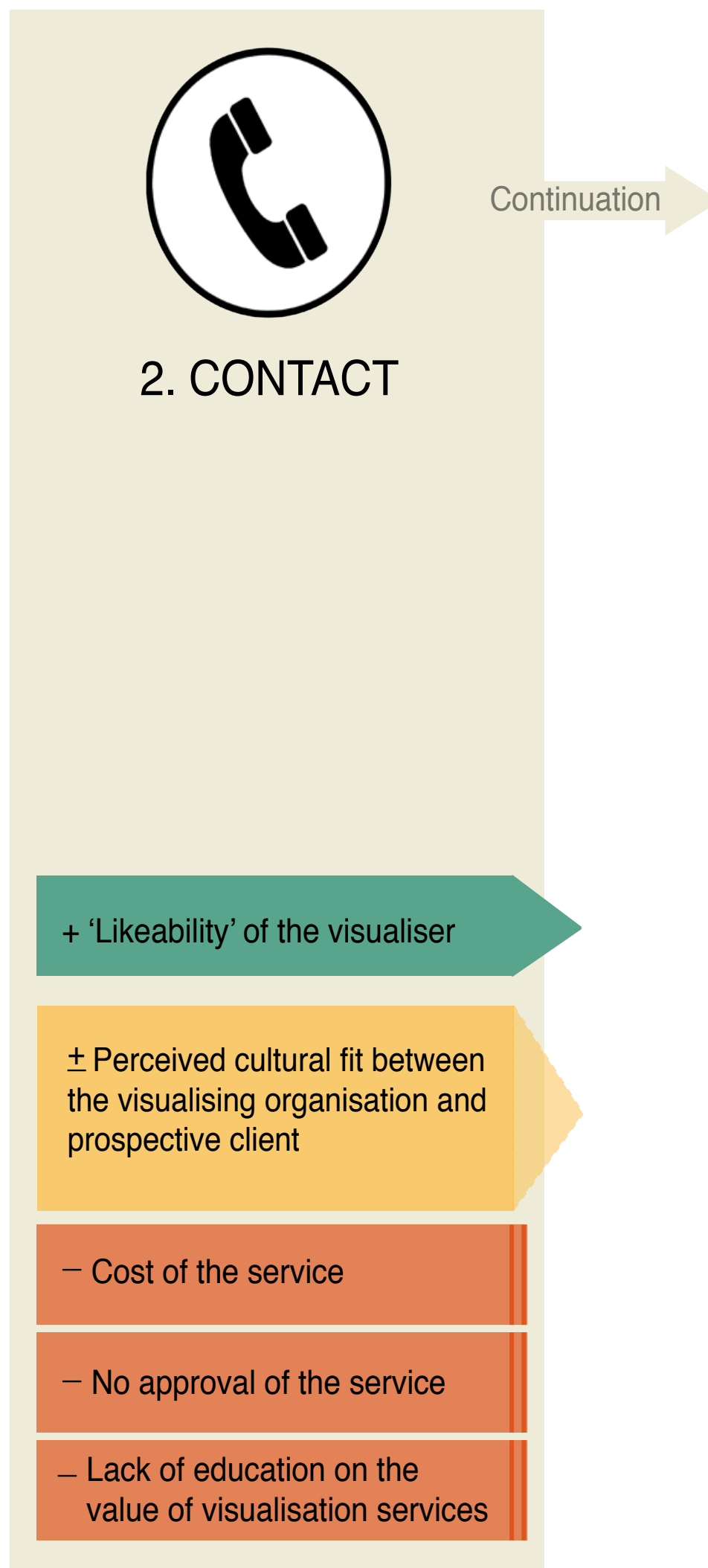

\subsubsection{Stage 2: Contact}

In the first interactions between a potential client and a visualisation organisation, a number of contextual factors inhibited respondents' clients from committing to visualisation services. One such inhibitor to commitment was the general lack of education on the value of visualisation services. However other inhibitors were outside of the client representatives' control. The cost of visualisation services and an inability to gain approval for the service were other commonly reported impediments to a prospective client's commitment to a visualisation service.

The contact stage revealed the importance of the first interactions between the visualisation organisation and the prospective client organisation for deciding whether to commit to the service. Visualisers facilitated visualisation service adoption, providing reassurance to the prospective clients in the contact stage by demonstrating their capabilities as visualisers.

Ultimately, the facilitating and inhibiting factors experienced by the prospective clients in the contact stage influenced the degree of value that the client perceived in the solution, which facilitated or inhibited their desire for continuation of the interaction, and commitment to the visualisation service. This reflects existing research on strategy tools which has suggested that critical indicators of success for strategy tools are the perceived value of the solution and the discretion of actors (Jarzabkowski \& Kaplan, 2015).

The distinction between externally developed visualisation and internally developed visualisation is an important one. Because strategy visualisation literature has focused on internal development of visualisation, the aforementioned inhibitors have received no attention. Clients wishing to hire visualisation services do not simply select and apply the tool, but must have consideration for their situated context, particularly the other actors in their organisation.

The multiple competing interests evident in the contact stage has implications for the internal adoption of visualisation. For example, a visualisation advocate may face difficulty introducing visualisation into their organisation, if managers lack an understanding of the value of visualisation. 


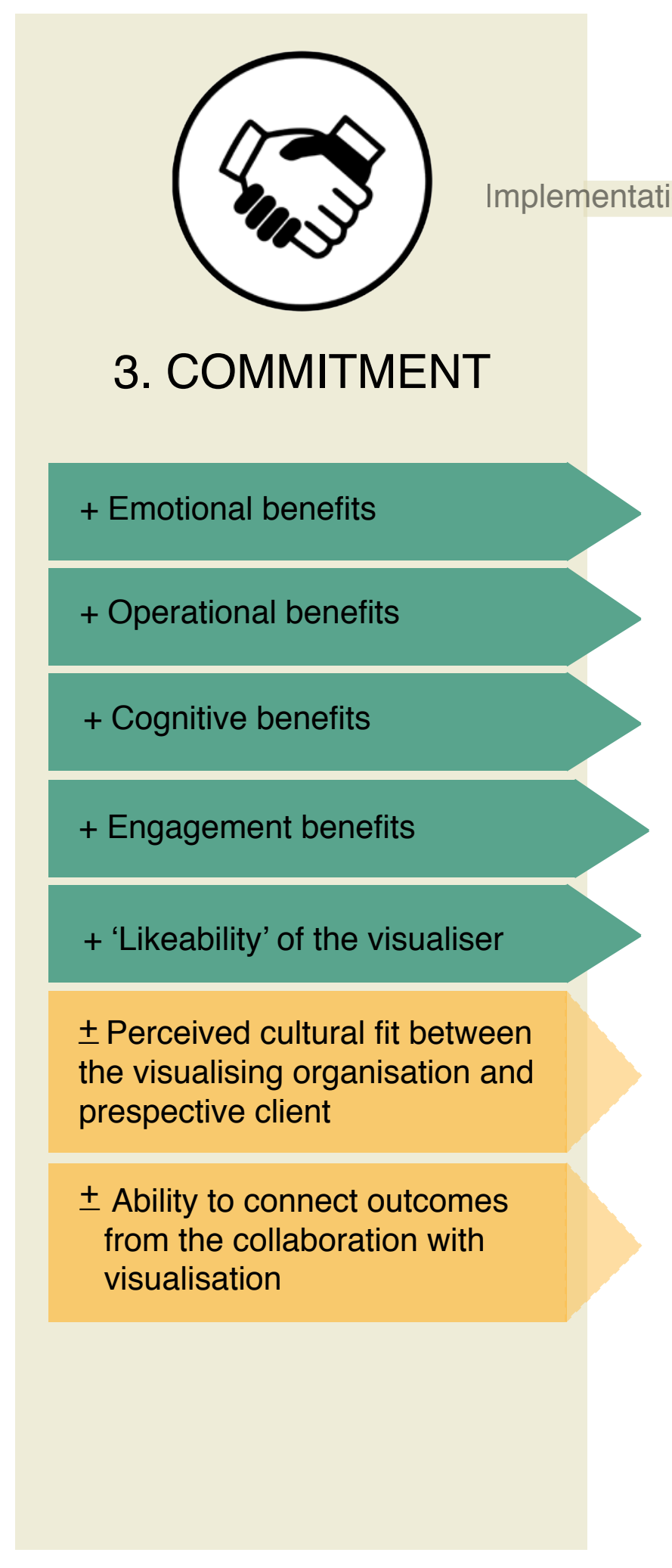

\subsubsection{Stage 3: Commitment}

I found that some facilitating and inhibiting factors were more prevalent when the visualisation organisation and client organisation committed to working together. Participants emphasised the importance of the experience of visualisation for facilitating clients' reconsideration of visualisation services. A common frustration for respondents was that it is not until clients have committed to using visualisation services that they can see these benefits. However, experiencing the benefits of visualisation did not necessarily mean that all clients understood the benefits, so not all clients facilitated the implementation of the visualisation services. Implementation is defined here as the dispersion of a visual solution in an organisation. Interviewees stated that some clients had the capability to connect the benefits of the artefact or the solution to organisational outcomes. These people became 'champions' of visualisation implementation. A higher perceived value of the solution during the engagement (e.g. if clients are champions of visualisation) meant that clients were more likely to actively evaluate the engagement (e.g. consider the visualisation for other projects) in the post-purchase evaluation stage. Conversely, clients that held a low perceived value of the solution in the commitment stage were less likely to engage in active post-purchase evaluation after the engagement was over, as the engagement was considered a one-off event. Thus in order to successfully implement the visualisation service, my results suggest that clients need to connect the collaboration outcomes with visualisation. This contributes novel insight to visualisation literature which has concentrated on the efficacy of visualisation, rather than exploring visualisation as a practice.

The findings also contribute to a better understanding of visualisation adoption in general. Once people have experienced visualisation, they are more likely to return to it. However, to make readoption more likely, practitioners also need to understand how the outcomes of visualisation connect to visualisation. Without this, visualisation vields little value. 


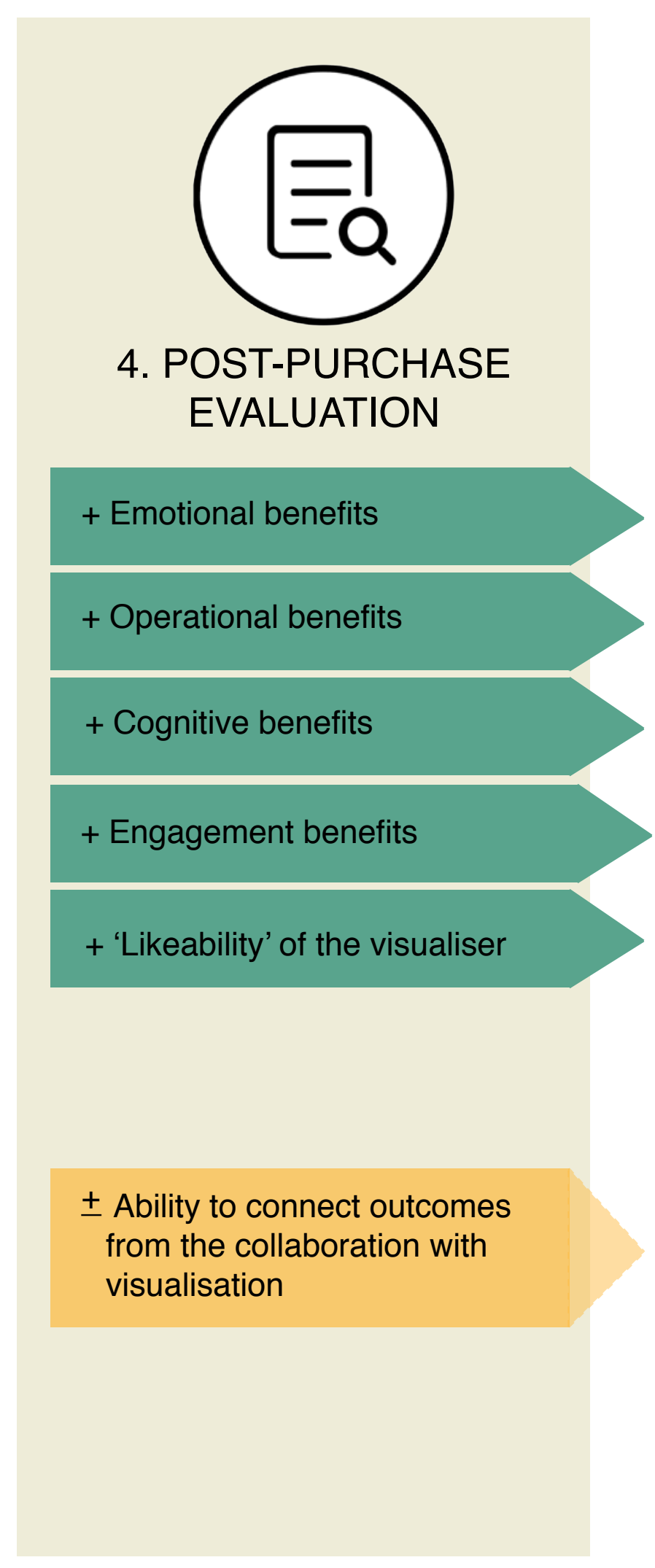

\subsubsection{Stage 4: Post-purchase Evaluation}

I constructed the post-purchase evaluation stage because I discovered, through analysis, facilitators and inhibitors to the reconsideration of visualisation services even after visualisation services ceased. In this stage, a client reflects on their experience and evaluates the value of the visual solution provided to them. While this stage focuses on the evaluation of visualisation services, the implications are transferrable to visualisation that has been internally developed and consequently evaluated.

After discussing the preliminary findings with respondents in the member checking interviews, respondents reported that the benefits extended long after the visualisation ended. This is represented in the quote below.

V7: "So operational benefits, engagement benefits, cognitive benefits, I'd almost move them a little bit further along. Because the benefits emerge during the process but also, largely are sold and implemented as kind of post-programme benefits."

Despite numerous benefits identified in the analysis, respondents suggested that engagement benefits of the visualisation facilitated clients' return to using visualisation services, as these benefits were easier to associate with collaboration. However, this can have negative consequences. At the extreme, an inability to see past the engagement benefits would contribute to the inhibiting factor, predisposition against visualisation. For example, participants indicated visualisation was only reconsidered due to its novelty in some instances. This has potential to perpetuate a low perceived value of visualisation, feeding the predisposition that visualisation is not 'serious work' and consequently fuelling the commoditisation of visualisation

As indicated in the explanation of the commitment stage (see Section 5.2.3), the ability to connect collaboration outcomes with visualisation is a factor that facilitates or inhibits implementation. This also affects reconsideration in the post-purchase evaluation stage. Respondents noted that clients who could understand bow visualisation benefits related to the collaboration outcomes tended to use the service again, implying that they had established an organisational need for it. This shows the significance of distinguishing between 'organisational need' and benefits of visualisation. 


\subsection{Managerial Implications}

\subsubsection{Variations}

The heuristic framework presents my interpretation of the adoption process and potential facilitating and inhibiting factors to visualisation adoption. This interpretation was formed to create the simplest possible explanation of visualisation adoption and present new insights for theory (Alvesson \& Sköldberg, 2000). As seen in Chapter 4, not every facilitator or inhibitor affects a client in the same way. Consequently, the framework is a tool which should be moulded to suit the needs of practitioners and researchers, rather than be considered a prescriptive framework. Variations to the model are encouraged. To illustrate, V7 conducted a quick sketch during a member checking interview, to illustrate how one variation could include the internal decision-making process of prospective clients (see Figure 13).

Other suggested variations from respondents were: Adding a feedback loop from the postpurchase evaluation stage to the contact stage (V7); splitting 'bad experience' into two categories (V9); adding interventions by the visualiser (e.g. explaining how the artefact can be used after the engagement) (V3); and adapting the process to suit visual thinking methodologies rather than "graphic capture" (V9).

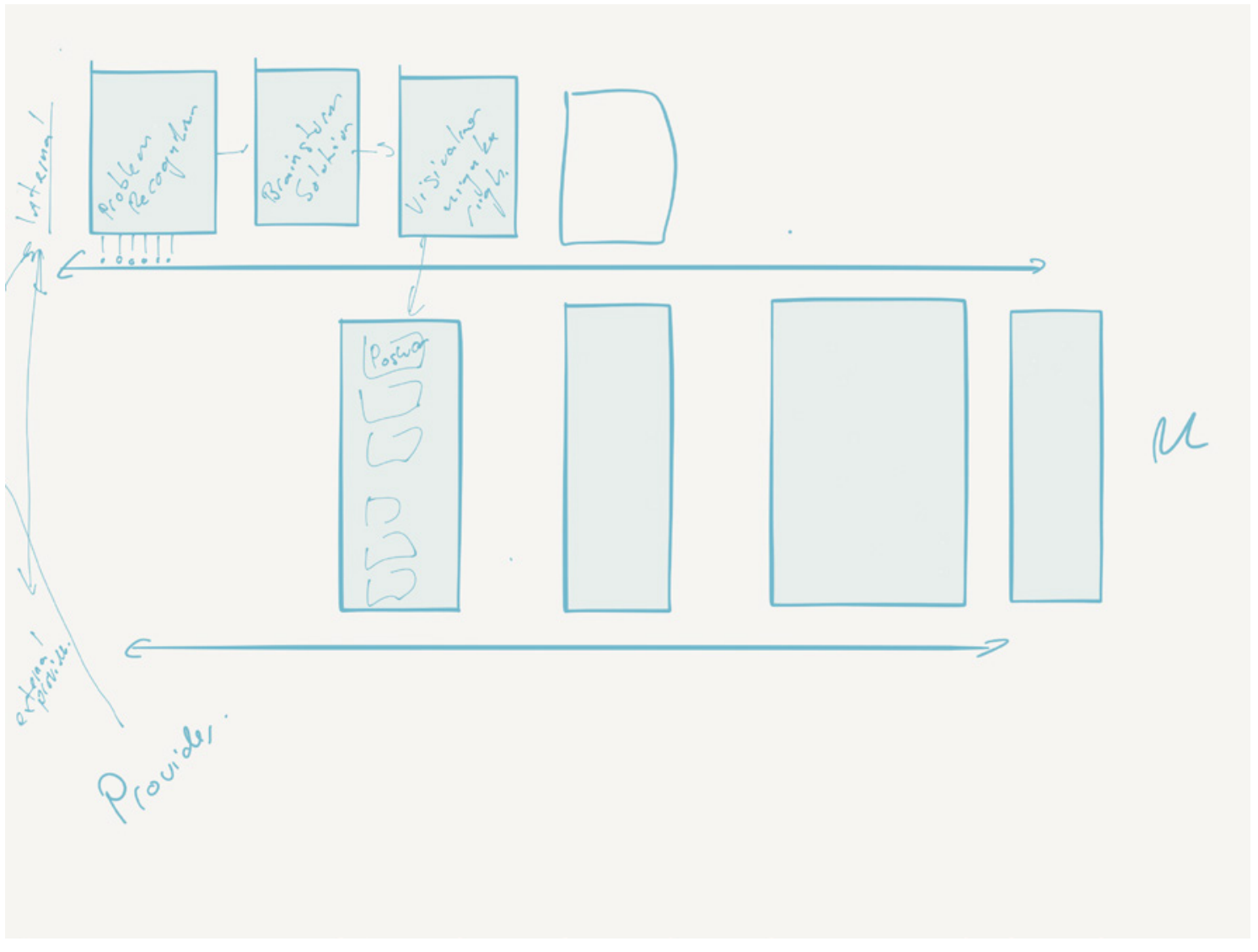




\subsubsection{Interventions}

Methods for overcoming inhibitors and exploiting facilitators were discussed in the interviews. Despite the interesting work that the visualisation organisations do for clients, respondents expressed difficulty in promoting their work.

V9: "Easily three quarters of the work that we do will never see the light of day [emphasis by interviewee]... Because it's giving away how this company works and that's just not okay. So we have a hard time showing the end product."

An inability to showcase clients' work due to confidentiality and proprietary barriers suggests that creativity is required on part of the visualisation organisation to convince prospective clients to adopt visualisation. Identifying methods for overcoming inhibitors and exploiting facilitators to visualisation adoption thus has practical utility for visualisation organisations.

Identification of interventions also has theoretical value. The literature review showed that scholars have recommended methods for overcoming challenges to visualisation in terms of creating, communicating and implementing visualisation. However, research on methods to overcome challenges associated with accepting and adopting visualisation has been largely overlooked. Meyer's (1997) study, which identifies different strategies to introduce visualisation to different managers, is an exception. His empirical study distinguishes managerial archetypes with differing levels of 'acceptance' to visualisation. For example, the 'reserved rational' type is said to have high acceptance barriers to visualisation due to little experience with visuals, and therefore should be slowly introduced to visuals. However, the findings in this thesis show that the acceptance of visualisation is not the same as the adoption of visualisation. There may be more than one decision maker (who may dislike visualisation) that needs to approve the visualisation before it can be adopted. Therefore, the following sections include proposed interventions to support the transitions between the stages of the visualisation adoption process (see Table 15 for the transitions). This was undertaken to suggest how and when interventions could be made in the visualisation adoption process, to overcome inhibiting factors and exploit facilitating factors. ${ }^{10}$ Representative quotes to corroborate all proposed interventions are provided and an intervention example is included for each transition (e.g. motivation).

10 Some of the inhibitors and facilitators noted in the intervention tables can be facilitators or inhibitors (as discussed in Chapter 4). However, for the purposes of describing interventions, a factor is clearly

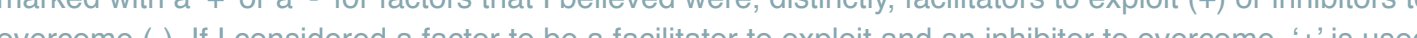

The interventions are provided to facilitate visualisation service adoption rather than internal development of visuals. However, the results framework has utility for managers wishing to encourage the adoption of visualisation within their organisation. This tool increases awareness of the possible factors that could be a barrier to the adoption of visuals (e.g. inhibitors in the pre-contact and contact stages), providing practitioners with a platform to develop interventions to overcome these inhibitors.

Table 15. Transitions between the stages of the visualisation adoption process

\begin{tabular}{ll} 
Transition & Stages \\
\hline Motivation & Pre-contact $\rightarrow$ Contact \\
Continuation & Contact $\rightarrow$ Commitment \\
Implementation & Commitment $\rightarrow$ Post-purchase Evaluation \\
Reconsideration & Post-purchase Evaluation $\rightarrow$ Pre-contact
\end{tabular}

Post-purchse Evithing Preconten 
Interviewees used multiple techniques to encourage prospective clients to commit to visualisation services (during the contact stage). However I realised such interventions would also be pertinent in the pre-contact stage. ${ }^{11}$ I established the interventions detailed in Table 16 because I believed they increase the perceived value of the solution before a prospective client experiences inhibiting factors in the contact stage.

As prospective clients have yet to make contact in the pre-contact stage, a visualisation organisation would face difficulty anticipating specific potential inhibiting factors faced by such clients. As seen in Chapter 4, not every practitioner experiences inhibiting factors the same way. In some cases, predisposition against visualisation is greater than in others. This means interventions cannot be targeted to a specific organisation as the prospective clients have yet to express their interest in the service. Therefore, interventions in the pre-contact stage should be publically available and broadly applicable, so that as many potential clients benefit from the interventions as possible.

To illustrate, visualisation organisation should detail on their company websites how visualisation could enable a prospective client to achieve organisational outcomes (see Intervention 1a in Table 16). This will overcome inhibitors such as a lack of experience (prior experience with visualisation) or the belief that visualisation is distracting (predisposition against visualisation) and enable the client to connect the service outcomes with visualisation in the commitment stage, as the client is made aware of what to expect. Displaying testimonials on the website from established companies with sanitised examples of work related to specific organisational needs would enhance the credibility of the claims made, and trustworthiness of the organisation, reducing the perceived risk of visualisation for prospective clients. Indeed, all of the visualisation organisations involved in this study include sanitised examples of work on their websites, display testimonials, or use logos from reputable clients such as Fortune 500 organisations.

\section{Inhibitor to overcome an or facilita
exploit

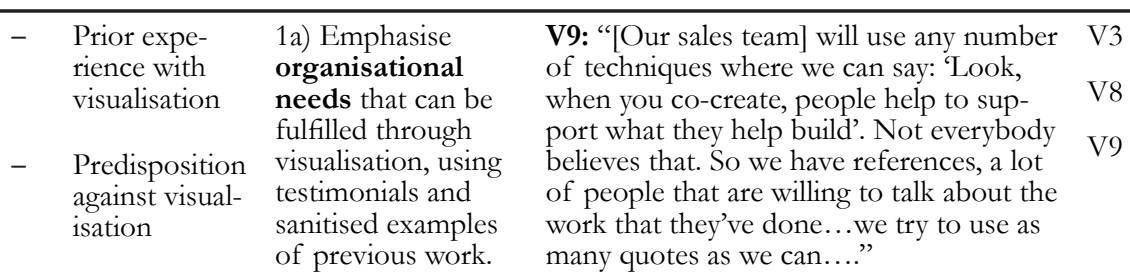 \\ many quotes as we can.}

- Prior experience with
visualisation

1b) Articulate
differences be
'good' and 'ba'c
visualisation

Cost of the Likeability'
of the visual-
iser(s)

Cost of the

1c) Leverage knowhow of the
sualiser or establis
culturat fit before cultural fit beforc
commitment stage

Perceived
cultural fit

between the
visualising

organisation
and prospec-

and prospec
tive client
Inter- When is the intervention

In pre-contact stage and contact stage to demonis useful (e.g. the visual can
be used after the event is over), when visualisation is perceived to be a risk, or
the client representative is the client representative is
unsure about the perceived unsure about the perceiv
value in comparison to

I In pre-contact stage and contact stage to convince
prospective clients of prospective clients of
higher quality compared to
other competitors. V1: "So I think we're in kind of a Wild V1 West territory right now.... I hope that as
clients get more educated, that they'll be able to see beyond the - 'Oh this works
sucks', but insteadl it's 'Oh the is pick the right person for this project, let's pick the right person or this project, lett
find somebody who understands proces
betse"
In pre-contact stage
to demonstrate competence through publically available pieces of work
(e.g.through website and
YouTuhe

In contact stage when
competing with other visucompeting with other visu
alisation organisations. 
Table 17. Interventions to facilitate continuation

As identified in Chapter 4, a number of inhibitors in the contact stage prevent organisations from committing to visualisation services. However many of these inhibitors are outside of the control of a visualisation organisation. For example, the degree for which the cost of the service acts an inhibitor to visualisation adoption depends on the client organisation's perception of cost and value of the solution. Respondents used interventions to overcome other inhibitors instead, in order to increase clients' perceived value of the solution. Table 17 outlines specific interventions that can be used to facilitate continuation to commitment.

In the contact stage, the visualisation organisation and client organisation will have begun interacting with each other. Respondents used targeted interventions in light of the knowledge gained about the prospective client from these interactions. As an example, V9 ran free visualisation workshops for potential clients (see Intervention $2 \mathrm{c}$ in Table 17). These examples demonstrated how the experience of visualisation is a powerful facilitating factor towards clients' return to visualisation services. However, as seen in Section 5.2.3, it is not until the commitment stage that clients can experience this. Thus, by showing potential clients the benefits of visualisation before they have made a commitment, visualisation organisations exploited the visualiser's knowhow to demonstrate their professionalism and capabilities. If done well, this will help to overcome the lack of education on the value of visualisation services by enabling prospective clients to 'try before they buy', reducing uncertainty about the service and educating clients about what 'quality' visualisation means.

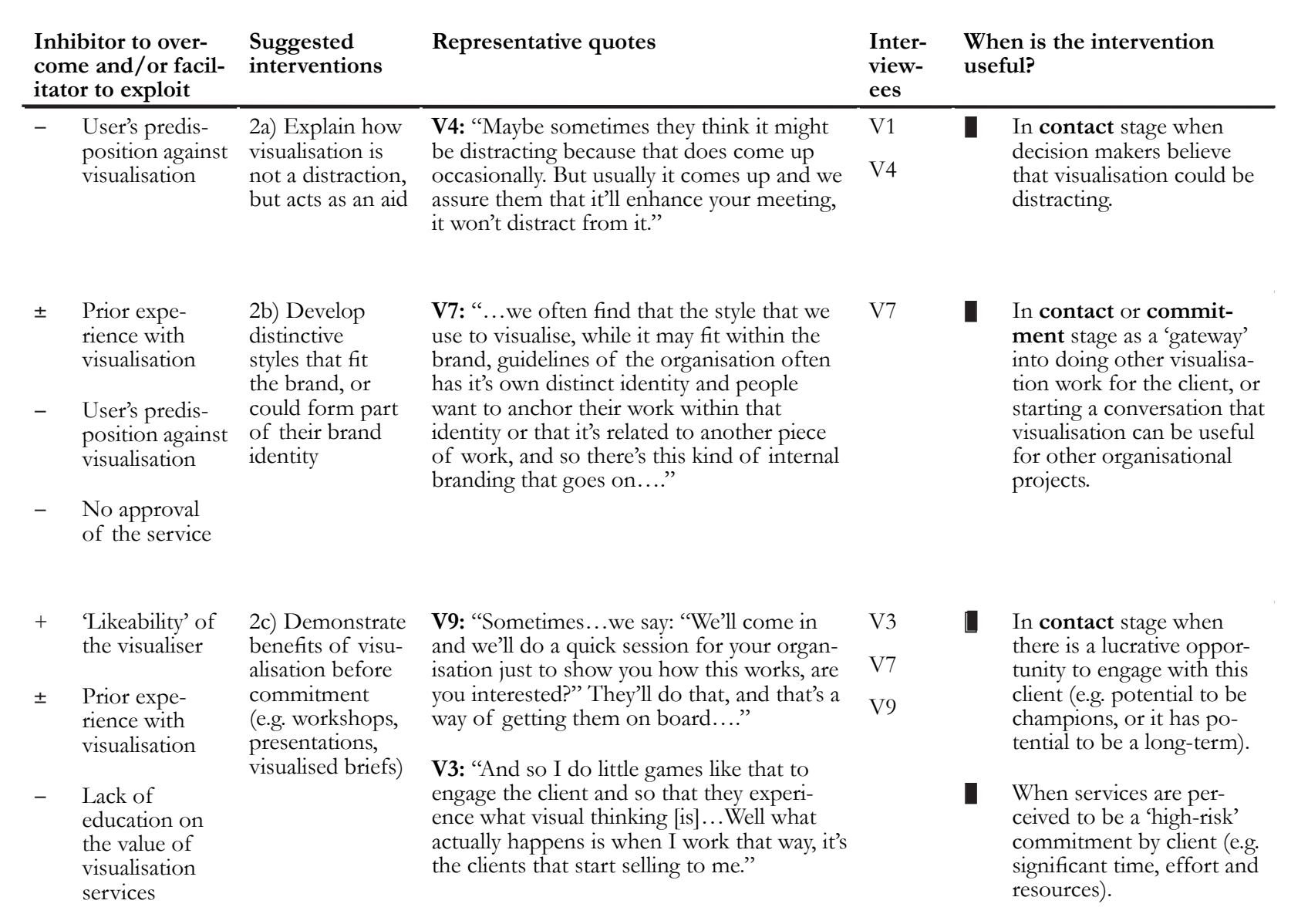


Table 18 displays an intervention which is useful for facilitating implementation (i.e. dispersing the visual solution throughout the client organisation). Only one intervention was identified, however this by no means suggests that facilitating implementation has minor significance. Ensuring that the visual solution is well dispersed throughout the organisation will encourage organisations to use visualisation even after the engagement has ended, thus increasing the chances that the client organisation will engage in post-purchase evaluation, rather than perceive the visual solution as a one-time event.

Involvement in the visualisation process enables those involved to understand and be enthused about the content (Eppler \& Platts, 2009). However, one respondent who creates visualisation artefacts noted that post-engagement, external consultants are unable to drive the knowledge about these artefacts and its utility throughout the organisation as clearly as someone who is in the organisation (see Intervention $3 a$ in Table 18). This respondent suggested training people to educate clients about how to use the visual solution. This is particularly important for visualisations that are complex or difficult to use, such as interactive strategy presentations, as Jarzabkowski and Kaplan (2015) indicate that strategy tools will be assessed on their ease of use.

Although visual artefacts may be displayed in the organisation, not everyone will have been involved in its construction and may interpret the visualisation in unintended ways. If visualisation content lacks clarity to 'outsiders', how can its audience be expected to comprehend and carry out its messages? To avoid ambiguity, visualisation organisations should ensure representatives from the client organisation know how to explain and discuss the visualisation solution, or send staff to the organisation to present the artefact. As such, people who have not been involved in the creation of the visualisation can comprehend it, increasing the chance that important content (e.g. strategy) is interpreted correctly. The implementation of strategy is critical to its success (Phaal \& Muller, 2009); therefore strategy visuals should not only be developed well, but need to be clarified to those who will enact the strategy so that they may realise value in carrying out the strategy.

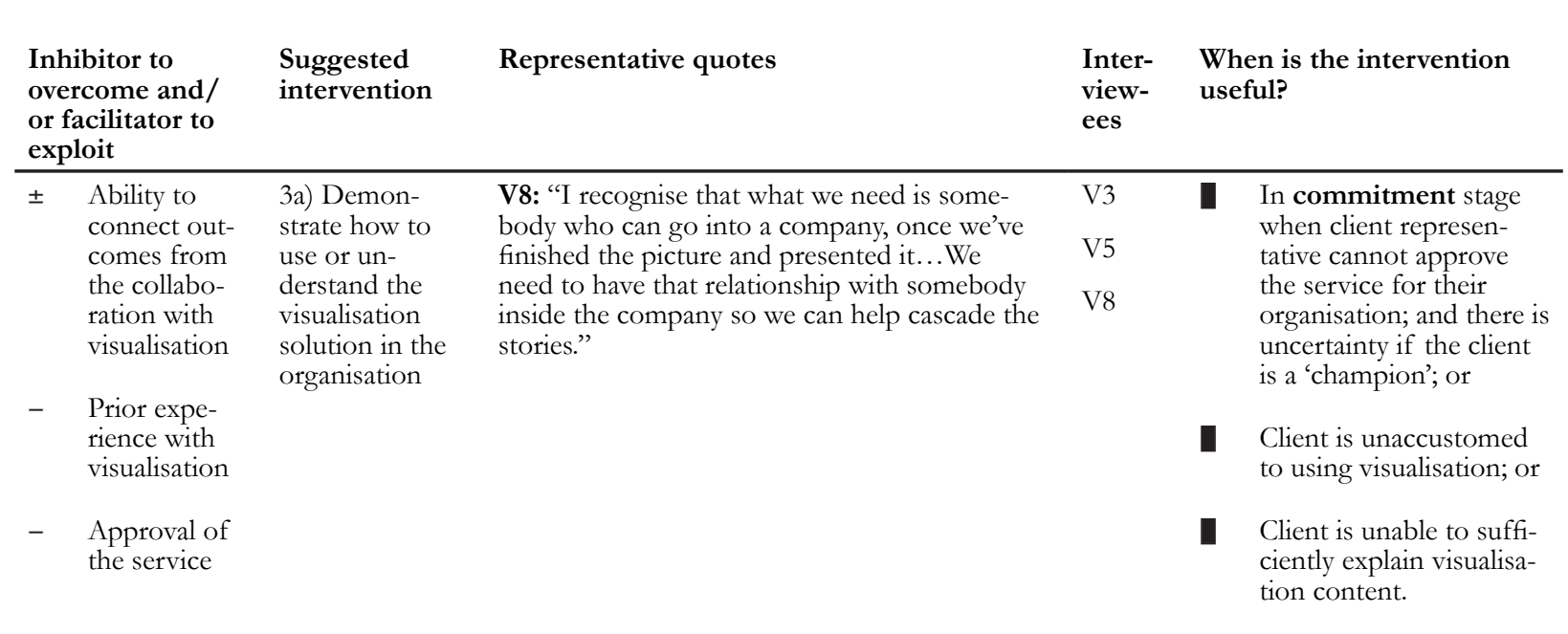


The client chooses whether to reconsider using a visualisation organisation's services in the post-purchase evaluation stage. Since this evaluation happens independent of the visualisation organisation, interventions to facilitate reconsideration must be implemented in the contact and commitment stages, while the two organisations are still interacting. Three possible interventions are detailed in Table 19.

One respondent, V8, emphasised co-creation during the commitment phase to demonstrate a deep understanding of an organisation that they were attempting to win a bid on behalf of a client. The respondent used a sketchy visual style to articulate that the bid was something that could be worked on, rather than a 'finished' product that is perceived as the 'answer' to the problem that the organisation is facing (see Intervention 4a, in Table 19). Emphasising co-creation in this way effectively showcases the knowhow of the visualiser, giving the visualiser an opportunity to discuss other needs that the client organisation has, as opposed to the client expecting to be given the solution. This also demonstrates the value of using a practice approach, as it shows that the doing of strategy (e.g. drafting strategy visualisations for clients) is important and should not be overlooked. The operational benefits and cognitive benefits that resulted from the visual solution should also be stressed in the contact and commitment stages, in order to prevent the client from only seeing the more 'tangible' engagement benefits. Doing so enables greater ability for clients to connect collaboration outcomes with visualisation, and reconsider using visualisation.

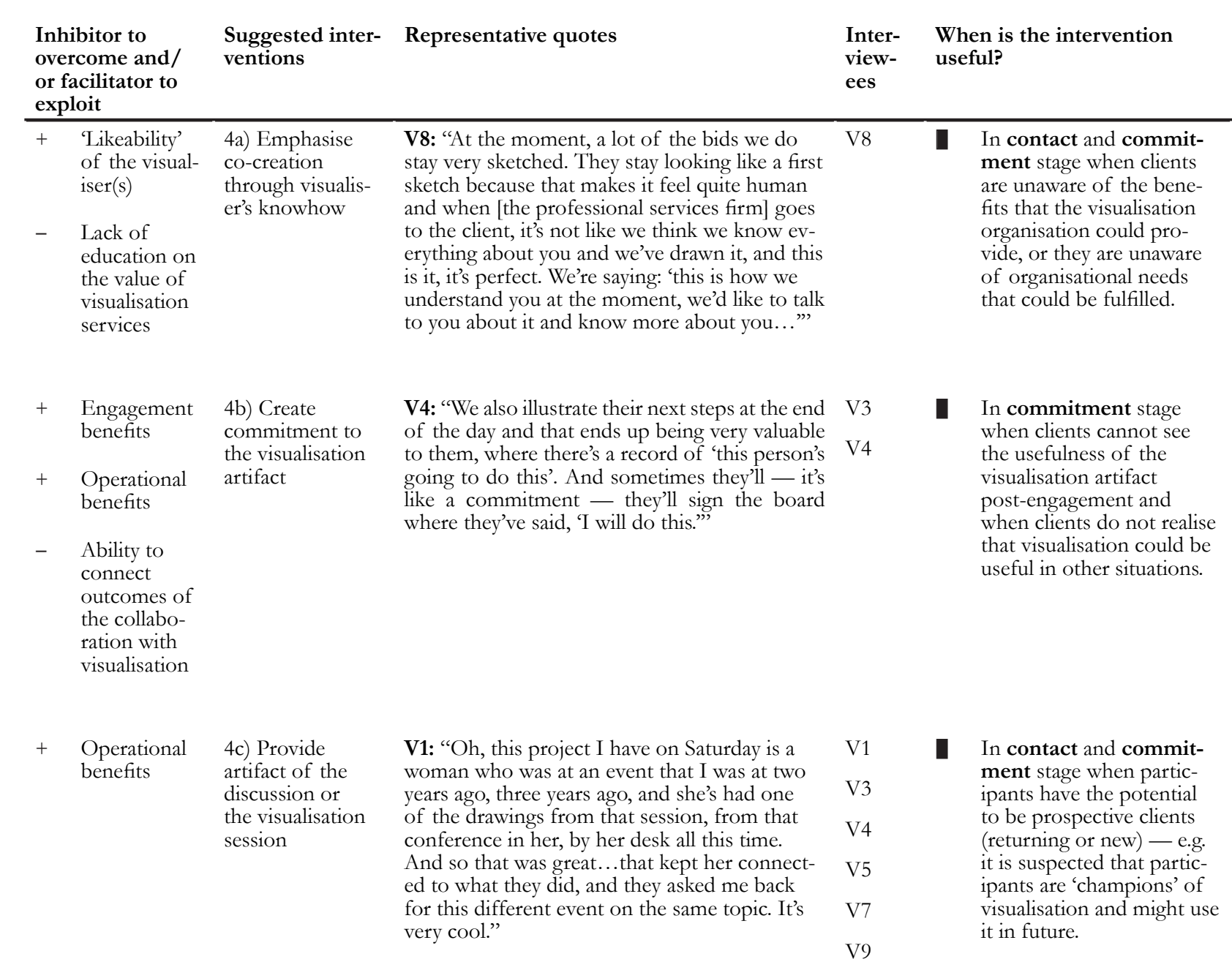




\subsection{Limitations and Implications for Future Research}

This study has contributed an understanding of facilitating and inhibiting factors to visualisation adoption, indicating why strategy visualisation use is not as widespread a practice as its advocates suggest it should be. However several limitations in the research design need to be acknowledged, while suggesting avenues for future research.

Although a number of important facilitators and inhibitors to visualisation adoption were identified, the study was reliant on the perceptions of visualisers and was confined to examination of the adoption or rejection of visualisation services. Nevertheless, the study does not claim to be representative of all visualisation adoption methods. Additionally, by asking representatives from visualisation organisations to comment on their experiences with clients, this study gained diverse perspectives on visualisation adoption behaviour that would have been otherwise difficult to ascertain. There is a rich opportunity for empirical investigation into the linkages between the identified factors and the contexts in which they unfold. Furthermore, the conceptual framework could be extended to investigate the adoption of other strategy tools. For example, researchers could compare the adoption of different tools within organisations to elucidate how some tools are institutionalised and widely accepted while others are not.

Additionally, one representative from each visualisation organisation was interviewed so responses could not be verified or 'triangulated'. This was partially mitigated through asking respondents to respond to the findings. Moreover, this research was intended to be an exploratory study to ascertain common facilitating and inhibiting factors to the adoption of visualisation. Future studies into this topic could engage in triangulation methods or use multiple methods of data collection (e.g. interviews, questionnaires, observations and archives) to increase the credibility of the findings (Rose, et al., 2014).

\subsection{Key Takeaways From the Research}

\subsubsection{Key Recommendations for Practice}

\section{Create enthusiasm and establish familiarity with visualisation}

- Engage decision makers by communicating ideas, strategies or even conversations by drawing it in informal settings. ${ }^{12}$

- Enthuse and excite the decision makers' audience. Enable the decision makers to witness positive reactions elicited by visualisation.

\section{Customise the visual}

- Tailor the visual to the manager(s) and the organisation. E.g. If a manager or organisational culture has an aversion to 'cartoons', consider using visua styles that they are comfortable with, such as infographics. Consider hiring professionals if uncertain about how to do so.

\section{Make it memorable}

- Establish organisational needs for the visualisation to fulfil (e.g. remembering key messages) and ensure the visualisation achieves this.

- Involve decision makers in the visualisation process. E.g. Use sticky notes to brainstorm, capturing new ideas.

\subsubsection{Key Research Contributions}

1. Identified common facilitating factors to visualisation adoption, but most importantly, identified common inhibitors to its adoption. This provides researchers with a framework to understand why visualisation is not a widely spread practice.

2. Shown how visualisation can clarify and support strategy making, indicating that even mundane practices can have important implications for strategy.

3. Demonstrated that viewing visualisation as a socially situated practice, will complement the existing 'how to do' and 'why to do' of strategy visualisation literature, to increase its value for practitioners, and thus its adoption.

12 For tips, see the visualisation resources identified in Section 2.3, e.g. Roam (2008) 


\subsection{Conclusion}

Through this research I sought to understand why, in practice, visualisation use is limited despite the proliferation of strategy literature on 'how to do' and 'why to do' visualisation. The main contribution of this research is the identification of common facilitators and importantly, the inbibitors to visualisation adoption. Based on an understanding of these factors, I developed a heuristic framework to show how visualisation is adopted, and related these facilitators and inhibitors to four process phases: pre-contact, contact, commitment and post-purchase evaluation. The effects of the facilitators and inhibitors for strategising were also explored, demonstrating that examination of 'mundane' practices such as visualisation adoption can clarify and support strategy making.

The practical implications of this research are numerous. This has the greatest benefit for visualisation organisations and management practitioners wishing to encourage visualisation adoption within their own organisation, clarifying potential facilitating and inhibiting factors to adoption. The heuristic framework also provides the ability to see how this adoption might occur. Secondly, the proposed interventions enable practitioners to manage inhibiting and facilitating factors to encourage visualisation adoption. While the study emphasises visualisation services, I strongly encourage practitioners to regard this framework as a tool which should be adapted to suit different needs. As demonstrated, if visualisation is used in a way that vields little organisational value (e.g. 'decoration' for an event), this perpetuates negative associations with visualisation, creating challenges for future adoption.

One implication for research is that, in order for strategy visualisation research to increase its practical relevancy, we require a deeper understanding of the 'doing' of visualisation. But, rather than shifting the gaze away from existing visualisation research which explores 'why to do visualisation' and 'how to do visualisation', the practice approach should be considered a complementary yet important pathway for establishing visualisation as a useful strategy tool. In embracing this conceptualisation of visualisation as a practice, and its adoption as a socially situated activity, I found that the benefits of visualisation not only need to be communicated well but also typically need to be experienced to facilitate adoption; even simple sketches are effective. As such, clients' experience of engagement benefits served as significant facilitators to visualisation adoption, because clients could relate visualisation to personal or organisational outcomes. However, experiencing visualisation benefits does not guarantee its adoption. I found that the benefits of visualisation extend beyond the outcomes related to the visualisation, to the perceptions of the client who used the visualisation. Other personal factors which impact upon adoption include: predispositions for or against visualisation, prior knowledge about visualisation and associated services, partiality towards visualisation consultants; and the capability to identify specific organisational needs for visualisation. Contextual factors, such as organisational culture, and ability to approve the service within an allocated budget, also influence the adoption of visualisation. The aforementioned facilitators and inhibitors experienced in each phase of visualisation adoption impact upon the perceived value of the solution, determining whether a prospective client will proceed to adoption. Consequently, designing and communicating visualisation tools (and other strategy tools), which has utility for managers, necessitates consideration of actors' experience of the practices and the context in which they are situated.

This research clarifies facilitating and inhibiting factors to visualisation adoption for researchers, providing a guide to promote greater uptake of strategy visualisation. However, empirical research opportunities exist to extend this research. The study was confined to visualisers' perceptions of facilitating and inhibiting factors to visualisation service adoption, thus contextual linkages could not be fully explored - such as studying how visualisation is adopted internally, within organisations. To improve our understanding of the facilitators and inhibitors to visualisation, future research could empirically test the framework within different settings (e.g. internal adoption of visualisation) and explore linkages of visualisation adoption to the identified facilitators and inhibitors. More broadly, this framework could be used to examine how other strategy tools are adopted. 
Acur, N., \& Bititci, U. (2003). Managing strategy through business processes. Production Planning \& Control, 14(4), 309-326.

doi:10.1080/0953728031000117977

Alvesson, M., \& Sköldberg, K. (2000). Reflexive methodology: New vistas for qualitative research ( $1^{\text {st }}$ ed.). London, England: Sage.

Alvesson, M., \& Sköldberg, K. (2009). Reflexive methodology: New vistas for qualitative research (2nd ed.). London, England: Sage.

Andrews, K. R. (1971). The concept of corporate strategy. Homewood, IL: Irwin.

Avgerinou, M. D. (2007). Towards a visual literacy index. Journal of Visual Literacy, 27(1), 29-46. doi:10.1080/23796529.2007.11674644

Avgerinou, M. D., \& Pettersson, R. (2011). Toward a cohesive theory of visual literacy. Journal of Visual Literacy, 30(2), 1-19.

doi:10.1080/23796529.2011.11674687

Bechky, B. A. (2003). Sharing meaning across occupational communities: The transformation of understanding on a production floor. Organization Science, 14(3), 312-330. doi:10.1287/orsc.14.3.312.15162

Bititci, U. S., Cocca, P., \& Ates, A. (2015). Impact of visual performance management systems on the performance management practices of organisations. International Journal of Production Research. Advance online publication. doi:10.1080/00207543.2015.1005770

Boyatzis, R. E. (1998). Thematic analysis and code development: Transforming qualitative information. Thousand Oaks, CA: Sage.

Bresciani, S., \& Eppler, M. J. (2015). The pitfalls of visual representations: A review and classification of common errors made while designing and interpreting visualizations. SAGE Open, 5(4), 1-13. doi:10.1177/2158244015611451

Bürgi, P. T., \& Roos, J. (2003). Images of strategy. European Management Journal, 21(1), 68-78. Retrieved from http://www.journals.elsevier.com 
/european-management-journal/

Buzan, T., \& Buzan, B. (2000). The mind map book. London, England: BBC.

Card, S. K., Mackinlay, J. D., \& Shneiderman, B. (1999). Readings in information visualization: using vision to think. San Francisco, CA: Morgan Kaufmann.

Carlile, P. R. (2006). Artifacts and knowledge negotiation across domains. In A. Rafaeli \& M. G. Pratt (Eds.), Artifacts and Organizations. Mahwah, NJ: Lawrence Erlbaum Associates.

Carmona, S., Iyer, G., \& Reckers, P. M. (2011). The impact of strategy communications, incentives and national culture on balanced scorecard implementation. Advances in Accounting, 27(1), 62-74. doi:10.1016/j.adiac.2011.01.004

Comi, A., \& Eppler, M. J. (2011). Assessing the Impact of Visual Facilitation on Inter-Organizational Collaboration: An Experimental Study. Journal of Universal Computer Science, 17(10), 1430-1454. doi:10.3217/jucs-017-10-1430

Cox, R., \& Brna, P. (1995). Supporting the use of external representations in problem solving: The need for flexible learning environments. Journal of Interactive Learning Research, 6(2/3), 239-302. Retrieved from http://www.aace.org/pubs/jilr/

Cummings, S., \& Angwin, D. (2011). Stratography: The art of conceptualizing and communicating strategy. Business Horizons, 54, 435-446. doi:10.1016/i.bushor.2011.04.005

Cummings, S., \& Angwin, D. (2015). Strategy builder: How to create and communicate more effective strategies: Chichester, England: John Wiley \& Sons.

De Bono, E. (1973). Lateral thinking. Creativity step by step. New York, NY: Harper Colophon.

De Salas, K., \& Huxley, C. (2014). Enhancing visualisation to communicate and execute strategy: Strategy-to-Process Maps. Journal of Strategy and Management, 7(2), 109-126. doi:10.1108/jsma-10-2012-0055

Deakin, H., \& Wakefield, K. (2013). Skype interviewing: Reflections of two PhD researchers. Qualitative Research, 14(5), 603-614. doi:10.1177/1468794113488126
Digman, L. A. (1990). Strategic management: Concepts, decisions, cases (2nd ed.). Homewood, IL: Irwin.

DiMicco, J. M., Pandolfo, A., \& Bender, W. (2004). Influencing group participation with a shared display. Paper presented at the Proceedings of the 2004 ACM conference on Computer Supported Cooperative Work, Chicago. Retrieved from http://www.acm.org/publications

Eppler, M. J., \& Bresciani, S. (2013). Visualization in management: From communication to collaboration. A response to Zhang. Journal of Visual Languages \& Computing, 24(2), 146-149. doi:10.1016/j.jvlc.2012.11.003

Eppler, M. J., \& Platts, K. W. (2009). Visual strategizing: The systematic use of visualization in the strategic-planning process. Long Range Planning, 42(1), 4274. doi:10.1016/j.lrp.2008.11.005

Free, C., \& Qu, S. Q. (2011). The use of graphics in promoting management ideas: An analysis of the Balanced Scorecard, 1992-2010. Journal of Accounting \& Organizational Change, 7(2), 158-189. doi:10.1108/18325911111139680

Galagan, P. A. (1993). Helping groups learn. Training \& Development, 47(10), 57-62. Retrieved from https://www.ebscohost.com/academic/business-sourcecomplete

Garreau, L., Mouricou, P., \& Grimand, A. (2015). Drawing on the map: An exploration of strategic sensemaking/giving practices using visual representations. British Journal of Management, 26(4), 689-712. doi:10.1111/1467-8551.12099

Golsorkhi, D., Rouleau, L., \& Vaara, E. (2010). Introduction: What is strategy as practice? In D. Golsorkhi, L. Rouleau, D. Seidl, \& E. Vaara (Eds.), Strategy as Practice (pp. 1-20). Cambridge, England: Cambridge University Press.

Graphic Footprints. (n.d.). All-Staff Retreat. Retrieved May 2, 2016, from http://graphicfootprints.com/projects/all-staff-retreat/

Grinder, J., \& Bandler, R. (1975). The structure of magic, vol. 1 and 2. Palo Alto, CA: Science and Behavior Books. 
Guba, E. G., \& Lincoln, Y. S. (1994). Competing paradigms in qualitative research. In D. N. K \& Y. S. Lincoln (Eds.), Handbook of Qualitative Research (pp. 105) London, England: Sage.

Güney, S., \& Taylor, J. R. (2014). Rethinking the role of roadmaps in strategic planning: A close-up analysis from project development in corporate R\&D. Qualitative Research in Organizations and Management: An International Journal, 9(4), 308-331. doi:10.1108/qrom-08-2012-1090

Gunn, R., \& Williams, W. (2007). Strategic tools: An empirical investigation into strategy in practice in the UK. Strategic Change, 16(5), 201-216. doi:10.1002/jsc.799

Hendry, J. (2000). Strategic decision making, discourse, and strategy as social practice. Journal of Management Studies, 37(7), 955-977. doi:10.1111/14676486.00212

Heracleous, L., \& Jacobs, C. D. (2008). Crafting strategy: The role of embodied metaphors. Long Range Planning, 41(3), 309-325. doi:10.1016/j.lrp.2008.02.011

Holloway, M. (2009). How tangible is your strategy? How design thinking can turn your strategy into reality. Journal of Business Strategy, 30(2/3), 50-56. doi:10.1108/02756660910942463

Horn, R. E. (1998). Visual language: Global communication for the 21st century. Bainbridge Island, WA: MacroVU Press.

Huff, A. S., \& Jenkins, M. (2002). Mapping strategic knowledge. London, England: Sage.

INK strategy. (n.d.). Home. Retrieved April 1, 2016, from

http://www.inkstrategy.com/

Irvine, A., Drew, P., \& Sainsbury, R. (2013). 'Am I not answering your question properly?' Clarification, adequacy and responsiveness in semi-structured telephone and face-to-face interviews. Qualitative Research, 13(1), 87-106. doi:10.1177/1468794112439086

JAM visual thinking. (n.d.). Looking into the future: Trend research for tomorrow's investments. Retrieved April 1, 2016, from http://www.jamvisualthinking.com/work/11
Janis, I. L. (1972). Victims of groupthink: A psychological study of foreign-policy decisions and fiascoes. Boston, MA: Houghton Mifflin.

Jarzabkowski, P. (2004). Strategy as practice: recursiveness, adaptation, and practices-in-use. Organization Studies, 25(4), 529-560. doi:10.1177/0170840604040675

Jarzabkowski, P., \& Balogun, J. (2009). The practice and process of delivering integration through strategic planning. Journal of Management Studies, 46(8), 1255-1288. doi:10.1111/j.1467-6486.2009.00853.x

Jarzabkowski, P., Balogun, J., \& Seidl, D. (2007). Strategizing: The challenges of a practice perspective. Human Relations, 60(1), 5-27. doi:10.1177/0018726707075703

Jarzabkowski, P., \& Kaplan, S. (2015). Strategy tools-in-use: A framework for understanding "technologies of rationality" in practice. Strategic Management Journal, 36(4), 537-558. doi:10.1002/smj.2270

Jarzabkowski, P., \& Paul Spee, A. (2009). Strategy-as-practice: A review and future directions for the field. International Journal of Management Reviens, 11(1), 69-95. doi:10.1111/j.1468-2370.2008.00250.x

Jarzabkowski, P., \& Sillince, J. (2007). A rhetoric-in-context approach to building commitment to multiple strategic goals. Organization Studies, 28(11), 16391665. doi:10.1177/0170840607075266

Jarzabkowski, P., Spee, A. P., \& Smets, M. (2013). Material artifacts: Practices for doing strategy with 'stuff. European Management Journal, 31(1), 41-54. doi:10.1016/j.emj.2012.09.001

Kaplan, R. S., \& Norton, D. P. (1996). Using the balanced scorecard as a strategic management system. Harvard Business Review, 74(1), 75-84. Retrieved from https://hbr.org

Kaplan, R. S., \& Norton, D. P. (2000). Having trouble with your strategy? Then map it. Harvard Business Review, 78(5), 167-176. Retrieved from https://hbr.org

Kaplan, R. S. (2008). Framing contests: Strategy making under uncertainty. Organization Science, 19(5), 729-752. doi:10.1287/orsc.1070.0340 
Kernbach, S., Eppler, M. J., \& Bresciani, S. (2015). The use of visualization in the communication of business strategies: An experimental evaluation. International Journal of Business Communication, 52(2), 164-187. doi:10.1177/2329488414525444

Kerr, C., Farrukh, C., Phaal, R., \& Probert, D. (2013). Key principles for developing industrially relevant strategic technology management toolkits. Technological Forecasting and Social Change, 80(6), 1050-1070. doi:10.1016/j.techfore.2012.09.006

Kim, W. C., \& Mauborgne, R. (2005). Blue ocean strategy. Boston, MA: Harvard Business School Press.

King, N. (2004). Using templates in the thematic analysis of texts. In C. Cassell \& G. Symon (Eds.), Essential Guide to Qualitative Methods in Organizational Research (pp. 256-270). London, England: Sage.

Kiyoshi, S. (1993). The new shop floor management: Empowering people for continuous improvement. New York, NY: Free Press.

Kraut, R. E., Fussell, S. R., \& Siegel, J. (2003). Visual information as a conversational resource in collaborative physical tasks. Human-Computer Interaction, 18(1), 13-49. doi:10.1207/S15327051HCI1812_2

Kvale, S., \& Brinkmann, S. (2009). Interviens: Learning the craft of qualitative research interviewing (2nd ed.). Los Angeles, CA: Sage.

Larkin, J. H., \& Simon, H. A. (1987). Why a diagram is (sometimes) worth ten thousand words. Cognitive Science, 11(1), 65-100. doi:10.1111/j.15516708.1987.tb00863.x

Logie, R. H. (1995). Visuo-spatial working memory. Hove, England: Lawrence Erlbaum.

Mantere, S., \& Vaara, E. (2008). On the problem of participation in strategy: A critical discursive perspective. Organization Science, 19(2), 341-358. doi:10.1287/orsc.1070.0296

March, J. G. (2006). Rationality, foolishness, and adaptive intelligence. Strategic Management Journal, 27(3), 201-214. doi:10.1002/smi.515
Meyer, J. A. (1997). The acceptance of visual information in management. Information \& Management, 32(6), 275-287. doi:10.1016/S03787206(97)00032-3

Mills, J., Neely, A., Platts, K., \& Gregory, M. (1998). Manufacturing strategy: A pictorial representation. International Journal of Operations \& Production Management, 18(11), 1067-1085. doi:10.1108/01443579810231660

Mintzberg, H. (1987). The strategy concept I: Five Ps for strategy. Californi Management Review, 30(1), 11-24. doi:10.2307/41165263

Mintzberg, H. (1994). The Rise and Fall of Strategic Planning: Reconceiving Roles for Planning, Plans, Planners. New York, NY: Free Press.

Mintzberg, H. (2004). Managers, not MBAs: A Hard Look at the Soft Practice of Managing and Management Development. San Francisco, CA: Berrett-Koehler.

Mintzberg, H., \& Van der Heyden, L. (1999). Organigraphs: Drawing how companies really work. Harvard Business Review, 77(5), 87-94. Retrieved from https://hbr.org

Morgan, G. (2006). Images of organization. Thousand Oaks, CA: Sage.

O'Leary, Z. (2014). The essential guide to doing your research project. London, England: Sage.

Onwuegbuzie, A. J., \& Leech, N. L. (2007). Validity and qualitative research: An oxymoron? Quality \& Quantity, 41(2), 233-249. doi:10.1007/s11135-006$9000-3$

Orlikowski, W. J. (2000). Using technology and constituting structures: A practice lens for studying technology in organizations. Organization Science, 11(4), 404428. doi:10.1287/orsc.11.4.404.14600

Orlikowski, W. J. (2010). Practice in research: phenomenon, perspective and philosophy. In D. Golsorkhi, L. Rouleau, D. Seidl, \& E. Vaara (Eds.), The Cambridge Handbook on Strategy as Practice (pp. 23-33). Cambridge, England: Cambridge University Press.

Orlikowski, W. J., \& Scott, S. V. (2008). Sociomateriality: Challenging the separation of technology, work and organization. The Academy of Management Annals, 2(1), 433-474. doi:10.1080/19416520802211644 
Orton, J. D. (1997). From inductive to iterative grounded theory: Zipping the gap between process theory and process data. Scandinavian Journal of Management, 13(4), 419-438. doi:10.1016/S0956-5221(97)00027-4

Osterwalder, A., \& Pigneur, Y. (2010). Business model generation: A handbook for visionaries, game changers, and challengers. Hoboken, NJ: John Wiley \& Sons.

Papadakis, V. M., Lioukas, S., \& Chambers, D. (1998). Strategic decision-making processes: The role of management and context. Strategic Management Journal, 19(2), 115-147. doi:10.1002/(SICI)1097-0266(199802)19:23.0.CO;2-5

Paroutis, S., Franco, L. A., \& Papadopoulos, T. (2015). Visual interactions with strategy tools: Producing strategic knowledge in workshops. British Journal of Management, 26(S1), S48-S66. doi:10.1111/1467-8551.12081

Pashler, H., McDaniel, M., Rohrer, D., \& Bjork, R. (2008). Learning styles concepts and evidence. Psychological Science in the Public Interest, 9(3), 105-119. doi:10.1111/j.1539-6053.2009.01038.x

Phaal, R., \& Muller, G. (2009). An architectural framework for roadmapping: Towards visual strategy. Technological Forecasting and Social Change, 76(1), 39-49. doi:10.1016/j.techfore.2008.03.018

Pickton, D. W., \& Wright, S. (1998). What's SWOT in strategic analysis? Strategic Change, 7(2), 101-109. doi:10.1002/(SICI)1099 1697(199803/04)7:2<101::AID-JSC332>3.0.CO;2-6

Platts, K., \& Hua Tan, K. (2004). Strategy visualisation: knowing, understanding, and formulating. Management Decision, 42(5), 667-676. doi:10.1108/00251740410538505

Porter, M. E. (1979). How competitive forces shape strategy. Harvard Business Review, 57(2), 137-145. doi:10.1225/79208

Quinn, J. B. (1978). Strategic change: "Logical incrementalism". Sloan Management Review, 20(1), 7-19. Retrieved from

http://search.proquest.com.helicon.vuw.ac.nz/docview

/224968803? accountid $=14782$
Reckwitz, A. (2002). Towards a theory of social practice: A development in culturalist theorizing. European Journal of Social Theory, 5(2), 243-263. doi:10.1177/13684310222225432

Riener, C., \& Willingham, D. (2010). The myth of learning styles. Change: The Magazine of Higher Learning, 42(5), 32-35. doi:10.1080/00091383.2010.503139

Roam, D. (2008). The back of the napkin: Solving problems and selling ideas with pictures. New York, NY: Portfolio.

Roos, J., Victor, B., \& Statler, M. (2004). Playing seriously with strategy. Long Range Planning, 37(6), 549-568. doi:10.1016/j.lrp.2004.09.005

Rose, S., Spinks, N., \& Canhoto, A. I. (2014). Management research: Applying the principles. Oxfordshire, England: Routledge.

Scaife, M., \& Rogers, Y. (1996). External cognition: How do graphical representations work? International Journal of Human-Computer Studies, 45(2), 185-213. doi:10.1006/ijhc.1996.0048

Scholey, C. (2005). Strategy maps: A step-by-step guide to measuring, managing and communicating the plan. Journal of Business Strategy, 26(3), 12-19. doi:10.1108/02756660510597065

Seidl, D., \& Whittington, R. (2014). Enlarging the strategy-as-practice research agenda: Towards taller and flatter ontologies. Organization Studies, 35(10), 1407-1421. doi:10.1177/0170840614541886

Sibbet, D. (2010). Visual Meetings: How graphics, sticky notes and idea mapping can transform group productivity. Hoboken, NJ: John Wiley \& Sons.

Sparrow, J. (1998). The role of physical representations in knowledge elicitation, knowledge in organizations. In J. Sparrow (Ed.), Knowledge in Organizations (pp. 51-78). Thousand Oaks, CA: Sage.

Steedman, P. (1991). On the relations between seeing, interpreting and knowing. London, England: Sage.

Stigliani, I., \& Ravasi, D. (2012). Organizing thoughts and connecting brains: Material practices and the transition from individual to group-level prospective sensemaking. Academy of Management Journal, 55(5), 1232-1259. doi:10.5465/amj.2010.0890 
Think in Colour. (n.d.). Jessamy Graphic Recording at Creative Innovation 2012. Retrieved May 2, 2016, from http://www.think-in-colour.com.au/gallery

/jessamy-in-action/a8wtqlrcuamqoq6-jpg-large/

Thomas, D. R. (2006). A general inductive approach for analyzing qualitative

evaluation data. American Journal of Evaluation, 27(2), 237-246.

doi:10.1177/1098214005283748

Tufte, E. (1990). Envisioning information. Cheshire, England: Graphics Press.

Tversky, B. (2005). Visuospatial reasoning. In K. Holyoak \& R. G. Morrison (Eds.), The Cambridge Handbook of Thinking and Reasoning (pp. 209-240). New York, NY: Cambridge University Press.

Vessey, I. (1991). Cognitive fit: A theory-based analysis of the graphs versus tables literature. Decision Sciences, 22(2), 219-240. doi:10.1111/j.15405915.1991.tb00344.x

Ware, C. (2004). Information visualization: Perception for design. San Francisco, CA: Morgan Kaufmann.

Ware, C. (2005). Visual queries: The foundation of visual thinking. In S. Tergan \& T. Keller (Eds.), Knowledge and Information Visualization: Searcbing for Synergies (pp. 27-35). Berlin, Germany: Springer.

Whittington, R. (2006). Completing the practice turn in strategy research. Organization Studies, 27(5), 613-634. doi:10.1177/0170840606064101

Whittington, R. (2007). Strategy practice and strategy process: Family differences and the sociological eye. Organiqation Studies, 28(10), 1575-1586. doi:10.1177/0170840607081557

Whittington, R., Molloy, E., Mayer, M., \& Smith, A. (2006). Practices of strategising/organising: Broadening strategy work and skills. Long Range Planning, 39(6), 615. doi:10.1016/j.lrp.2006.10.004

Whyte, J., Ewenstein, B., Hales, M., \& Tidd, J. (2008). Visualizing knowledge in project-based work. Long Range Planning, 41(1), 74-92.

doi:10.1016/j.lrp.2007.10.006
Wright, R. P., Paroutis, S. E., \& Blettner, D. P. (2013). How useful are the strategic tools we teach in business schools? Journal of Management Studies, 50(1), 92125. doi:10.1111/j.1467-6486.2012.01082.x

XPLANE. (n.d.). How do you make a respected training program even better? Retrieved April 1, 2016, from http:/ /www.xplane.com/work/how-do-you-make-arespected-training-program-beven-bett/view/ 


\section{AP}
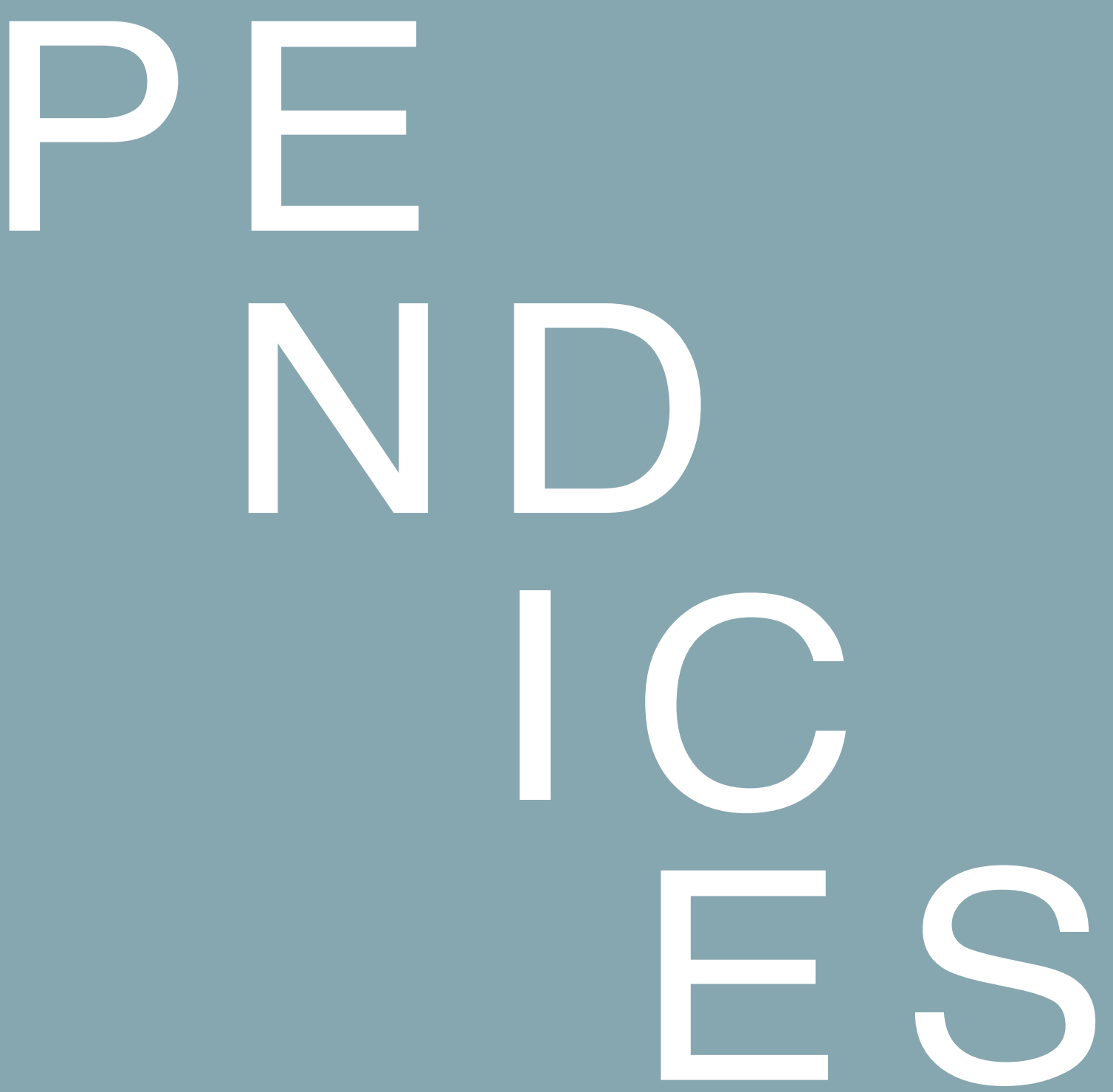

Appendix A: Examples of Strategy Visualisation

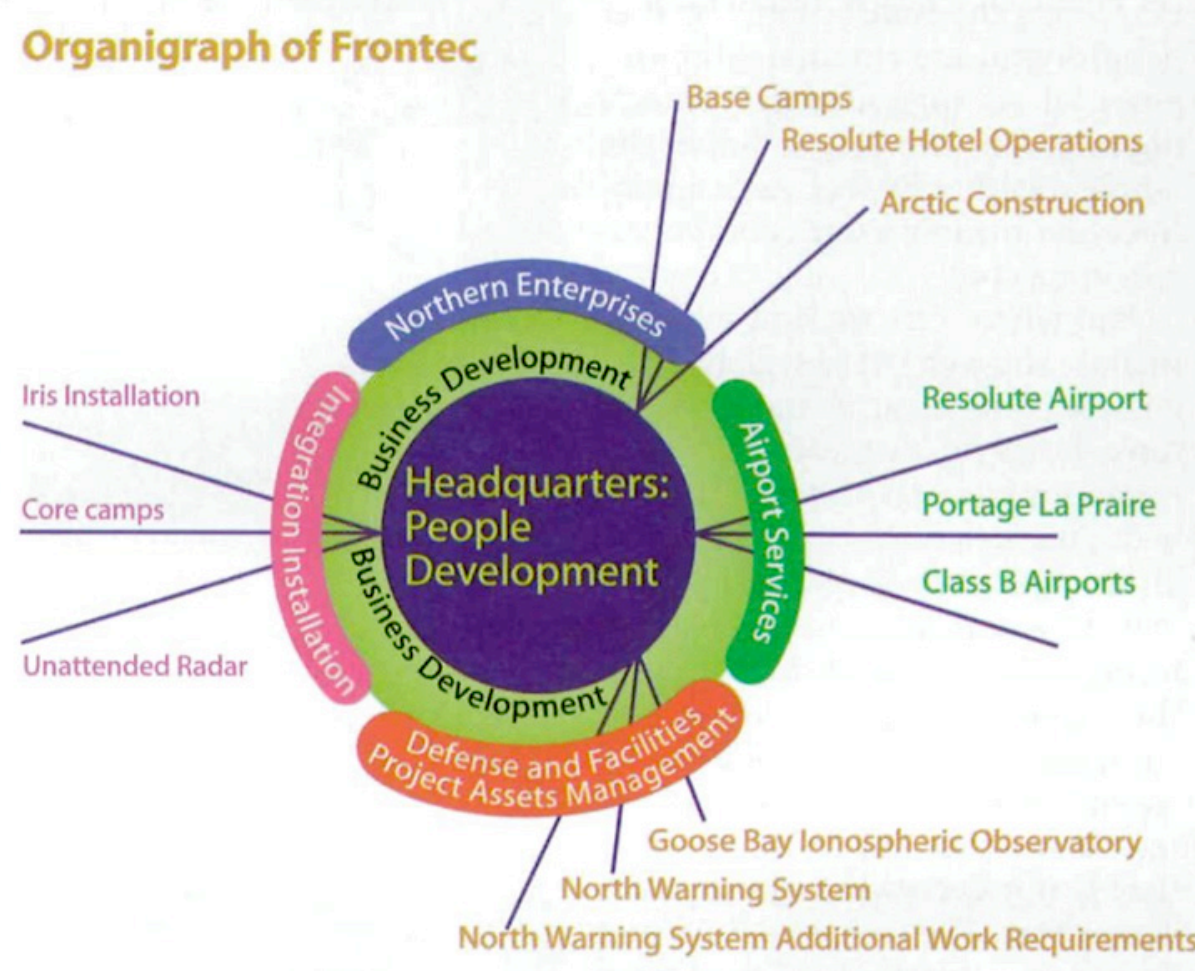

Figure 14. Example of an Organigraph created to show how the Canadian organisation Frontec, was developed around its core competences (Mintzberg \& Van der Heyden, 1999) 


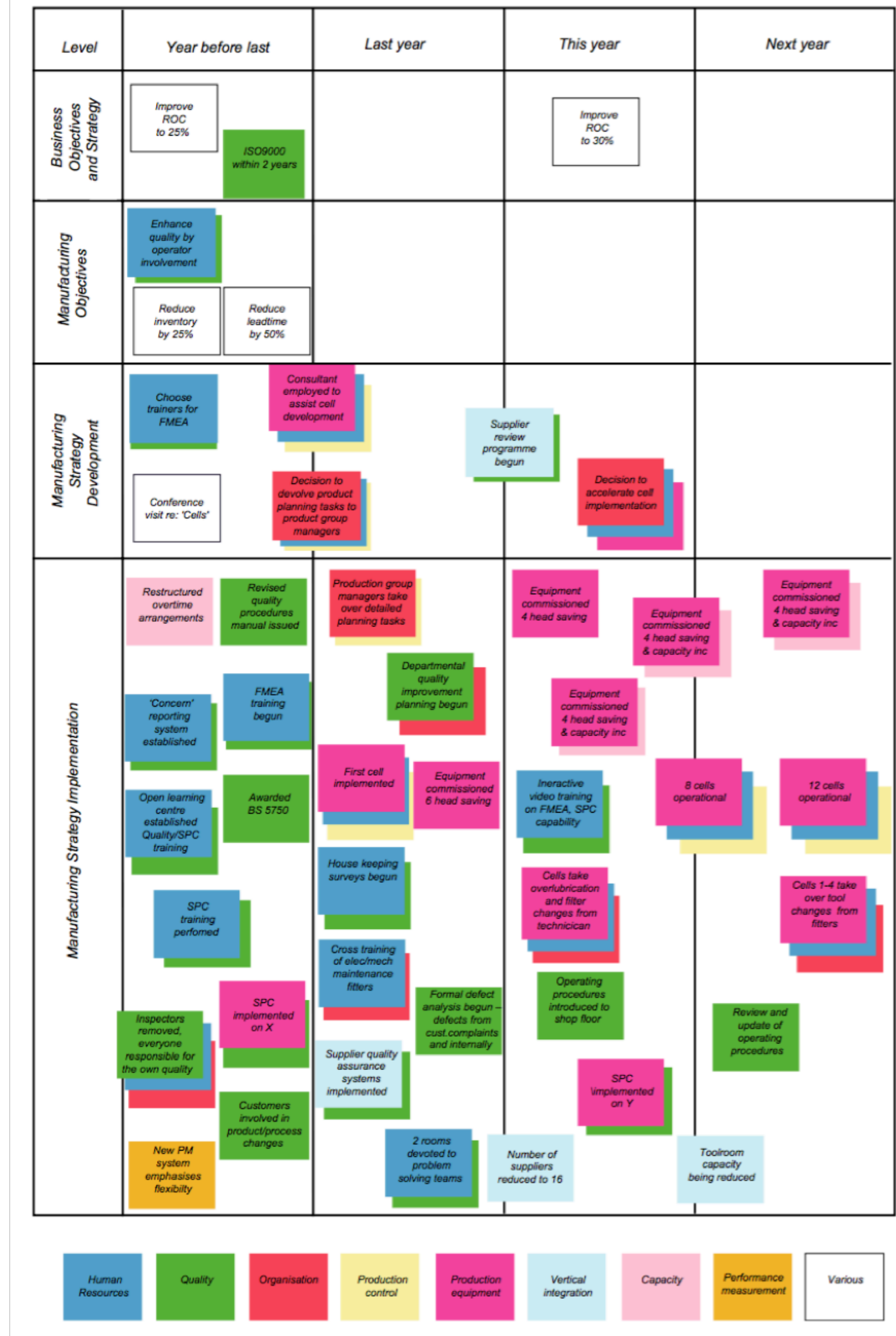

Figure 15. Example of a strategy chart for an auto components manufacturer (Eppler \& Platts, 2009)

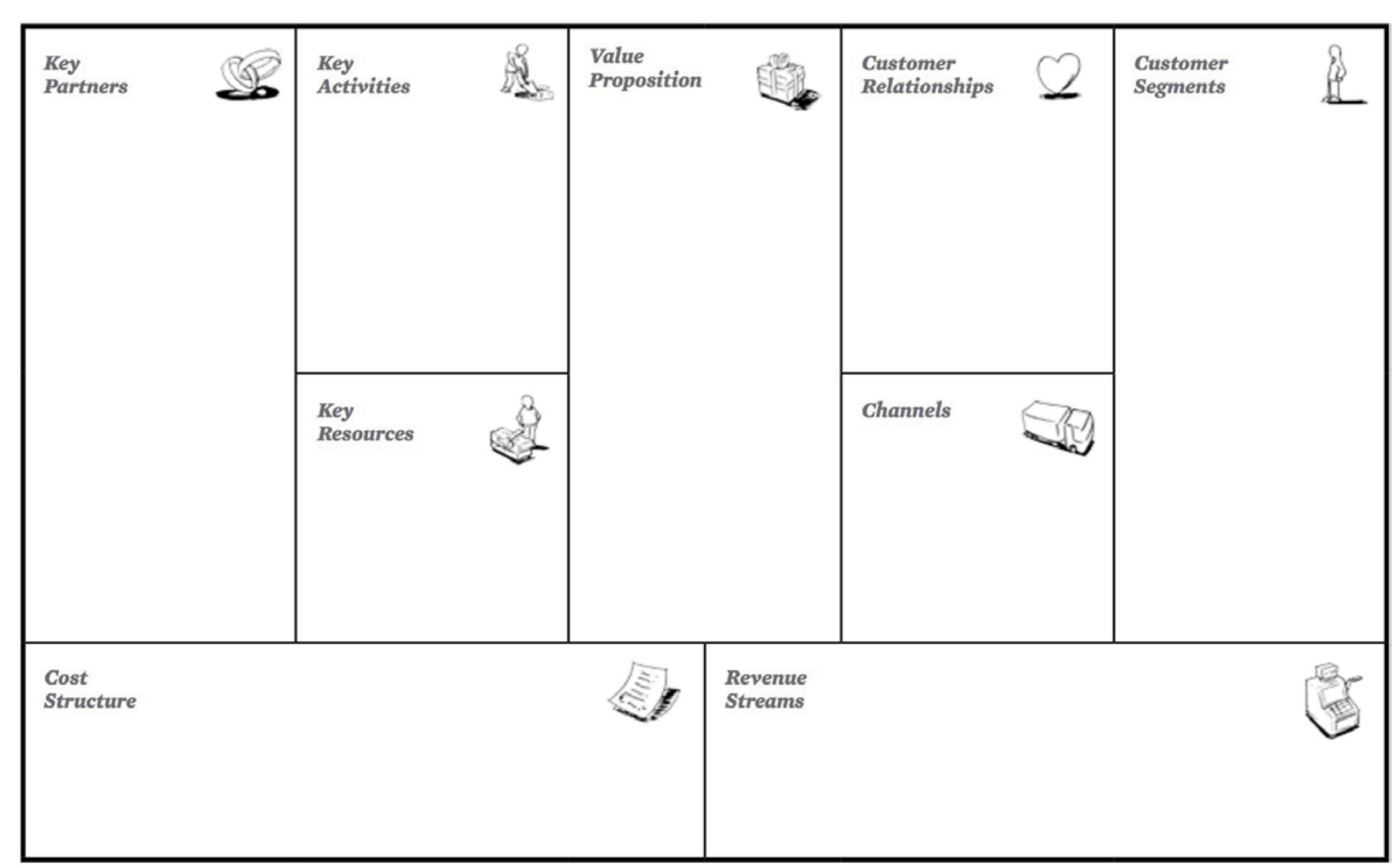

Figure 16. The Business Model Canvas (Osterwalder \& Pigneur, 2010)

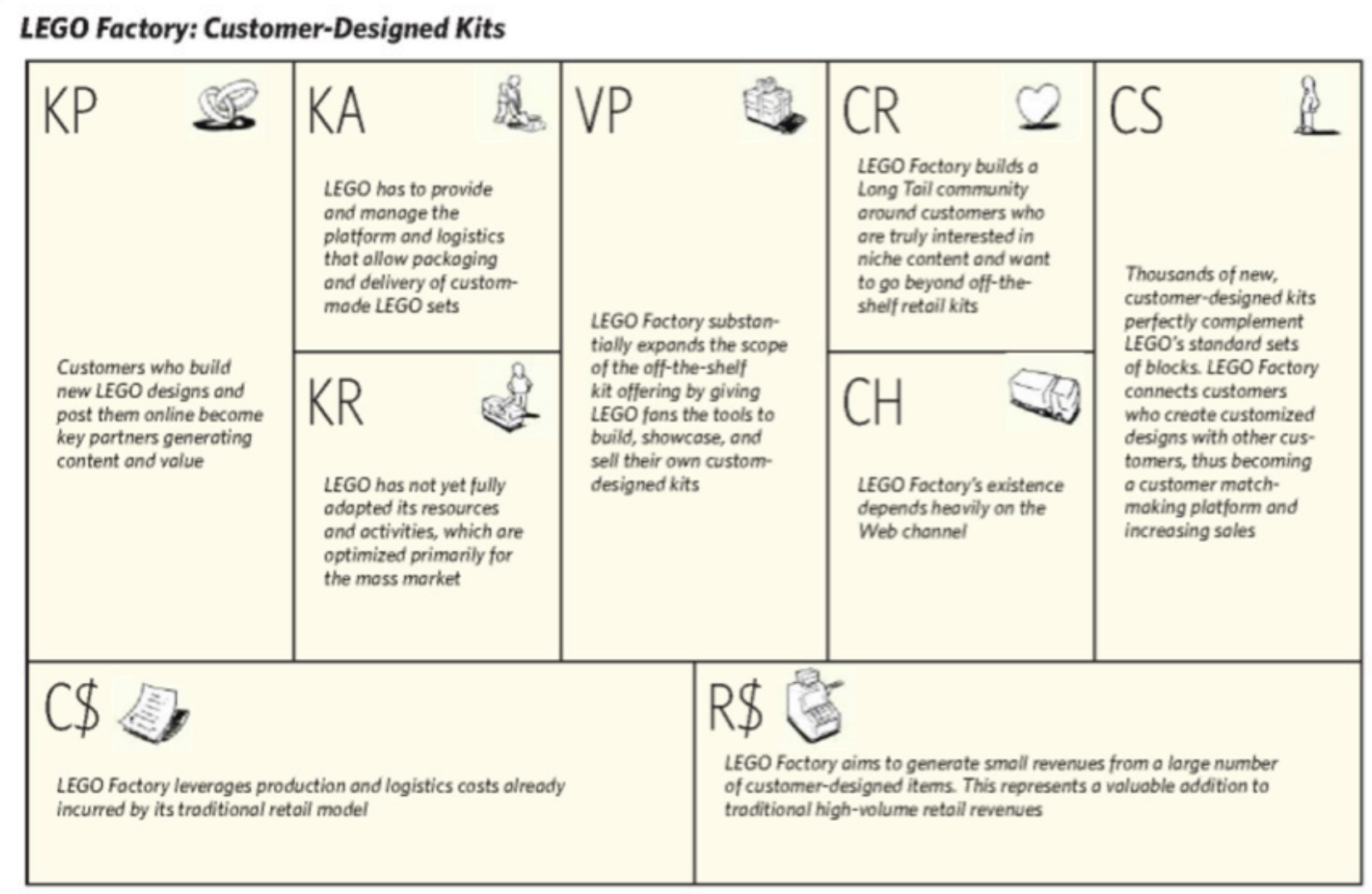

Figure 17. Example of LEGO Factory business model as displayed on the Business Model Canvas (Osterwalder \& Pigneur, 2010) 

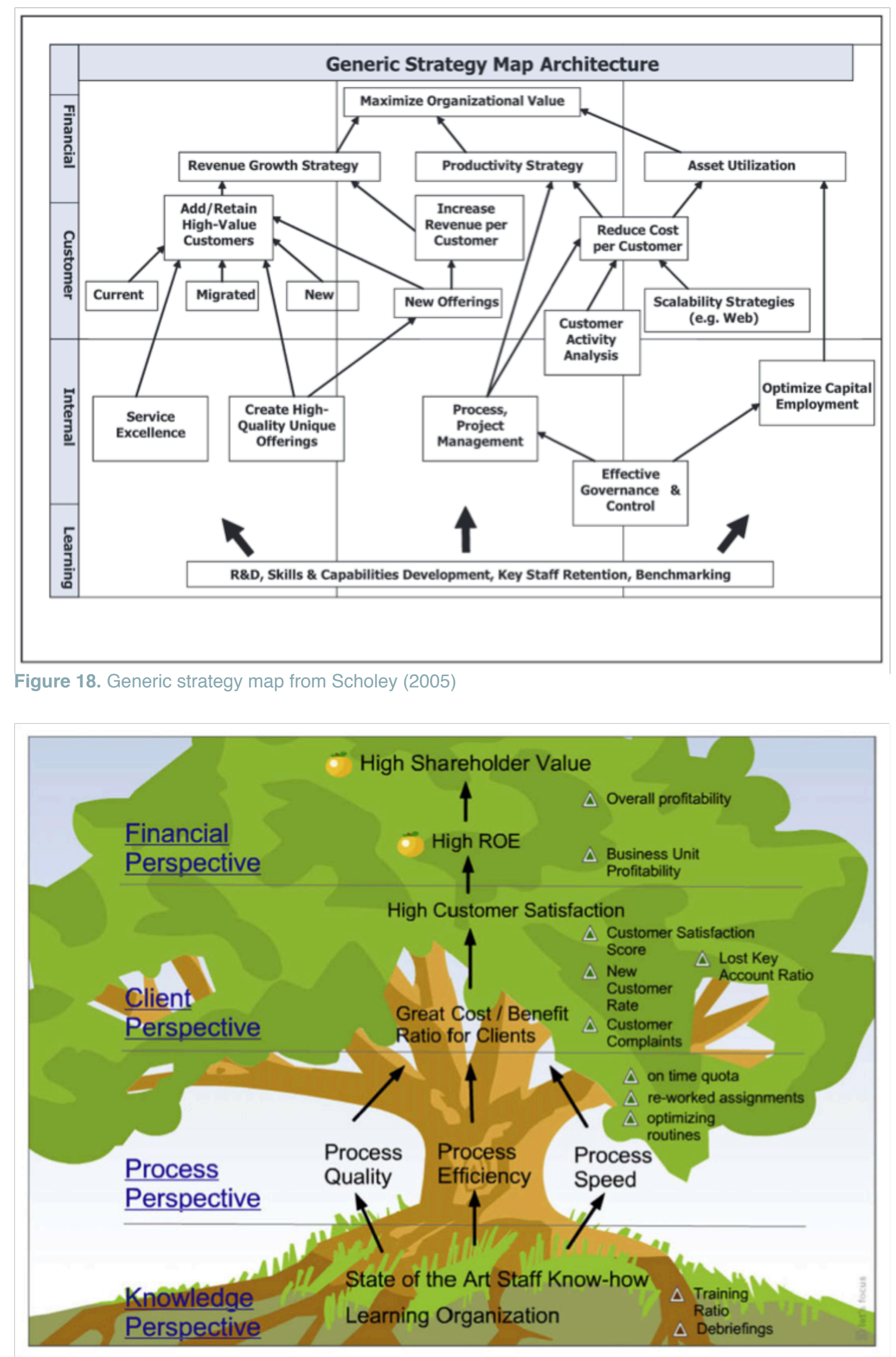

Figure 19. Example of an interactive Balanced Scorecard represented as a visual metaphor, created by Eppler \& Platts (2009) to assist with strategy communication 


\section{Appendix B: Information Sheet for}

\section{Participants}

\section{5 氧: VICTORIA}

\section{INFORMATION SHEET FOR PARTICIPANTS}

Thank you for your interest in this project. Please read this information before deciding whether or not to take part. If you decide to participate, thank you. If you decide not to take part, thank you for considering my request.

\section{Who am I?}

My name is Cassandra Ong and I am a Masters student in the School of Management at Victoria University of Wellington. This research project is work towards my thesis.

\section{What is the aim of this project?}

This project aims to understand how firms use visuals to represent their strategies or use visuals to enhance their strategic thinking. I also seek to understand the opportunities that firms have for visualising and the barriers that may discourage firms from presenting their strategies visually. This research has been approved by the Victoria University of Wellington Human Ethics Committee with approval number 0000022402

\section{How can you help?}

If you agree to take part I will interview you over Skype, FaceTime or through a phone call. However if you are located in Wellington, New Zealand and consent to take part, I can interview you in person at a public place, such as a café or at the Victoria University Railway Campus. I will ask you questions about your organisation and how your clients engage with your services. The interview will take approximately 30 minutes. I will record the interview with a digital audio recorder and write it up later. You can stop the interview at any time, without giving a reason. After the interview has taken place I may also ask you to provide claification on the interview or to comt can withdraw from the study by February 29th 2016. If you withdraw, the information you provide will be destroyed or returned to you.

\section{What will happen to the information you give?}

This research is confidential. I will not name you in any academic publications, and I will not include any information that would identify you, your organisation or your clients. Only my supervisor and will read the notes or transcript of the interview. The interview transcripts, summaries and any recordings will be kept securely and destroyed 5 years after the research ends.

\section{What will the project produce?}

The information from my research will be used in my Masters thesis. I may also use the results of my research for conference presentations and academic reports. Presentations and reports that use findings from this study will not identify you, your organisation or your clients.

If you have any questions or problems, who can you contact?

f you have any questions, either now or in the future, please feel free to contact either:

Student:

Cassandra Ong

School of Management

Victoria University of Wellington

Email: ongcass@myvuw.ac.nz

\section{Human Ethics Committee information}

fou have any concerns about the ethical conduct of the research you may contact the Victoria University HEC Convener: Associate Professor Susan Corbett.

Email susan.corbett@vuw.ac.nz or telephone +64-4-463 5480. 


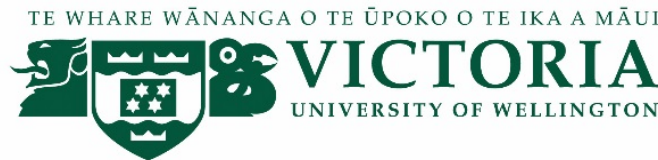

\section{CONSENT TO PARTICIPATE IN INTERVIEWS}

- I have been provided with adequate information relating to the nature and objectives of this research project.

- I have understood this information and have been given the opportunity to seek further clarification or explanations.

- I agree that I will be participating in an audio-recorded interview.

I understand that:

- I may withdraw from this study by February $26^{\text {th }} 2016$, and any information that I have provided will be returned to me or destroyed.

- The researcher and supervisor will have access to the raw data but my name will be changed beforehand to maintain confidentiality.

- Any information or opinions I provide will be kept confidential and reported only in an aggregated/non attributable form.

- The results will be used for a Masters report and summary results of this survey may be published in academic or professional journals and/ or presented at professional or academic conferences, but that my name will have been changed, and no identifiable information that is traceable to me will be included.

- When this research is completed, the raw data obtained will be destroyed after 5 years.

\section{Results of the research project}

I would like to receive a summary of the results of this research when completed and have added my preferred email address below.

I would like to receive a copy of the final report and have added my preferred email address below.

\section{INTERVIEW SCHEDULE}

1. Can you start by telling me about your firm and the services it provides?

2. Can you tell me about your role in the organisation and your background?

3. How did you become interested in visualisation?

4. In your opinion, what makes visualisation useful for your clients?

5. What problems do you help to resolve for firms through the use of visuals?

6. What are the processes that you use to promote these benefits?

7. How do clients come to you?

8. Approximately what percentage of prospective clients end up purchasing and adopting your services? ? $^{13}$

9. From your experience, what things support your clients' interest and continued engagement with visualisation?

10. What are the barriers that get in the way of clients using visuals?

11. From your experiences, are there certain characteristics that make clients more likely or less likely to seek your visualising services? If so, what are they?

12. Are there certain characteristics that make clients more likely or less likely to utilise your services?

13. Is there anything else you would like to add?

Signature of participant:

Date:

Email address: 
Appendix E: Results Framework

Development
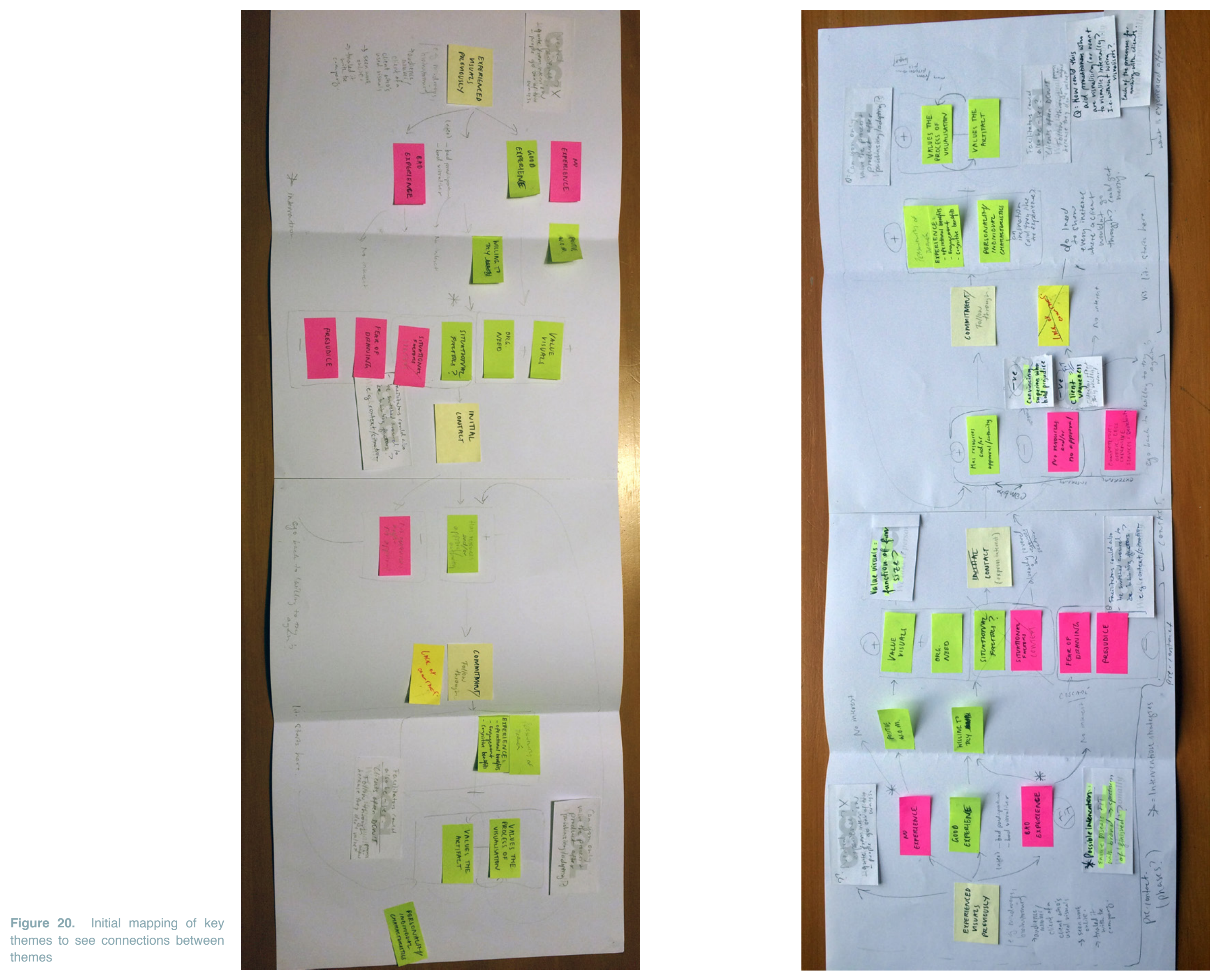

Figure 21. Revision of key 

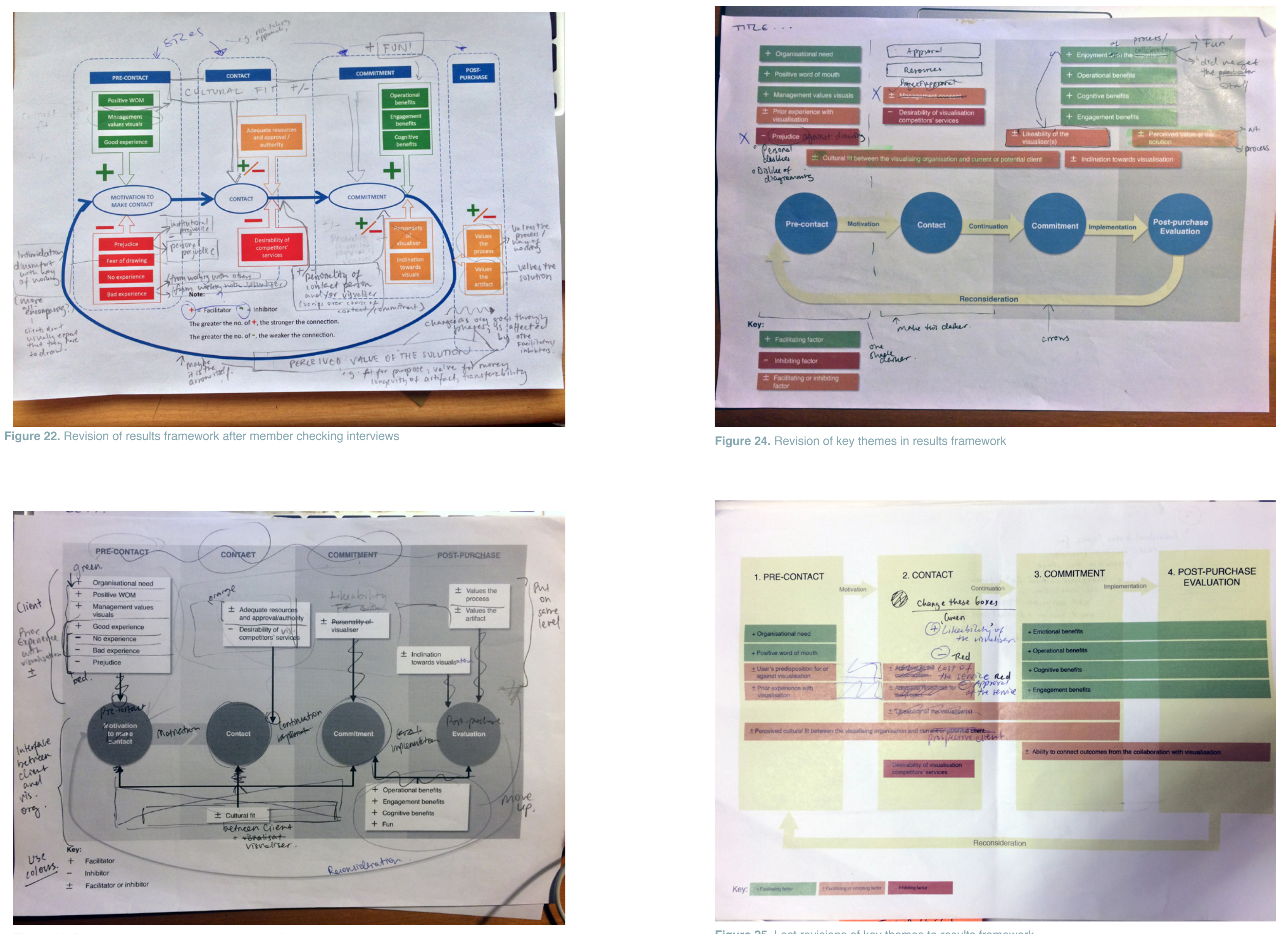

Figure 23. Revision of results framework after feedback from my supervisor 